U.S. Department of Energy

Office of Civilian

Radioactive Waste Management

and

Electric Power

Research Institute
Topics:

Spent-fuel storage Fuel rods

Radioactive waste management Spent-fuel handling

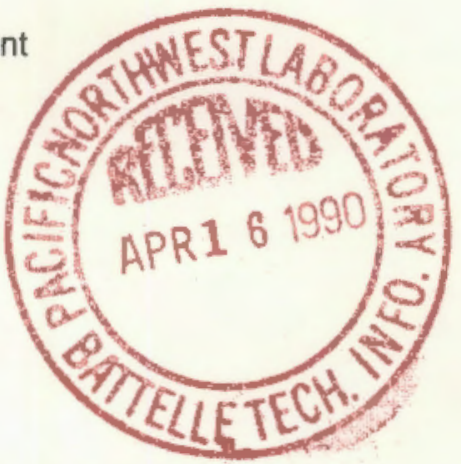

EPRI NP-6722

Project 2240-2

PNL-7172

UC-85

Interim Report

February 1990

\title{
Fuel Consolidation Demonstration: Consolidation Concept Development
}

Prepared by

Northeast Utilities Service Company

Berlin, Connecticut

and

Combustion Engineering, Inc.

Windsor, Connecticut 



\section{R E P O R T S U M M A R Y}

SUBJECTS Radioactive waste management / Light water reactor fuel

TOPICS Spent-fuel storage

Radioactive waste management

Fuel rods

Spent-fuel handling

AUDIENCE Fuels engineers / R\&D scientists

\section{Fuel Consolidation Demonstration: Consolidation Concept Development}

Utilities can substantially increase the capacity of spent-fuel storage pools by using fuel consolidation systems. Recently, engineers obtained valuable information from a demonstration at the Northeast Utilities Service Company Millstone unit 2 nuclear power station in Connecticut. Operating experience based on this demonstration provided crucial data for evaluating fuel consolidation systems designed for widespread use.

BACKGROUND

Utilities must find a way to store spent nuclear fuels until DOE can provide a permanent repository, which is unlikely before the turn of the century. Advanced storage alternatives under consideration include on-site dry storage and spent-fuel consolidation. The latter approach affords economic advantages by effectively increasing the capacity of existing reactor storage pools. EPRI, Northwest Utilities Service Company (NUSCO), DOE, Baltimore Gas \& Electric Company, and Combustion Engineering, Inc., cosponsored a program to develop analytic methods and to demonstrate a full-scale fuel consolidation storage system.

OBJECTIVE To describe the design, structure, and operation of the Millstone unit 2 fuel consolidation and storage system, including disposal of the fuel-assembly scrap that remains after consolidation.

APPROACH The development of equipment and techniques to consolidate spent fuel was an evolutionary process that finally resulted in the consolidation system used in the Millstone-2 demonstration. Beginning with a reference design, investigators fabricated equipment components, cold-tested the components for operability, and, as necessary, redesigned equipment to meet functional requirements. The report was then structured and written so that the function of various components could be easily understood.

RESULTS The report physically and functionally describes the consolidation system components and the procedures used to operate the system. Special attention is given to the problems of treating and disposing of assembly scrap hardware, including a discussion of the safety considerations of handling Zircaloy. In addition, the report provides an evaluation of considerations 
involved in adapting the system to consolidate various types of LWR fuel manufactured by different vendors. On the basis of the work described in this report, investigators determined that the fuel consolidation demonstration equipment would meet NRC licensing criteria.

Through its fuel consolidation demonstration and several other research projects, EPRI is developing a range of viable alternatives to help electric utilities meet the pressing need for spent-fuel storage. EPRI considers the current spent-fuel consolidation project (RP2240-2) to be a key element in its ongoing program to fill this need. The current report on this project focuses on the concept development phase of the work and is one of a series of EPRI documents covering the spent-fuel consolidation demonstration. The first report addressing the project (EPRI NP-4327, revision 1) provided a program overview for the fuel consolidation demonstration. Two other published reports in the series focus on methods development (report NP-5945) and storage area analysis (report NP-6551). Three additional reports will follow, two of which will address licensing and the results of the hot and cold demonstration; the third will provide a final overview of the project.

\section{PROJECT RP2240-2}

EPRI Project Manager: Ray W. Lambert

Nuclear Power Division

Contractor: Northeast Utilities Service Company

For further information on EPRI research programs, call EPRI Technical Information Specialists (415) 855-2411. 


\title{
Fuel Consolidation Demonstration: Consolidation Concept Development
}

\author{
NP-6722 \\ Research Project 2240-2 \\ PNL-7172 \\ UC-85 \\ Interim Report, February 1990 \\ Prepared by \\ COMBUSTION ENGINEERING, INC. \\ 1000 Prospect Hill Road \\ Windsor, Connecticut 06095 \\ Project Manager \\ R. L. Moscardini \\ Under the direction of \\ NORTHEAST UTILITIES SERVICE COMPANY \\ 107 Selden Street \\ Berlin, Connecticut 06037 \\ Project Manager \\ G. N. Betancourt
}

Prepared for

U.S. Department of Energy Richland Operations Office $825 \mathrm{Jadwin}$ Avenue Richland, Washington 99352

Project Manager

C. E. Collantes
Baltimore Gas \& Electric Clavert Cliffs Nuclear Power Station Lusby, Maryland 20657

\section{Project Manager \\ P. A. File}

\section{Electric Power Research Institute \\ 3412 Hillview Avenue \\ Palo Alto, California 94304 \\ EPRI Project Manager \\ R. W. Lambert}

High Level Waste Program

Nuclear Power Division 


\section{ORDERING INFORMATION}

Requests for copies of this report should be directed to Research Reports Center (RRC), Box 50490, Palo Alto, CA 94303, (415) 965-4081. There is no charge for reports requested by EPRI member utilities and affiliates, U.S. utility associations, U.S. government agencies (federal, state, and local), media, and foreign organizations with which EPRI has an information exchange agreement. On request, RRC will send a catalog of EPRI reports.

\section{DISCLAIMER}

This report was prepared as an account of work sponsored by the United States Government. Neither the United States nor the United States Department of Energy, nor any of their employees, makes any warranty, express or implied, or assumes any legal liability or responsibility for the accuracy, completeness, or usefulness of any information, apparatus, product, or process disclosed, or represents that its use would nol infringe privately owned rights. Reference herein to any specific commercial product, process, or service by trade name, mark, manufacturer, or otherwise, does not necessarily constitute or imply its endorsement, recommendation, or favoring by the United Stales Government or any agency thereot. The views and opinions of authors expressed herein do not necessarily state or reflect those of the United States Government or any agency thereol.

\section{NOTICE}

This report was prepared by Combustion Engineering as an account of work sponsored by Northeas Utilities Service Company (NUSCO), the U.S. Department of Energy (DOE), the Electric Power Research Institute, Inc. (EPRI), Combustion Engineering. Inc. (C-E), and Baltimore Gas and Electric Company (BG\&E). Neither NUSCO, DOE, EPRI, C-E, BG\&E, their employees or members of EPRI, nor any person acting on their behalf: (a) makes any warranty, express or implied, with respect to the use of any information, apparatus, method, or process disclosed in this report or that such use may not infringe privately owned rights; or (b) assumes any liabilities with respect to the use of, or for damages resulling from the use of, any information, apparatus, method, or process disclosed in this report. 
ABSTRACT

EPRI, Northeast Utilities Service Company (NUSCO), DOE, Baltimore Gas \& Electric Company, and Combustion Engineering, Inc. (C-E) are engaged in a program to develop a system for consolidating spent fuel, in which the consolidated fuel will be licensable by NRC for storage in the spent-fuel storage pool. Fuel consolidation offers a means of substantially increasing the capacity of spent-fuel storage pools.

Consolidation equipment design, development, construction, and testing are being performed by $\mathrm{C}-\mathrm{E}$ in Windsor, Connecticut. Seismic and structural evaluation of the capability of the Millstone unit 2 spent-fuel pool and building to accommodate the increased fuel capacity is being conducted by NUSCO. NUSCO plans to obtain a license to store consolidated fuel in the Millstone-2 spent-fuel storage pool. NUSCO also plans to perform a hot demonstration of the integrated consolidation system with spent fuel at Millstone-2.

This report describes the consolidation system design that forms the basis for the detailed design of the equipment comprising the system, including information on the fabrication and testing of the equipment (Appendix A).

Appendix B describes an evaluation of the ability of the system under development to consolidate LWR spent-fuel assemblies other than the $14 \times 14$ fuel of $C-E$ design stored at Millstone-2. A comparison was made of fuel-assembly designs on the basis of information available in open literature. It was concluded that with appropriate dimensional modifications, the spent-fuel consolidation system equipment design is applicable to almost all PWR fuel-assembly configurations. 



\section{ACKNOWLEDGMENTS}

The Fuel Consolidation Demonstration Project is jointly sponsored by Northeast Utilities Service Company (NUSCO), the Electric Power Research Institute (EPRI), the U.S. Department of Energy (DOE), Baltimore Gas and Electric Company (BG\&E), and Combustion Engineering $(C-E)$, and its success is heavily dependent on the ability of the participants to smoothly interact and cooperate. Special acknowledgment is extended to $A 1$ an Cope who headed the $C-E$ team authoring the report and to Ellen Clements and George Coe of COECORP who assembled three independent but related reports into this single volume.

The following organizations and individuals are appreciatively acknowledged for their support and contributions to this ambitious demonstration program.

Technical Management Committee

M. Kupinski, Chairman (NUSCO)

G. N. Betancourt (NUSCO)

R. W. Lambert (EPRI)

C. E. Collantes (DOE-RL)

Northeast Utilities Service Company

T. J. Mawson

R. R. Calabro

R. A. Isakson

E. Krinick

\section{Baltimore Gas \& Electric}

J. A. Mihalcik

P. A. File

DOE Headquarters

D. E. Shelor

C. E. Head

\section{Electric Power Research Institute}

R. F. Williams

Combustion Engineering

R. L. Moscardini

A. J. Anthony

J. F. Theroux

M. V. Couture

B. F. Allen

M. J. Falzarano

P. S. Miller

\section{Pacific Northwest Laboratories}
L. A. Strope
G. H. Beeman
J. M. Creer

DOE Richland Operations office

J. P. Collins

D. E. Trader 

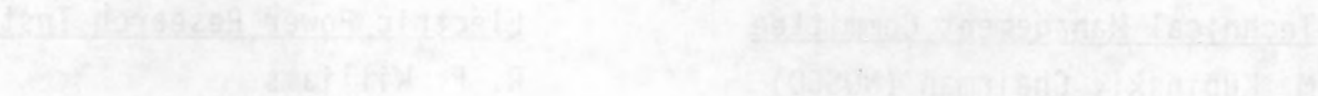


\section{CONTENTS}

Section

Page

1 INTRODUCTION

$1-1$

Consolidation System

1-1

Generic Application

1-4

Millstone Unit 2 Fuel Storage Pool

1-4

Design Requirements

$1-4$

System Design Support Studies

$1-6$

2 DESCRIPTION OF PROCESS AND COMPONENTS

2-1

Consolidation Process

2-1

Interim Transfer Canister

2-4

Guide Tube Cutter

2-7

Multiple Rod Pulling Tool

2-10

$X-Y$ Positioning Table

2-14

Filter System

2-14

Volume Reduction System/Compactor

2-18

Temporary Fuel Storage Rack

2-20

Hoist Assembly

2-20

Control Console

2-20

Hydraulic Power Unit

2-23

Lower Work Platform

2-23

TV System

2-26

Rod Transfer Tool

2-27

Miscellaneous Tooling

2-27

Consolidated Fuel Storage Box

2-29

Fuel Racks

2-29 
3 DISPOSAL OF FUEL ASSEMBLY SCRAP AND WASTE 3-1

4 SAFE HANDING OF ZIRCALOY 4-1

5 VOLUME REDUCTION OF ASSEMBLY MATERIALS

\section{APPENDIX A CONSOLIDATION TOOLING AND EQUIPMENT}

DESIGN, FABRICATION AND TESTING

A-1

APPENDIX B APPLICATION OF SYSTEM TO NON-CE FUEL

B-1 


\section{ILLUSTRATIONS}

Figure

Page

1-1 Fuel Consolidation System 1-2

1-2 Fuel Assembly 1-5

2-1 Equipment Layout 2-2.

2-2 Process Flow Chart 2-3

2-3 Interim Transfer Canister 2-5

2-4 Transfer Canister Assembly 2-6

2-5 Corrugated Guide Plate 2-8

2-6 Guide Tube Cutter 2-9

2-7 Multiple 14x14 Fuel Rod Pulling Tool 2-11

2-8 Multiple Rod Pulling Head 2-12

2-9 X-Y Positioning Table 2-15

2-10 Rod Pick and Drop Patterns in Fuel Assembly $\begin{array}{ll}\text { and Interim Transfer Canister 2-16 } & \end{array}$

2-11 Filter System Schematic 2-17

2-12 Compactor 2-19

2-13 Hoist Assembly 2-21

2-14 Multiple Rod Puller Control Console 2-22

$\begin{array}{lr}\text { 2-15 Lower Work Platform 2-24 } & \end{array}$

2-16 Rod Transfer Tool 2-28

2-17 Consolidated Fuel Storage Box and Cover Assembly 2-30

2-18 Spent-Fuel Storage Rack 2-31 



\section{SUMMARY}

EPRI is engaged in a program with Northeast Utilities (NU), the Department of Energy (DOE), Baltimore Gas and Electric (BG\&E) and Combustion Engineering (C-E) to develop a consolidated spent-fuel storage system licensable by the United States Regulatory Commission (USNRC), and to perform a full-scale demonstration of the system at Millstone Unit 2. The system has been developed from an existing C-E conceptual design. This report describes the fuel consolidation and storage system design which is the basis for detailed design of the equipment comprising the system. An appendix describes the detailed design, fabrication and testing of the consolidation equipment.

\section{GENERIC APPLICATION}

The overall system is generic to light water reactor (LWR) nuclear power plant and fuel designs in the United States, but the equipment in this program is being specifically designed for Millstone Unit 2 and C-E $14 \times 14$ fuel. Relatively minor modifications are required to consolidate other PWR fuel designs.

\section{CONSOLIDATION SYSTEM DESCRIPTION}

The layout of the fuel consolidation equipment is shown in Figure $5-1$. This equipment will be located in the shipping cask area of the Millstone Unit 2 fuel storage pool. A temporary fuel storage rack and a lower work platform stand on the floor of the pool and are serviced by a gantry crane, called a hoist assembly, which spans the cask pool. Fuel assemblies to be consolidated, which have a minimum of $85 \%$ of the design burnup and 5 years' subsequent residence time in the pool, are deposited in the temporary storage rack by the Millstone spent-fuel handling machine. Design burnup is defined as the average expected burnup of fuel having a given initial enrichment. Consolidation takes place in the lower work platform, which supports seven individual work stations. A traversing carriage on top of the lower work platform aligns fuel manipulating equipment accurately with the individual stations. This carriage is called the $X-Y$ table. 


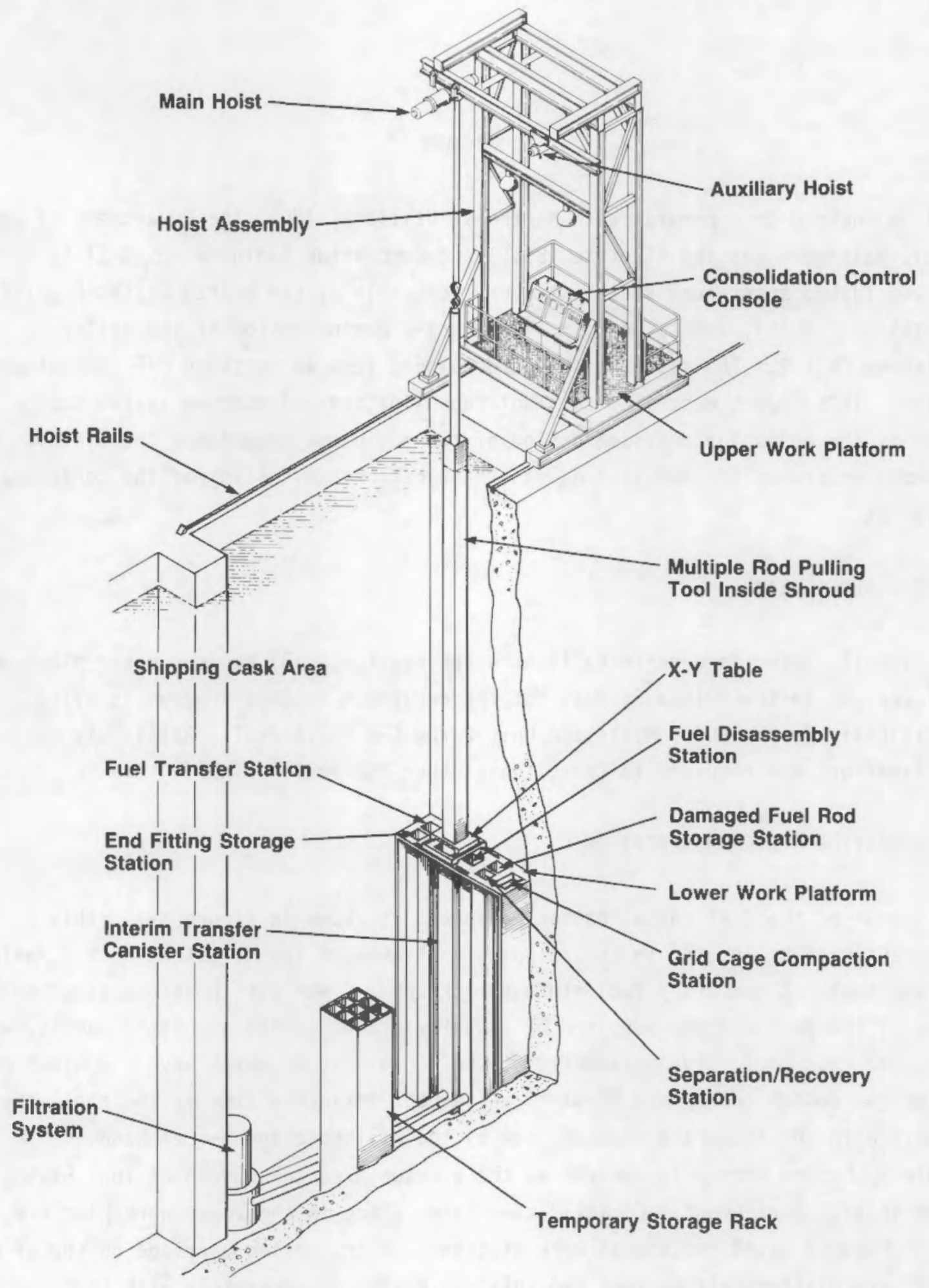

Figure S-1. Fuel Consolidation Equipment Layout 
The fuel is disassembled in the fuel disassembly work station by cutting off the upper end fitting and then removing fuel rods singly or up to one row at a time by means of a multiple rod pulling tool (MRPT). Rod pulling forces are maintained between preset limits. Fuel rods are then deposited in an interim transfer canister (ITC) located in the adjacent interim transfer canister station.

The ITC has channels which guide the rods into a close-packed triangular array at the bottom. The floor of the ITC is movable and is held in place by a gate. If a row of fuel rods pulled by the MRPT contains a damaged rod, it is separated from the row at the separation/recovery station before the row is deposited in the ITC. The damaged rod is transferred to a storage canister in the damaged fuel rod storage station. The fuel rods and the movable floor in the ITC are transferred by gravity into a consolidated fuel storage box located in the fuel transfer station. Descent of the rods is controlled by a telescoping cylinder acting on the underside of the movable floor. A rod transfer tool is used to verify completion of the transfer. The close-packed triangular rod array results in a compaction ratio of $2: 1$. Filled consolidated fuel storage boxes are removed for storage in the spent-fuel storage pool.

Fuel assembly end fittings are placed in storage boxes at the end fitting storage station for storage in the fuel pool. Zircaloy grid cages and control guide tubes are compacted by hydraulic rams in the compaction station and may then either be transported to a waste storage facility or stored in the spent-fuel storage pool.

A filtration system is connected to the fuel disassembly, ITC, fuel transfer and compactor work stations to collect and filter out radioactive particulates generated by operations performed at these stations. The MRPT is enclosed by a shroud assembly which provides guidance and alignment.

The consolidation system is controlled from a console on the upper work platform on the hoist assembly. Control logic is programmable to allow for changes as experience is gained. A TV system is provided for remote viewing of all. consolidation operations.

\section{SPENT-FUEL STORAGE RACKS}

The spent-fuel storage pool at Millstone Unit 2 will be divided into two regions. Region I is the high enrichment, core offload region. Region II is reserved for 
fuel with at least $85 \%$ of design burnup. Consolidated fuel may be stored in either region. The $\mathrm{C}-\mathrm{E}$ designed storage racks are free-standing modules of monolithic welded honeycomb construction. The racks in Region I contain poison inserts for neutron absorption.

\section{DESIGN SUPPORT STUDIES}

Disposal of fuel assembly scrap as waste to be stored at a waste storage facility proved to be more complex than originally anticipated. Two studies in support of this aspect of fuel consolidation were performed. In the first, the quantity, isotopic content, and activity of the waste materials were estimated; then the influence of these and various other factors such as volume reduction and shipping regulations on waste disposal costs was assessed. The second study was a review of industry experience in the safe handling of Zircaloy while it is being processed.

Conclusions from the two studies, applicable to $C-E$ fuel which has stainless steel end fittings with Zircaloy guide tubes and grid cages, were that only the guide tube/grid cage assemblies should be considered for shipping as waste, the end fittings being stored in the spent-fuel pool, and that Zircaloy particles trapped by the underwater filtration system may require special precautions for safety when removed from the water for shipment.

Methods of reducing the volume of fuel assembly scrap were also studied, primarily from the view point of storing the scrap in the spent-fuel pool. Various types of commercially available reduction equipment were evaluated, both as to the degree of volume reduction of the scrap materials and to the compatibility of the equipment with the irradiated underwater operating environment. The target volume reduction ratio for the study was 10:1. Scoping tests performed by vendors showed that granulation had the greatest potential for volume reduction, followed by shredding, and compaction. The available granulating and shredding machines, however, required major redevelopment to make them suitable for the operating environment, and compaction was therefore selected for the fuel consolidation system. Shearing and compacting in two or three directions into briquettes was finally adopted as the reference concept. after an experiment with longitudinal compacting failed to achieve a satisfactory volume reduction ratio. 


\section{APPENDICES}

Appendix A provides information on the consolidation tooling equipment, tooling equipment design, fabrication, and testing.

Appendix B discusses a review of the fuel consolidation system for generic application to fuel assemblies of other sizes and manufacturers. The review included a search of open literature for information regarding features of non-C-E fuel assembly designs. The designs were reviewed for applicability as well as exceptions to the design and operation of the $C-E$ system. Fuel assembly configurations of spent fuel presently being stored in 54 pressurized water reactors (PWRS) and 30 boiling water reactors (BWRs) were reviewed. Fuel assembly manufacturers reviewed included Babcock and Wilcox, Exxon, General Electric, and Westinghouse. Physical configurations of fuel assemblies were compared with the C-E consolidation system tooling and procedures. With some modifications (e.g.. dimensional changes) in tooling and equipment, the C-E spent-fuel consolidation system is applicable to all but two configurations of spent-fuel assemblies. The two exceptions are the early design of Palisades $(C-E)$ and Yankee Rowe (Westinghouse) fuel assemblies, which require a different type of cutting tool to remove the upper end fitting. When the upper end fitting is removed, however, fuel rod withdrawal and consolidation equipment and procedures are similar. Later design Palisades and Yankee Rowe fuel assemblies have mechanically removable upper end fittings: therefore no special cutting equipment is required. Later studies conducted by NU and $C-E$ revealed that additional tooling and changes in the current consolidation equipment designs would be required in order to efficiently consolidate BWR type fuels. 



\section{Section 1}

\section{INTRODUCTION}

EPRI is engaged in a program (1) with Northeast Utilities (NU), Baltimore Gas and Electric (BG\&E) and Combustion Engineering (C-E) to develop a consolidated spent-fuel storage system 1 icensable by the United States Nuclear Regulatory Commission (USNRC), and to perform a full-scale demonstration of the consolidation system at Millstone Unit 2. The system has been developed from an existing $\mathrm{C}-\mathrm{E}$ conceptual design. This report describes the fuel consolidation and storage system design which is the basis for detailed design of the equipment comprising the system. Appendix A gives a summary of the detailed design, fabrication and testing of this equipment.

\section{CONSOLIDATION SYSTEM}

Fuel consolidation is a means of increasing spent fuel storage capacity by disassembling spent-fuel assemblies and storing the fuel rods in a tighter array.

The fuel consolidation system depicted in Figure 1-1 permits the coordinated disassembly of spent-fuel assemblies and the subsequent repackaging of the fuel rods into close-packed arrays. The fuel rods from two fuel assemblies can be accommodated in a consolidated fuel storage box that is compatible for long-term storage within the spent fuel racks and occupies the same space as a single intact fuel assembly. The remaining portions of the spent-fuel assembly, upper and lower end fittings, guide tubes, and grid cages, are stored or disposed of separately from the fuel rods.

Fuel consolidation operations are performed within the area of the spent-fuel cask pool, where the equipment of the system is installed. The basic components of the fuel consolidation system are:

(1) The hoist assembly, a gantry crane spanning and traversing the cask pool, that handles the consolidation system tools.

(2) The guide tube cutting tool, that cuts the fuel assembly guide tubes to free the upper and lower end fittings.

(3) The sleeve removal tool, that, prior to guide tube cutting, removes sleeves from those tubes which have been repaired by sleeving. 


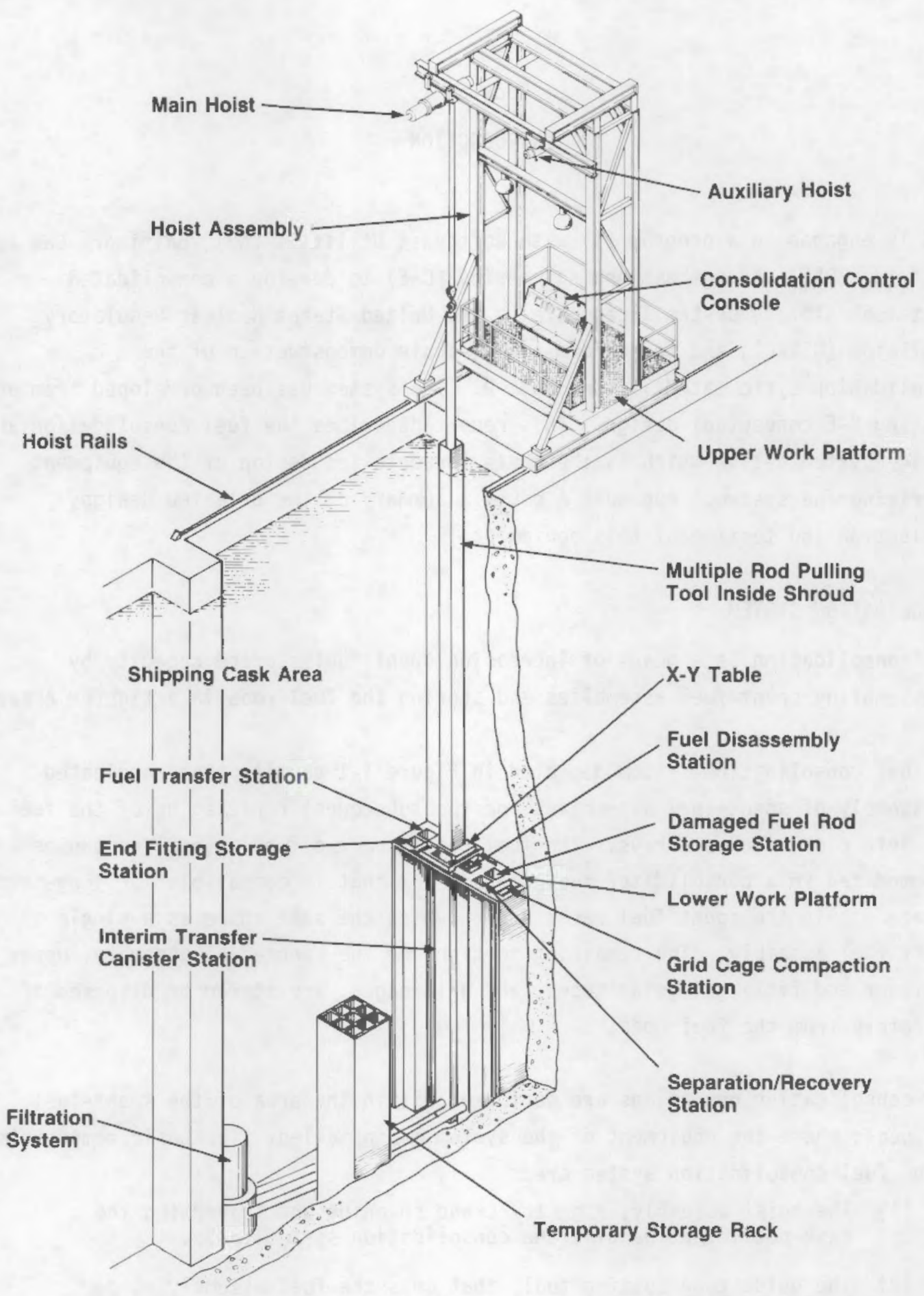

Figure 1-1. Fuel Consolidation System 
(4) The multiple rod pulling tool (MRPT), that pulls fuel rods out of the fuel assembly.

(5) The interim transfer canister (ITC), that guides the fuel rods from the open square array of the fuel assembly at the inlet to the canister into a close triangular array at its discharge end.

(6) The lower work platform, that stands on the floor of the pool and supports the work stations where the various consolidation operations are performed. These stations are: fuel disassembly (for fuel rod and end fitting removal); interim transfer canister (for depositing fuel rods in the ITC); fuel transfer (for discharging fuel rods from the ITC into a consolidated fuel storage box); end fitting storage (for depositing end fittings into an end fitting storage box); compactor (for reducing the envelope volume of the fuel assembly grid cages and guide tubes and then depositing them in a compacted waste canister for storage); separation/recovery (for separating out a damaged fuel rod from a row of rods before depositing the remaining rods in the ITC); and damaged fuel rod storage (for depositing a damaged or broken fuel rod in a damaged rod storage box).

(7) The $X-Y$ table, that traverses the top of the lower work platform in both longitudinal and transverse directions to align the lower end of the MRPT accurately with the fuel disassembly, ITC, separation/recovery, and damaged fuel rod storage stations.

(8) The rod transfer tool, that is used in conjunction with the ITC at the fuel transfer station to confirm a complete transfer of fuel rods from the interim transfer canister into the consolidated fuel storage box, or to warn of a sticking rod.

(9) The filtration system, that stands on the floor of the pool and filters out particulate matter to maintain cask pool water clarity and minimize the escape of radioactive crud into the pool. The filter system is connected to the fuel disassembly, interim transfer canister, fuel transfer, and compactor work stations.

(10) The consolidation control console. All consolidation operations are controlled from this console and the upper work platform (on the hoist assembly) on which it stands.

(11) The underwater television camera systems, that enable visual monitoring of consolidation operations.

(12) Miscellaneous tools, that are used for such activities as removal of end fittings, a single fuel rod, and the grid cage/guide tube assembly, and for changing filter cartridges.

(13) The main power distribution cabinet, also known as the motor control cabinet, that handles all electrical power routing.

(14) The hydraulic, pneumatic and deionized water system cabinets that contain the control valves, pumps and compressor for their respective systems. 
While fuel is being consolidated, the gate between the spent fuel pool and the cask pool is kept closed to minimize the spread of contamination into the spent fuel pool. Consolidation is performed in batches, and a temporary storage rack with nine cells is installed in the cask pool to accommodate intact fuel assemblies and filled consolidated fuel storage boxes.

The spent fuel consolidation process and the system components are described in Section 2.

\section{GENERIC APPLICATION}

The system design described in this report is generic to light water reactor (LWR) nuclear power plant and fuel designs in the United States, but the equipment in the system is specifically designed for Millstone Unit 2 and the C-E $14 \times 14$ fuel assembly, which is shown in Figure 1-2. A discussion of the equipment modifications necessary for other LWR fuel assembly designs and sizes is contained in (2).

\section{MILLSTONE UNIT 2 SPENT FUEL STORAGE POOL}

The spent-fuel storage pool at Millstone Unit 2 will be divided into two regions. Region I is the high-enrichment, core offload region. Region II is reserved for fuel that has sustained at least $85 \%$ of its design burnup. Design burnup is defined as the average expected burnup of fuel having a given initial enrichment. It is anticipated that, in a fuel consolidation campaign, fuel assemblies to be compacted will be taken only from Region II. Consolidated fuel storage boxes containing the fuel rods from these assemblies may be stored in either of the fuel pool regions. The spent-fuel storage racks to be installed at Millstone Unit 2 are described in Section 2.

\section{DESIGN REQUIREMENTS}

Design and performance requirements for the fuel consolidation system and equipment for Millstone Unit 2 are set forth in ( $\underline{3})$. The principal general requirements are as follows:

- The equipment will normally be used at 12-month intervals for a period of approximately two months. The equipment should be designed, to the maximum extent practical, to operate continuously and without maintenance during the period of operation.

- The equipment shall be designed to remain in a safe condition under postulated off-normal conditions. 


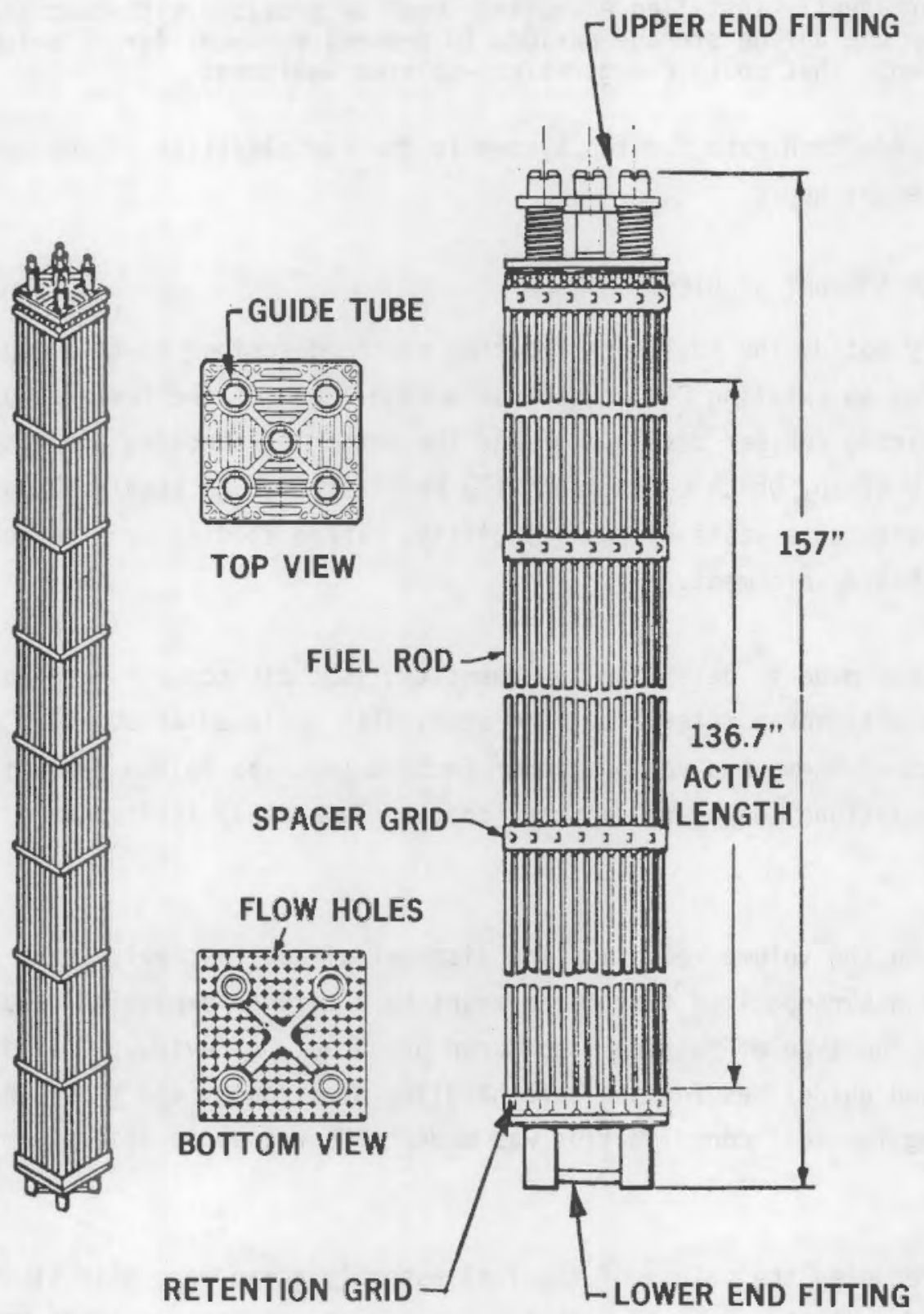

Figure 1-2. Fuel Assembly 
- The equipment shall be designed such that the fuel loads and accelerations are kept within acceptable limits.

- The equipment shall be designed such that surfaces which come in contact with the fuel do not damage the fuel rods.

- Permanently installed equipment shall be provided with restraints for use during storage periods to prevent movement during seismic events that could damage safety-related equipment.

The target production rate for the system is the consolidation of one spent- fuel assembly in eight hours.

\section{SYSTEM DESIGN SUPPORT STUDIES}

As previously noted, the fuel consolidation system described in this report was developed from an existing C-E conceptual design. One of the features of the $C-E$ concept requiring further development was the method of handling and disposing of fuel assembly scrap, which can potentially be classified as low-level waste and shipped off-site to a waste disposal facility. Three studies were performed in support of this development.

A study (4) was made to determine the quantity, isotopic content, and activity of the fuel assembly scrap materials. The study also included an economic analysis of the impact of these and various other factors (such as volume reduction and shipping regulations) on waste disposal costs. This study is discussed in Section 3.

With regard to the volume reduction and disposal of fuel assembly scrap Zircaloy material, it was recognized that there might be a fire or explosion hazard, depending on the type of cuttings and scrap produced. A review ( $\underline{5}$ ) of industry experience and guidelines for the safe handling of Zircaloy and their application to processing for fuel consolidation was made. The review is discussed in Section 4.

Methods of reducing the volume of the fuel assembly scrap were also studied ( $\underline{6})$. Commercially available types of reduction equipment and other methods were evaluated for the potential degree of volume reduction of the scrap materials. simple scoping tests were performed. The evaluation is discussed in section 5 . 
Section 2

DESCRIPTION OF PROCESS AND COMPONENTS

The equipment layout is shown schematically in Figure 2-1 and the basic process is depicted in the flow chart of Figure 2-2.

\section{CONSOL IDATION PROCESS}

A spent-fuel assembly is removed from the temporary storage rack and placed in the fuel disassembly station of the lower work platform. Here the upper end fitting is separated from the assembly by cutting the guide tubes, and then is deposited in the end fitting storage station. Fuel rods are removed up to one row at a time by the multiple rod pulling tool, which places them in the interim transfer canister situated in an adjacent station. The rods are reconfigured in the canister into a closepacked triangular array at the bottom. If a row of fuel rods removed by the multiple rod removal tool contains damaged rods, the undamaged rods are first separated from the row at the separation/recovery station. The damaged rods are deposited in the damaged fuel rod storage station; then the undamaged rods are picked up again and loaded into the interim transfer canister. After removal of the fuel rods from the assembly, the guide tubes are cut again just above the bottom grid cage to release the lower end fitting. The remaining grid cage/guide tube assembly is transferred to the compactor station where $i$ ts volume is reduced to $1 / 10 \mathrm{its}$ original envelope. The lower end fitting is transferred to the end fitting storage station.

When the interim transfer canister is fully loaded, containing the fuel rods and poison rods from two fuel assemblies, it is positioned over a consolidated fuel storage box located at the fuel rod transfer station. Rods are transferred from the canister into the storage box by gravity, and the rate of descent of the fuel rods is controlled by a telescoping cylinder mounted at the bottom of the transfer station. A rod transfer tool is used to verify completion of the transfer or give warning of a sticking rod. A cover is installed on the consolidated fuel storage box, which is then transferred to the temporary storage rack, and subsequently to a spent-fuel pool storage rack. 


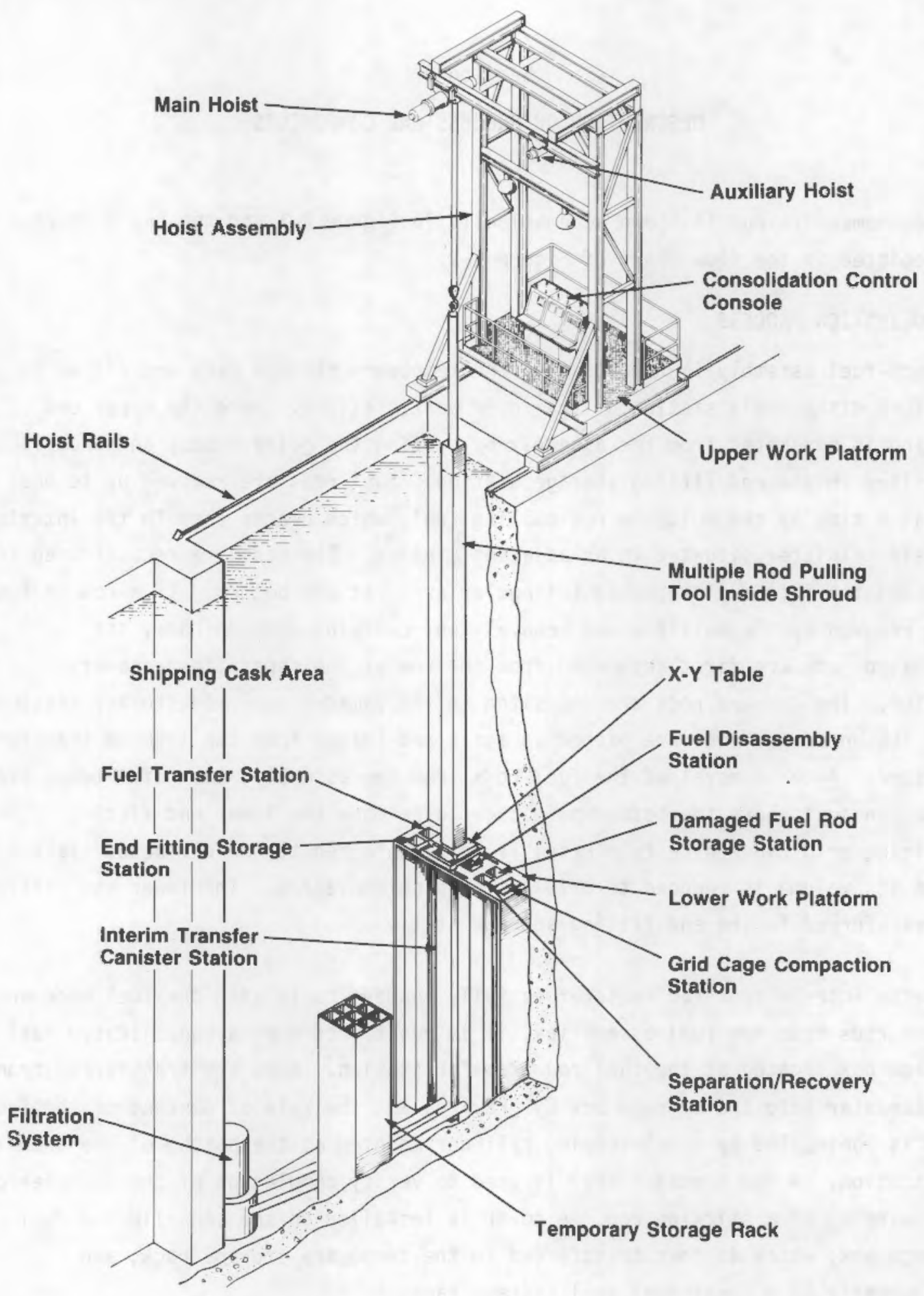

Figure 2-1. Equipment Layout 


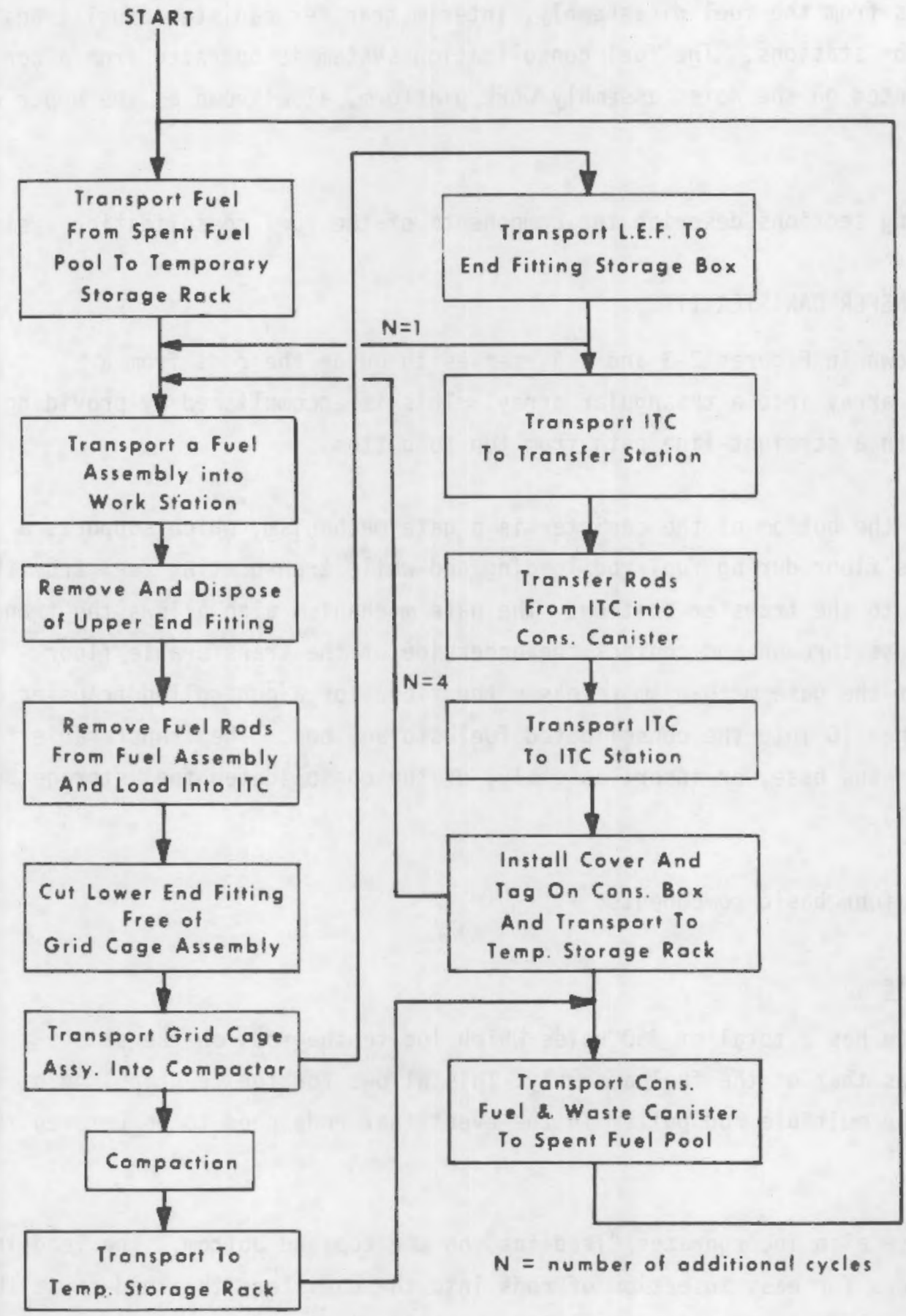

Figure 2-2. Process Flow Chart 
The $X-Y$ positioning table travels along the upper plate of the lower work platform to provide accurate location of the multiple rod pulling tool and its shroud at the individual work stations. The filtration system collects particulates from the fuel disassembly, interim transfer canister, fuel transfer and compactor stations. The fuel consolidation system is operated from a control console mounted on the hoist assembly work platform, also known as the upper work platform.

The following sections describe the components of the fuel consolidation system.

\section{INTERIM TRANSFER CANISTER (ITC)}

The ITC, shown in Figures $2-3$ and 2-4, serves to guide the rods from a rectangular array into a triangular array. This is accomplished by providing each rod with a straight-line path from top to bottom.

Attached to the bottom of the canister is a gate mechanism, which supports a transferable floor during fuel rod loading and while transporting fuel from the ITC station to the transfer station. The gate mechanism also allows the transfer piston to pass through and contact the underside of the transferable floor. Actuation of the gate mechanism releases the floor for a controlled transfer of rods from the ITC into the consolidated fuel storage box. The transferable floor then becomes the base, or insert assembly, of the consolidated fuel storage box (Figure 2-14).

The ITC has four basic components:

\section{The Top Plate}

The top plate has a total of 360 holes which locate the rods on the same centerline as that of the fuel assembly. This allows for the re-grappling of fuel rods with the multiple rod puller in the event that rods need to be removed from the ITC.

The top plate also incorporates "lead-ins" on the top and bottom. The lead-in at the top allows for easy insertion of rods into the canister; the lead-in at the bottom allows rods to re-enter the holes in the unlikely event that it is necessary to recover from an unsuccessful transfer. The canister allows for a reverse transfer if the rods have entered the consolidated fuel storage box by no more than 5 feet. 


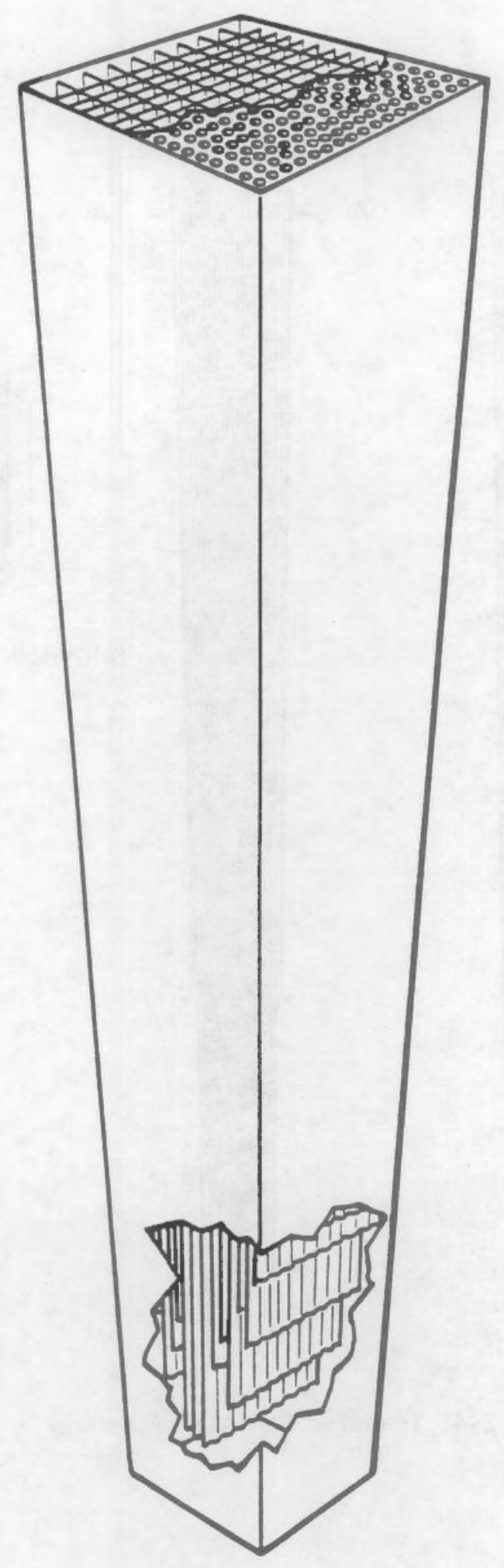

Figure 2-3. Interim Transfer Canister 

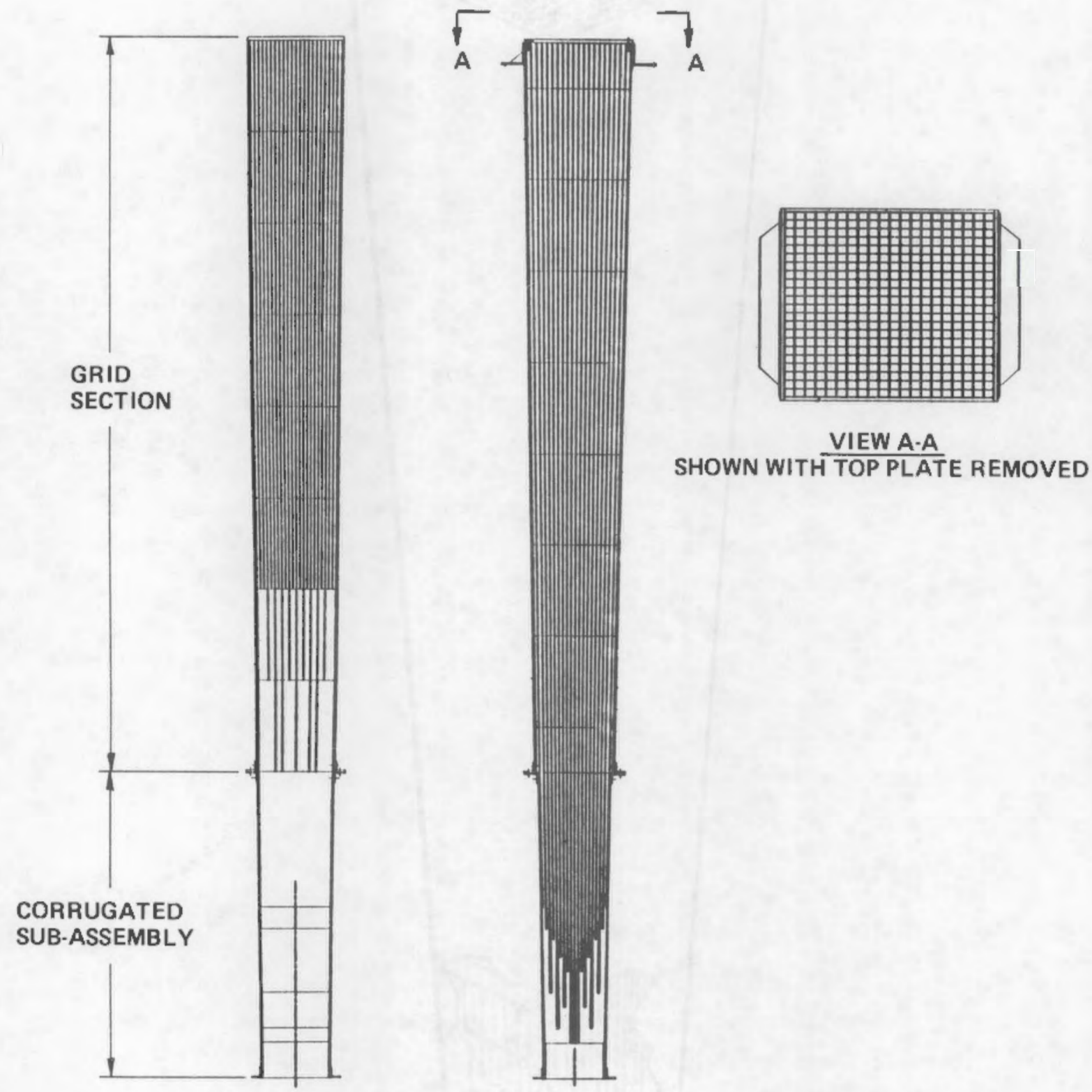

Figure 2-4. Transfer Canister Assembly 
The Grid Section

The grid section provides an individual, funneled path for each of the rods, thus guiding them from a loosely-packed rectangular array to a tightly-packed rectangular array. It is constructed of numerous slotted and interlocking plates which are assembled to form smooth and continuous tapering paths for all the fuel rods. The grid section mates directly with the corrugated sub-assembly described in the following section.

\section{The Corrugated Sub-assembly}

The corrugated sub-assembly serves to guide the rods from the tightly-packed rectangular array, arranged by the grid section, into the tightly-packed triangular array required for storage. This is accomplished using guide plates which are formed with gradually occurring converging corrugations as shown in Figure 2-5.

\section{The Gate Mechanism}

The gate mechanism consists of three machined plates sandwiched together but separated by bearings. The upper plate is also the framework which provides additional torsional rigidity to the ITC assembly.

The center plate can be rotated slightly to allow the transferable floor either to pass through the opening or be supported by the gate.

The lower plate is rigidly attached to the upper plate and is designed with tapered edges to facilitate the mating of the ITC with the consolidated fuel storage box.

\section{GUIDE TUBE CUTTER}

The guide tube cutter pictured in Figure 2-6 is a single-pass, internal tubing cutter. The consolidation system requires the use of three variations of this cutter, because there are three possible diameters to contend with in removing upper and lower end fittings. They are as follows:

- Upper end fitting removal of an unsleeved fuel assembly.

- Upper end fitting removal of a sleeved fuel assembly.

- Cutting within the necked-down area of the guide tube for removal of the lower end fitting. 


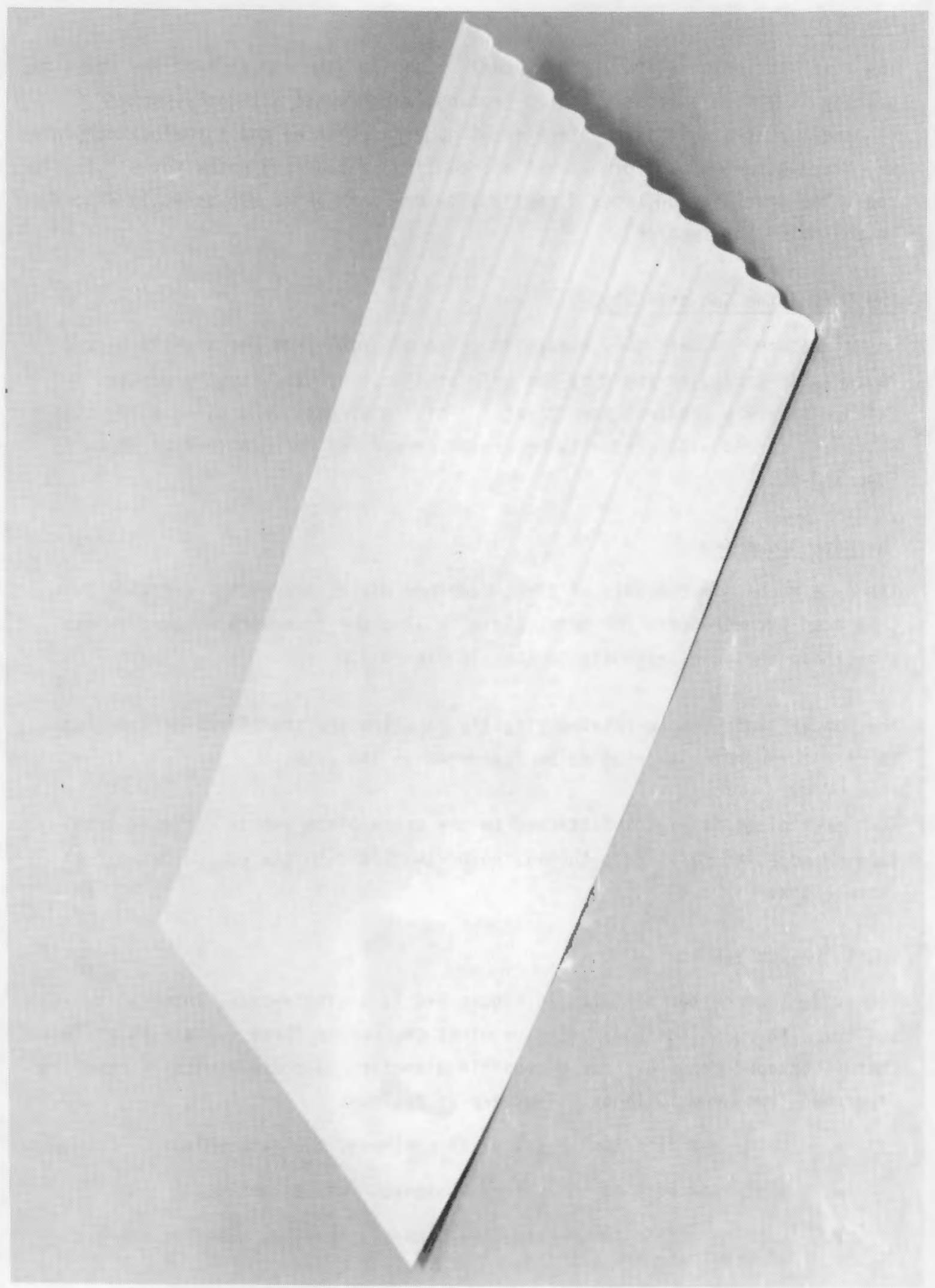

Figure 2-5. Corrugated Guide Plate

$$
\text { 2-8 }
$$




$$
\text { t }
$$


The commercially available cutter tool bit angles utilized in the guide tube cutter have been optimized to give reasonable cutter life with an improved cut, which has no loose residue, while also providing good penetrating characteristics.

The principles of operation are: (1) while turning clockwise the tool bit penetrates the wall of the tubing, (2) continued clockwise motion shears through the tubing until the penetration point is again reached, and (3) the tubing is severed. Because the cutter bit still protrudes beyond the tubing wall, the loose portion of the tubing is held by the guide tube cutter. For removal the loose piece of tubing is grasped with remote operated pliers, and the cutter is turned counterclockwise to release the tubing section. If, as in the majority of cases, the severed tube is attached to an as yet still fixed member, the guide tube cutter is released by turning counter-clockwise while extracting the tool.

\section{MULTIPLE ROD PULLING TOOL (MRPT)}

The multiple rod pulling tool as shown in Figure 2-7 is comprised of three sub-assemblies: (1) pulling head, (2) shroud, and (3) mast.

The shroud assembly sits on the $X-Y$ table and can be located above any of four stations (fuel disassembly, ITC, separation, or damaged fuel rod). The mast and pulling head assemblies are supported on the hoist assembly, and are guided by their shroud during their vertical travel. The main features for each of the three sub-assemblies are highlighted below.

\section{Pulling Head}

The pulling head assembly shown in Figure $2-8$ is the mechanism that grasps from 1 to 14 fuel rods for removal from the fuel assembly. The grippers of the pulling head are oriented to pick one row of 14 rods. Each gripper can be individually controlled from the main console either to release a rod, or to pull the fuel rod with maximum forces of 50 and 100 pounds. Each gripper module contains a preloaded spring, double-acting pneumatic cylinder, and a linear variable differential transformer (LVDT). The modular construction is designed to facilitate replacement of cylinders, grippers and LVDT. The pre-loaded spring provides fail-safe spring closure of the grippers. The double-acting cylinder can be pressurized on one side to release the rod remotely, or the cylinder can be pressurized on the opposite side of the piston to add to the fail-safe clamping force of the spring in the event that a rod requires more than 50 pounds pulling force. 


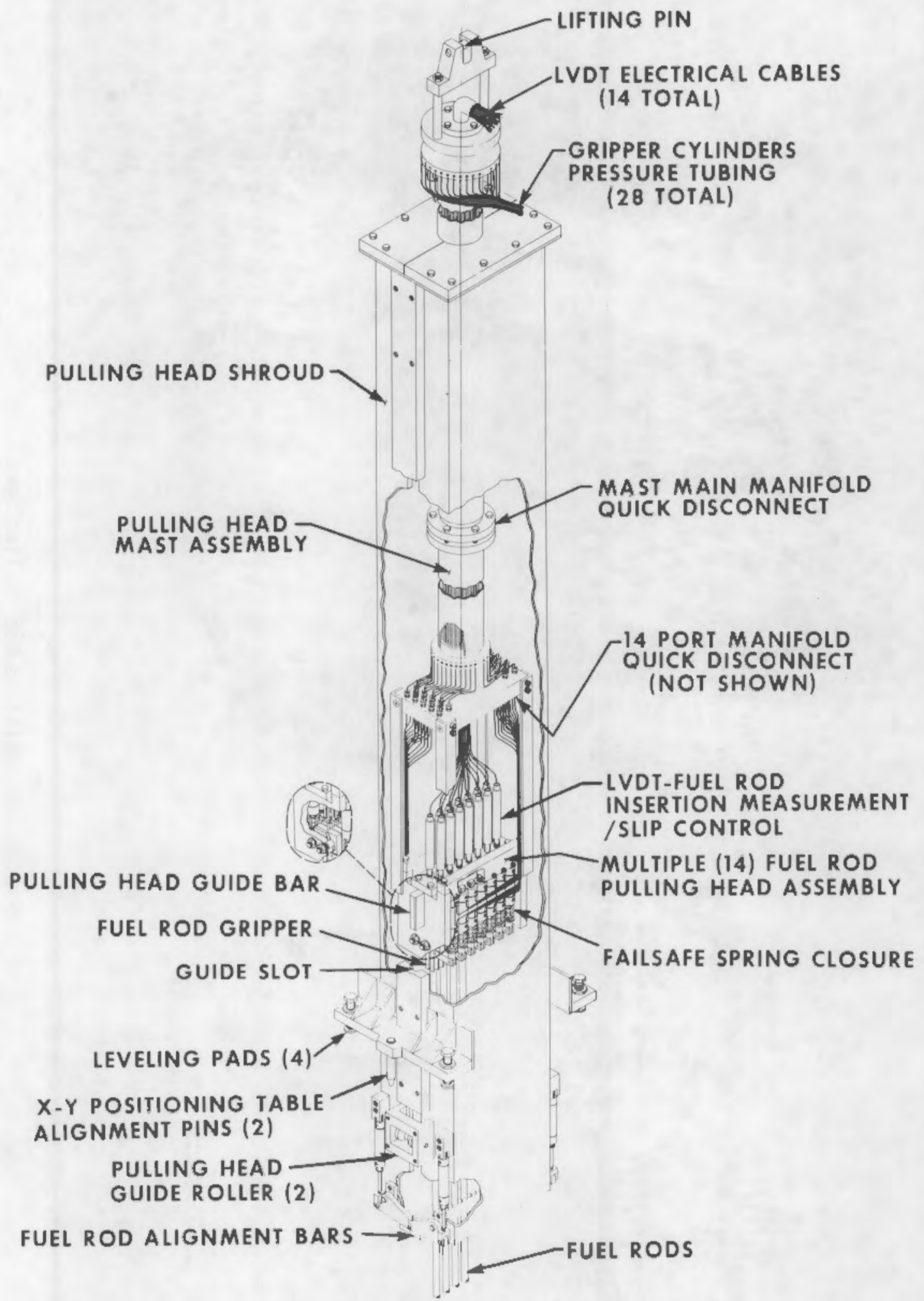

Figure 2-7. Multiple 14X14 Fuel Rod Pulling Tool 


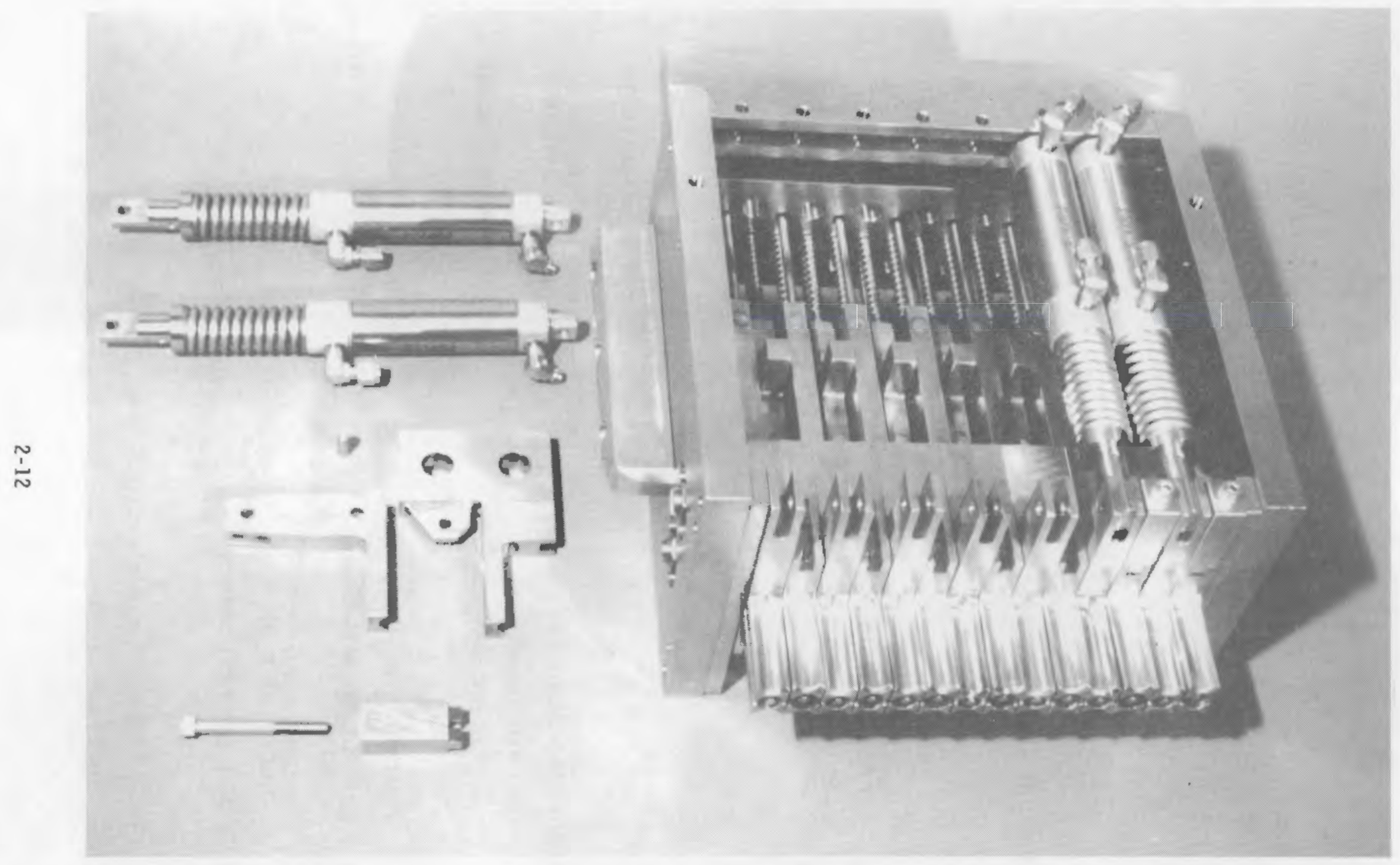

Figure 2-8. Multiple Rod Pulling Head 
The LVDT provides information to the control logic of the penetration of a rod within the pulling grippers. The MRPT control console logic includes minimum and maximum rod insertion limits to prevent accidental raming of a rod or gripping of a rod with insufficient gripping area. The LVDT also has the very important function of detecting any rod slippage. Detection of rod slippage immediately stops the hoist, and identifies the rod which has slipped to the operator.

\section{Shroud Assembiy}

The main functions of the shroud assembly are to:

- Guide the pulling head, mast, and fuel rods.

- Collect and vent any gases released during the rod pulling effort.

- Align the fuel rods for insertion into the ITC.

- Align the pulling head with the $X-Y$ table for accurate positioning of the MRPT above the various stations.

The guidance system consists of a guide slot, within which fits the pulling head guide bar, providing coarse guidance over the full travel of the MRPT head. A spring-loaded guide roller system provides for precise MRPT head location when the head is positioned for grasping the fuel rods.

The fully enclosed shroud is vented to the plant's gas handling system to capture any released gases.

Remotely retractable fuel rod alignment bars are located at the bottom of the shroud. The alignment bars are retracted to allow the pulling head to exit the shroud and grapple the fuel rods. As soon as the pulling head is lifted past them, the alignment bars are closed to maintain precise fuel rod alignment for correct insertion into the ITC. These fuel rod alignment bars are also designed to gauge the maximum allowable rod diameter. If a fuel rod has an excessive diameter or localized blister, it will not pass through the alignment bar. Rod slippage will occur and identify a possibly damaged rod. The alignment bar is then partially retracted to allow the localized deformation to pass by, and then closed to continue alignment and gauging operations.

Also attached to the shroud assembly are the support pads, which include leveling pads, and the $X-Y$ positioning table alignment pins. 
Mast Assembly

The mast assembly supports the MRPT from the hoist, and contains all of the pneumatic and instrumentation lines. Sectional construction design of the mast assembly facilitates handling and field installation.

The multiple rod pulling tool has a dedicated air compressor capable of delivering sufficient pressure for actuation of the multiple rod puller grippers.

$X-Y$ POSITIONING TABLE

The $X-Y$ positioning table depicted in Figure 2-9 locates the multiple rod pulling tool at any point above the fuel disassembly station, ITC station, damaged fuel rod station, or the recovery (separation) station.

The remotely controlled $X-Y$ table is fastened to the top surface of the lower work station. The $X-Y$ table is propelled by rodless cylinders using pressurized water and is equipped with LVDTs providing a locating accuracy, in either the " $X$ " or "Y" direction, of 0.050 inches. The LVDT signal is connected to remote readouts and to the control console logic. The $X-Y$ table includes provisions for rotating the multiple rod pulling tool 90 degrees to accommodate the removal and insertion patterns shown in Figure 2-10.

\section{FILTER SYSTEM}

The filter system schematically depicted in Figure 2-11 consists of two pump and filter units running in parallel, manifolded to four work stations to provide positive downward flow in each station. The pump and filter units are sized to ensure sufficient velocity at the MRPT and work station interface to entrain and filter out released crud before it can disperse within the cask laydown area.

Filtration occurs in several stages to minimize filter usage and therefore minimize the volume of waste products. A strainer at the pump inlet protects the pump from large chips. This strainer also collects zirconium alloy chips which may be released in the consolidation effort. Downstream from the pump are two filter stages, the final stage being capable of removing particles as small as 2 microns. The 2-micron level corresponds to a predicted crud removal of greater than $99 \%$. 


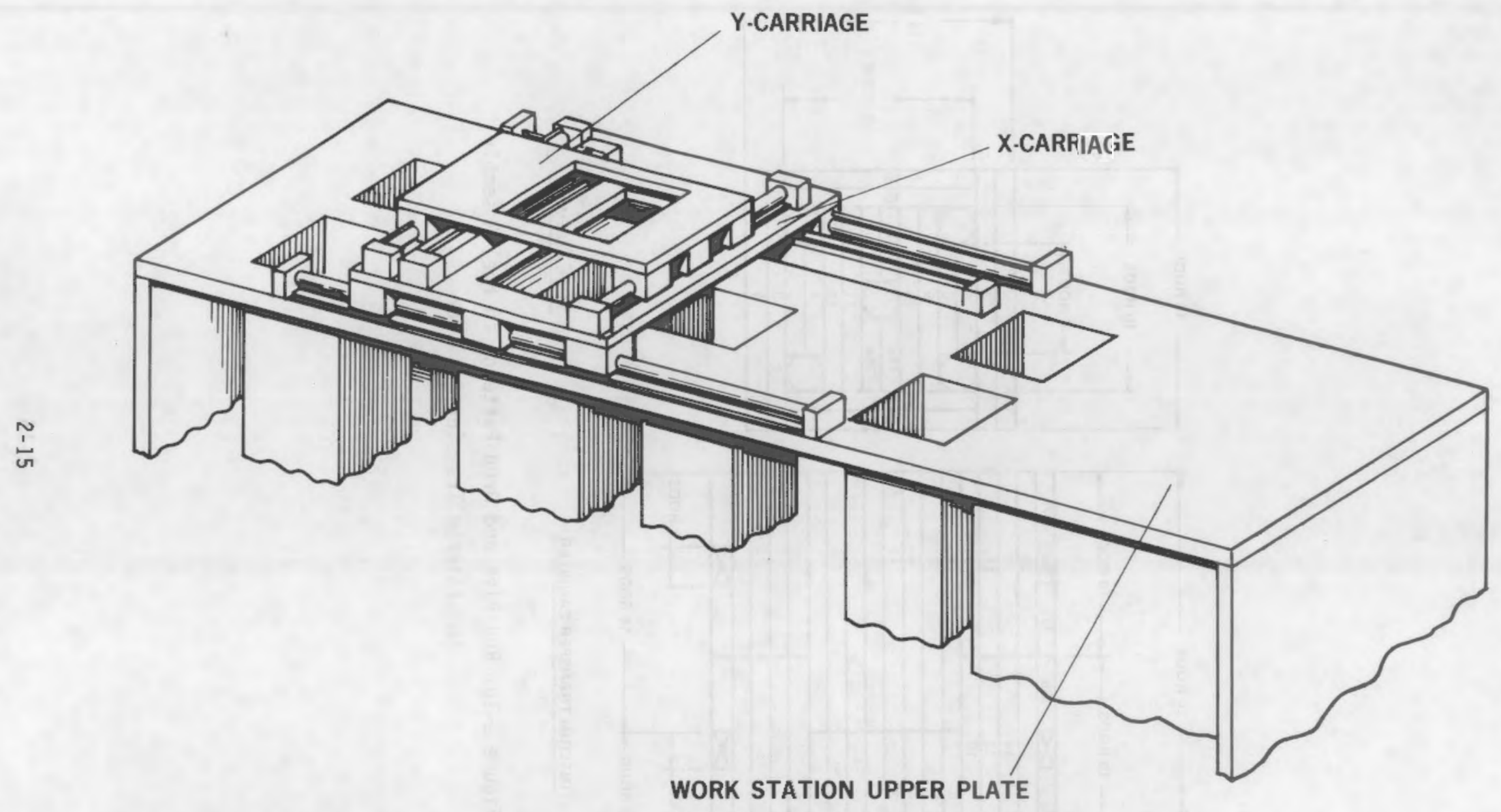

Figure 2-9. X-Y Positioning Table 


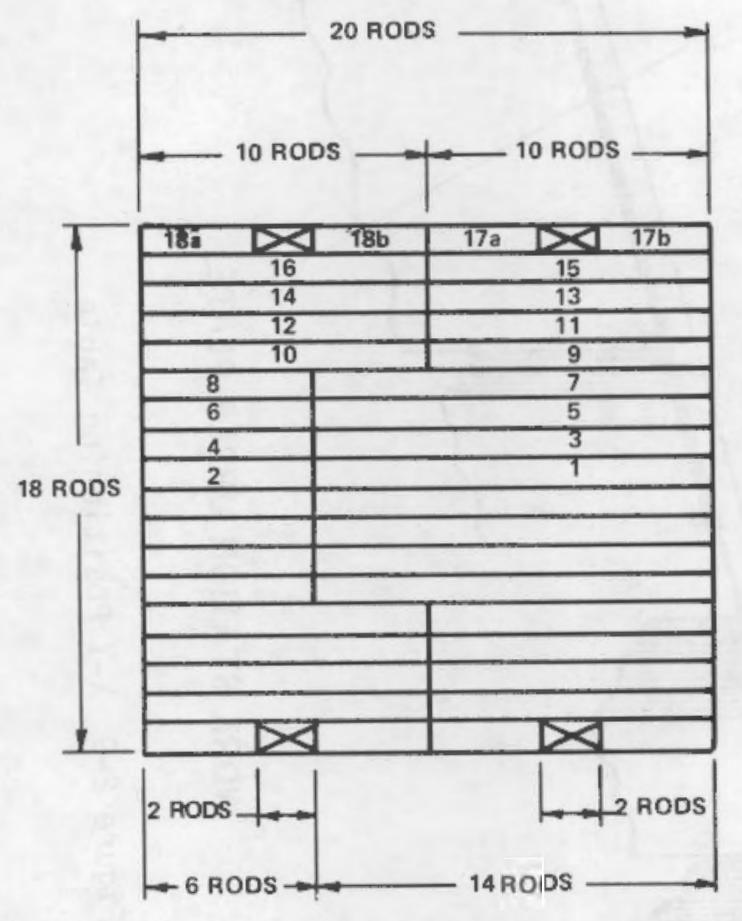

INTERIM TRANSFER CANISTER

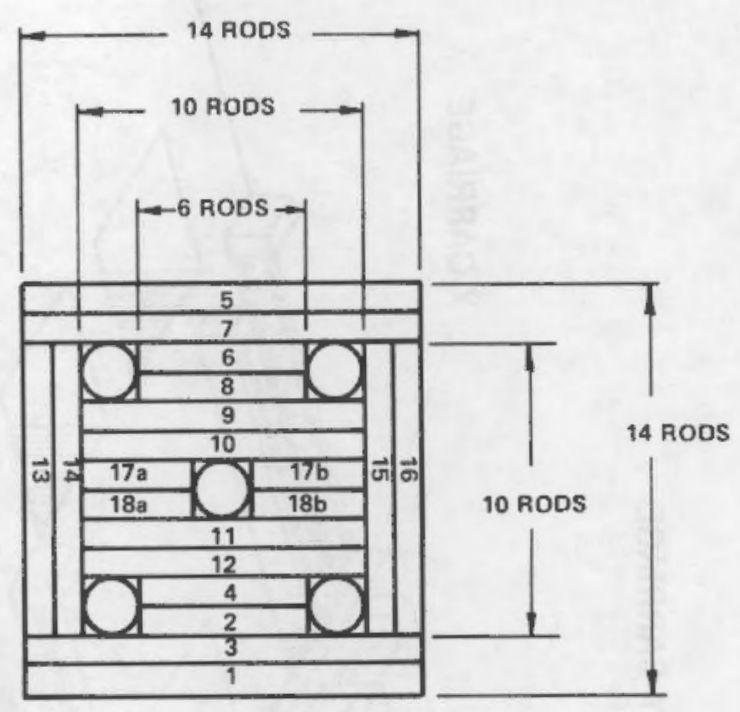

FUEL ASSEMELY

Figure 2-10. Rod Pick and Drop Patterns in Fuel Assembly and Interim Transfer Canister 


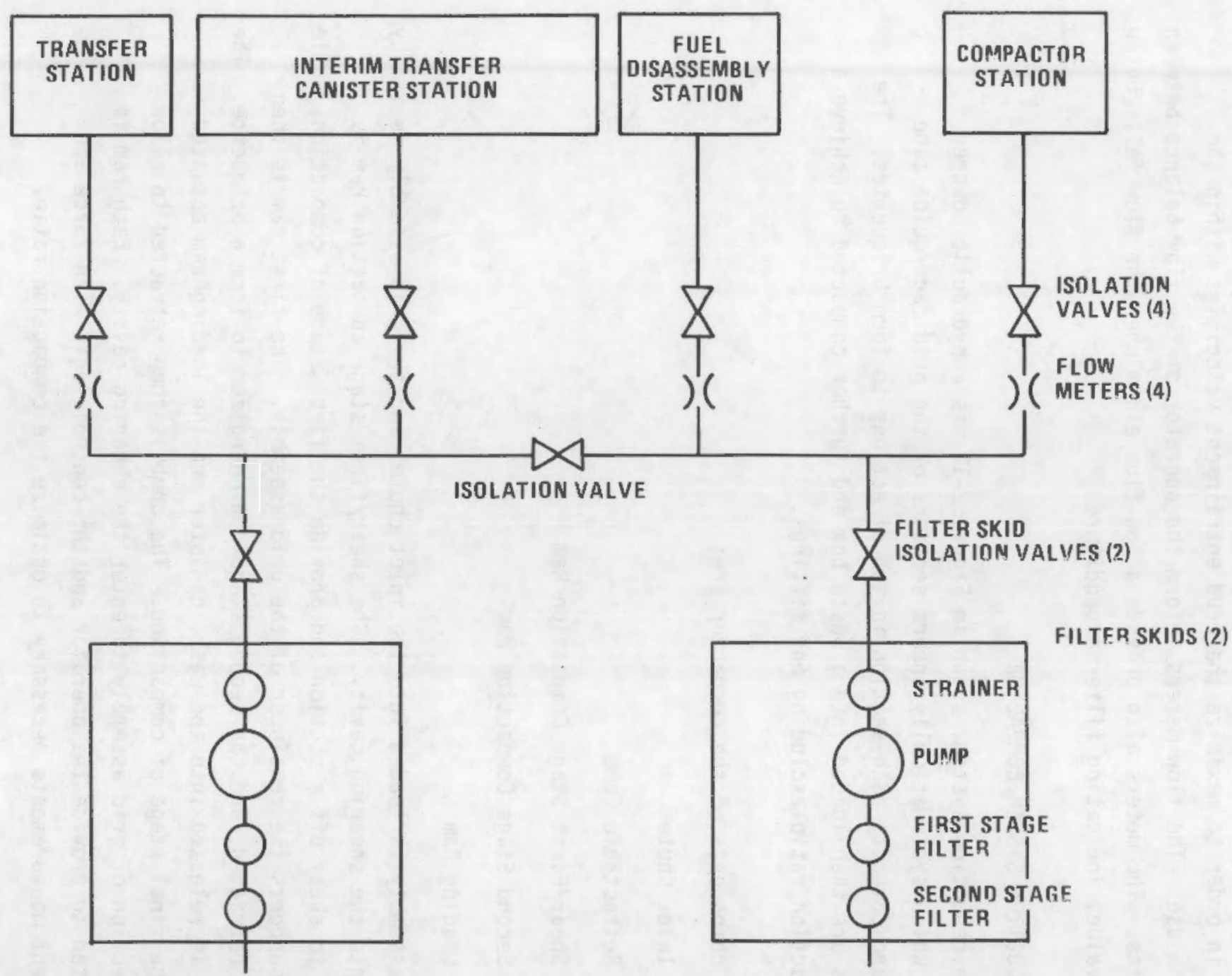

Figure 2-11. Filter System Schematic 
The pump/filter suction manifold has branches connecting to the fuel disassembly station, interim transfer canister station, transfer station, and compactor station. Each of these branches contains an isolation valve and a flow sensor. The valves are used to balance the flow between stations, or isolate unused stations, in order to maximize the crud entrainment velocities within the stations in use. The flow meters inform the operator of the flow balance between the circuits. The meters also provide a low-flow alarm when the flow falls below a preset value, indicating filter expenditure.

\section{VOLUME REDUCTION SYSTEM/COMPACTOR}

The volume reduction system, shown in Figure $2-12$, is a hydraulic powered compactor which systematically shears sections of the grid cage/guide tube assembly and compacts each section in two directions to form briquettes. The briquettes are then loaded into a waste box and further compacted to achieve a 10:1 compaction ratio excluding end fittings.

The major components of the compactor are:

- Inlet Chute

- Retractable Comb

- Shear/First Stage Compaction Ram

- Second Stage Compaction Ram

- $\quad$ Loading Ram

The grid assembly is loaded into the inlet chute, and the grid assembiy is fed by gravity into the shearing cavity. The shear/first stage compaction ram is activated to shear off a section and provide the first stage of compaction, while the comb supports the remainder of the grid assembly. The first ram is then partially retracted, and the second stage ram energized to form a briquette. The briquette is released into the waste canister and the loading ram actuated to provide the final stage of compaction. The comb is then retracted to allow another section of grid assembly to enter the shearing cavity. Each ram is instrumented to provide the operator and the control logic with force and displacement measurements necessary to optimize the compaction ratio. 


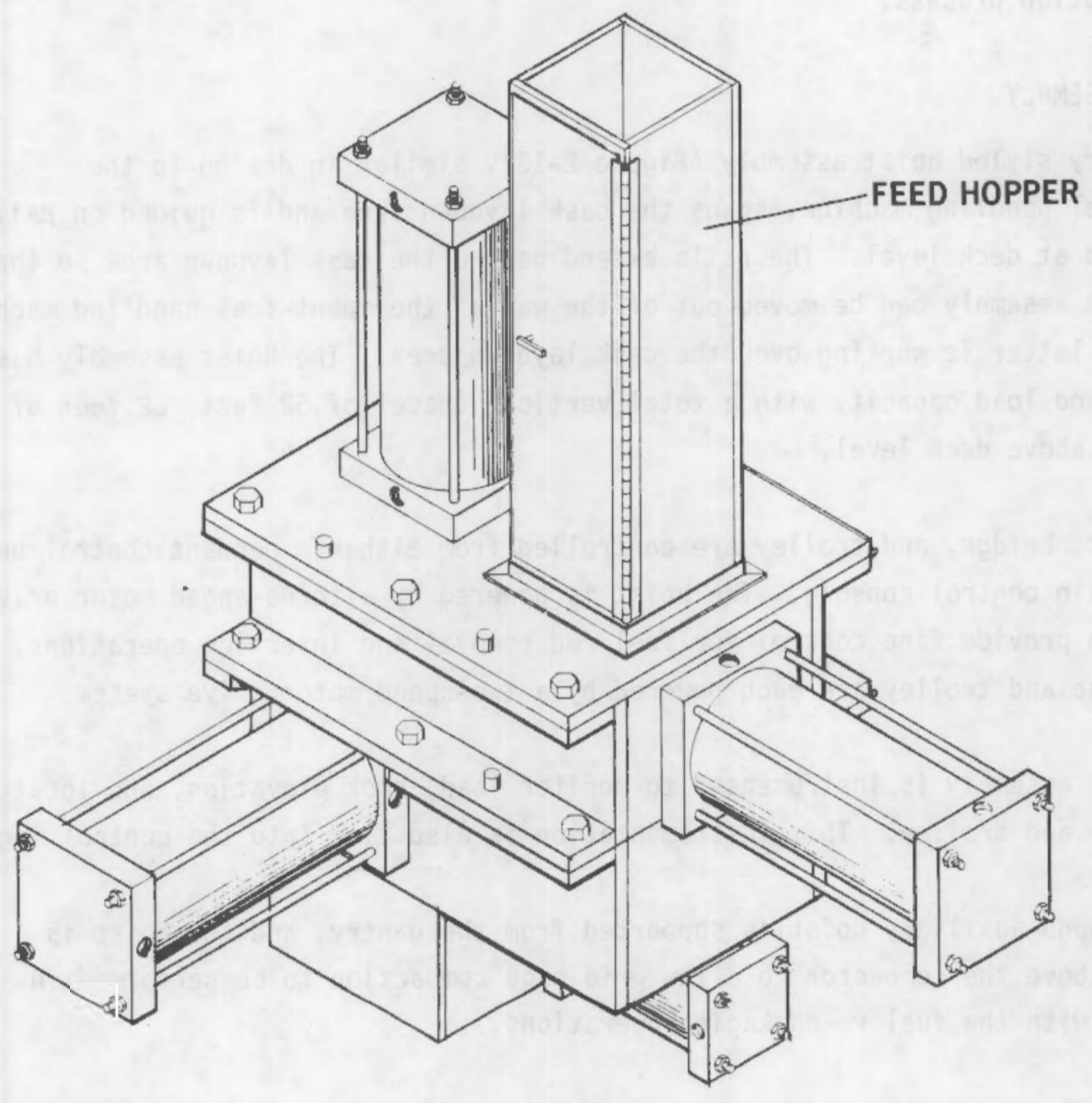

Figure 2-12. Compactor 
TEMPORARY FUEL STORAGE RACK

The temporary fuel storage rack is a free-standing assembly, located within the cask laydown area, and is used to temporarily store nine fuel assemblies in a $3 \times 3$ array for batch processing. The spent-fuel pool can then be isolated from the processing area by installation of the cask laydown gate, thus minimizing crud infiltration and accidental contamination of the spent-fuel pool during the fuel consolidation process.

\section{HOIST ASSEMBLY}

The gantry styled hoist assembly (Figure 2-13), similar in design to the spent-fuel handling machine, spans the cask laydown area and is guided on rails installed at deck level. The rails extend beyond the cask laydown area so that the hoist assembly can be moved out of the way of the spent-fuel handling machine when the latter is working over the cask laydown area. The hoist assembly has a 6,000-pound load capacity with a total vertical travel of 52 feet, 22 feet of which is above deck lever.

The hoist, bridge, and trolley are controlled from either a pendant control unit or the main control console. The hoist is powered by a three-speed motor drive system to provide fine control for fuel rod removal and insertion operations. The bridge and trolley are each powered by a two-speed motor drive system.

The hoist assembly is instrumented to monitor load, hook elevation, and locations of bridge and trolley. This instrumentation is also tied into the control logic.

A 1000-pound auxiliary hoist is supported from the gantry, and the hoist is located above the compactor to allow grid cage compaction to be performed in parallel with the fuel re-packaging operations.

A work platform, which supports the operators and the main control console, is attached to the hoist assembly.

CONTROL CONSOLE

The main control console, located on the work platform of the hoist assembly, houses a programmable controller and the readouts and controls for the hoist assembly, compactor system, multiple rod puller, filter system, X-Y positioning table and TV system. Figure 2-14 illustrates the multiple rod pulling tool control console. 


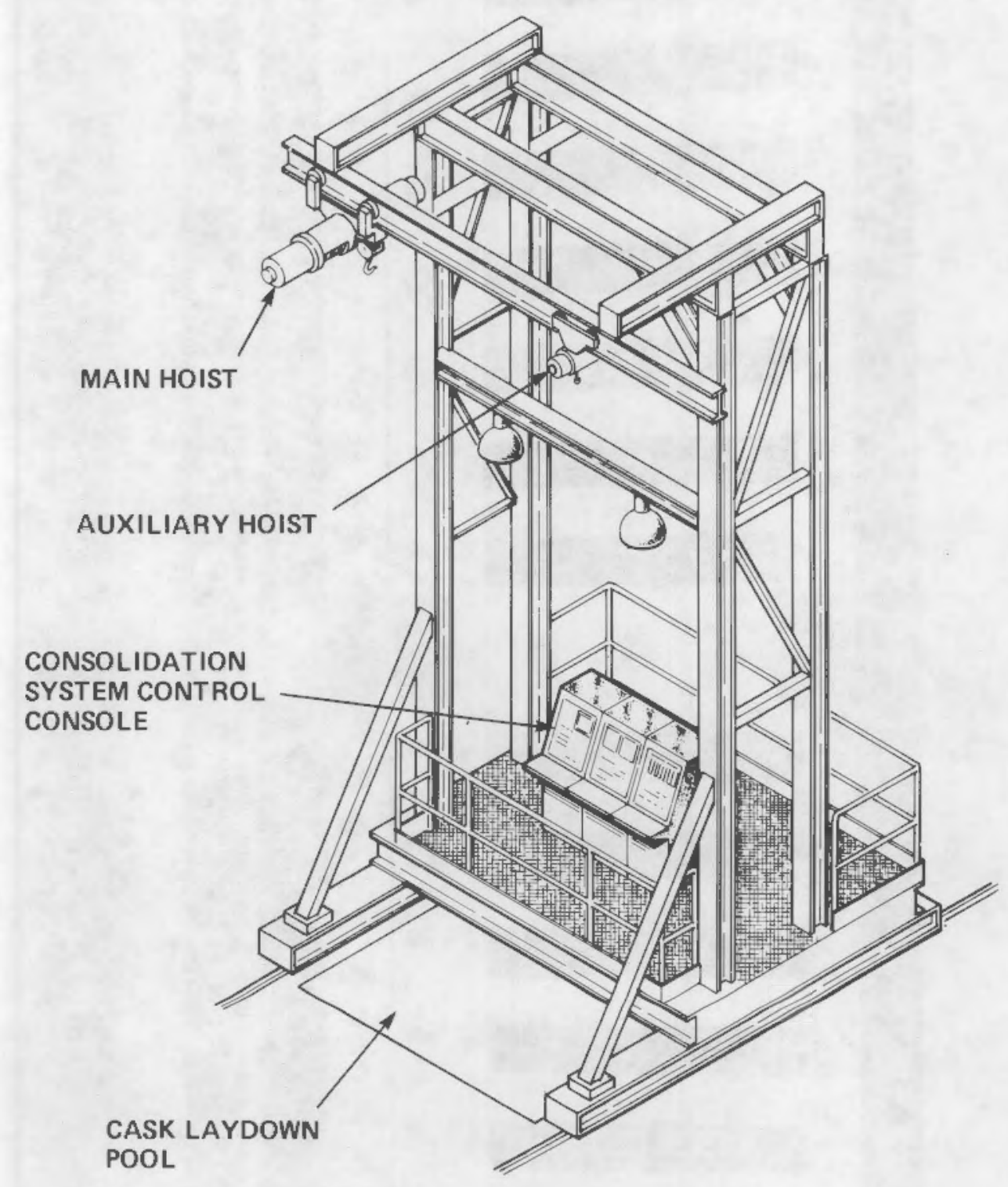

Figure 2-13. Hoist Assembly 


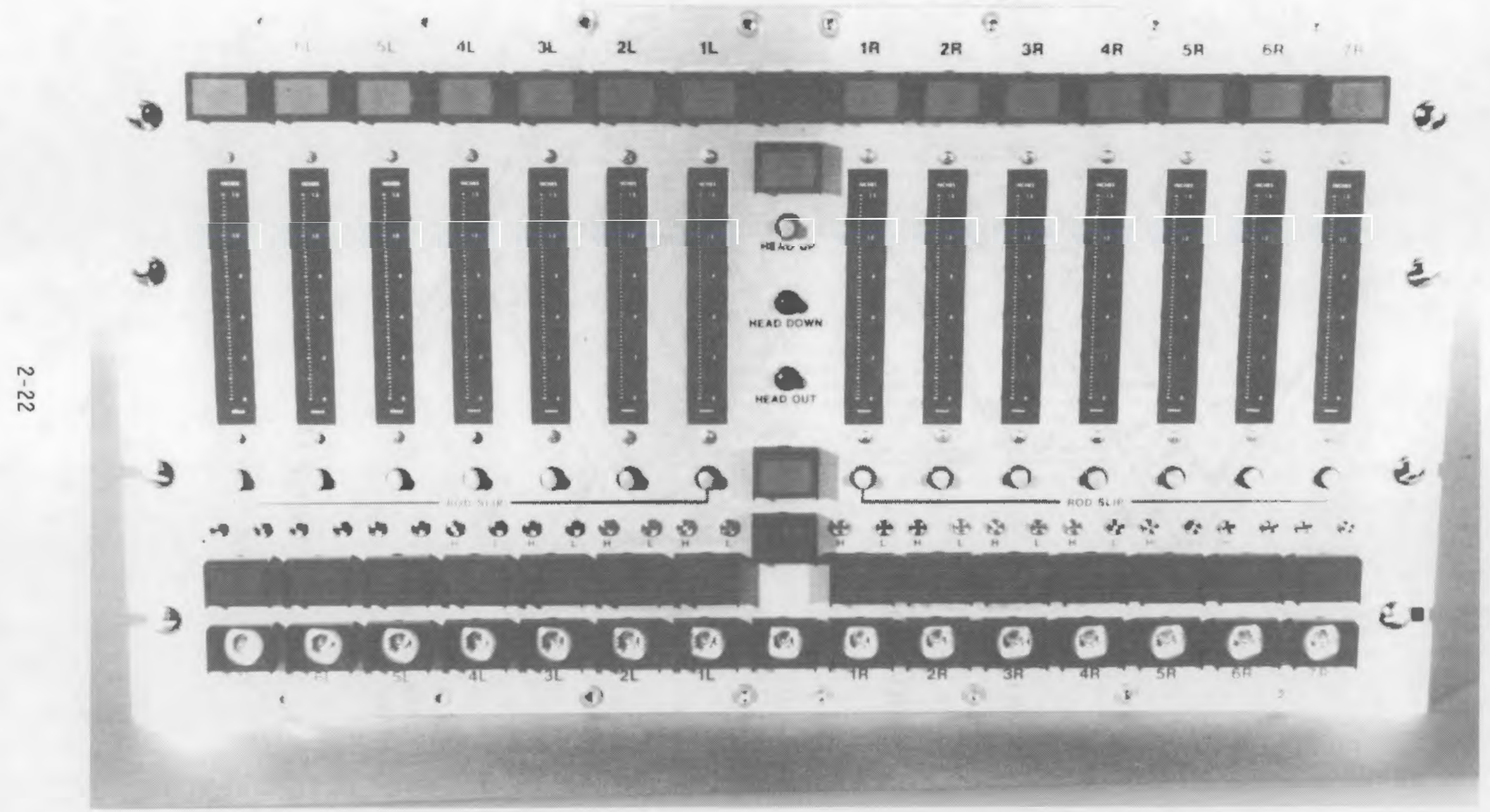

Figure 2-14. Multiple Rod Puller Control Console 
The programmable controller monitors the entire fuel consolidation process, and the controller interfaces the logic of the numerous controls to minimize operator error. In addition, the programmable controller facilitates modification of the process logic as experience is gained.

\section{HYDRAULIC POWER UNIT}

The hydraulic power unit, a "stand-alone" electrically powered cabinet located at deck level, contains the pumps, tank, and servo valves used to control the functions of the compactor, transfer piston, and the sleeve removal tool. The servo valves and pumps are controlled by the logic from the main control console.

\section{LOWER WORK PLATFORM}

The main function of the lower work platform (Figure 2-15) is to support the individual stations listed below:

- Fuel Disassembly Station

- Interim Transfer Canister Station

- Damaged Fuel Rod Station

- Separation/Recovery Station

- End Fitting Station

- Fuel Rod Transfer Station

- Compactor Station

The lower work platform is supported by the cask laydown area floor. Adjustable support pads are incorporated into the lower work platform design for proper leveling and load distribution. The platform is located and stabilized by brackets tied to pool wall embedments.

Mounted to the top plate of the work platform are the following:

- Camera tracking system.

- $X-Y$ table.

- ITC and fuel rod transfer stabilization framework. 


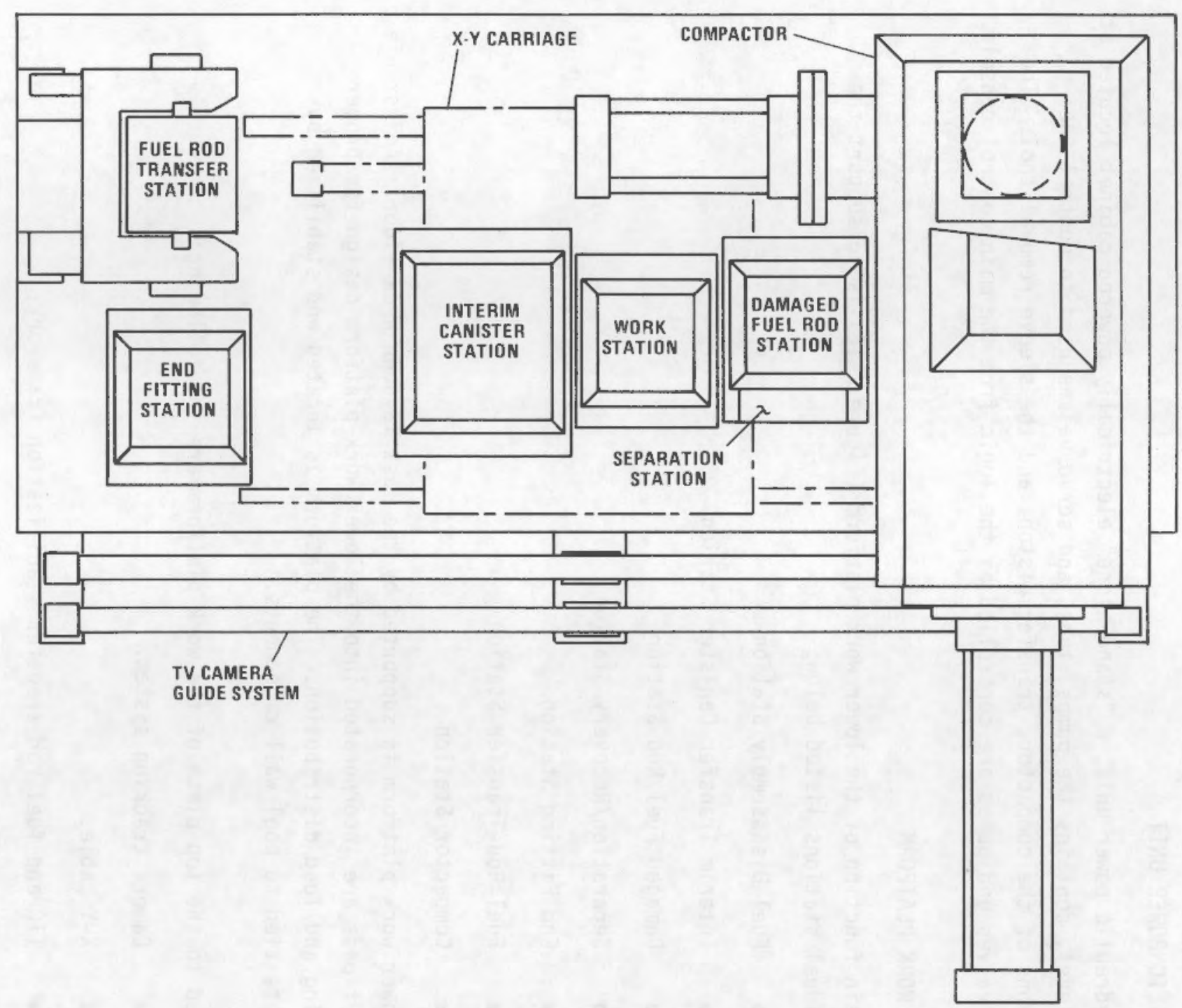

Figure 2-15. Lower Work Platform 
A cut-out for tool storage is provided at the pool wall interface, in addition to the cut-outs for the previously mentioned stations. Details of the seven individual work stations are given in the paragraphs following.

\section{Fuel Disassembly Station}

This is the station where the spent fuel assembly is disassembled and fuel rods removed. It is a fully enclosed shroud connected to the filter manifold. The work station is equipped with a holddown mechanism which secures the lower end fitting and prevents the fuel assembly from being lifted out of the work station during rod removal.

An accurate reference point is required to locate the MRPT precisely to grapple the desired fuel rods. This is accomplished with the use of a piston-operated index clamp, mounted on the $X-Y$ table base plate, which has guide bars that automatically center the top spacer grid of the fuel assembly in the disassembly station.

\section{Interim Transfer Canister Station}

This station is where the fuel rods are loaded by the MRPT into the interim transfer canister.

The ITC station is shrouded and connected to the filter system manifold to capture any crud released during rod insertion.

\section{Separation/Recovery Station}

Separation of damaged rods from those undamaged is achieved at the separation/ recovery station. This station is comprised of a single row of 14 tubes with closed bottoms which permit the release of undamaged rods for future re-grappling, after disposal of damaged rods in the damaged fuel rod container.

\section{Damaged Fuel Rod Station}

The damaged fuel rod station contains the damaged fuel rod canister. The damaged fuel rod canister consists of a consolidated fuel storage box with tubes whose inside diameters provide sufficient clearance for damaged or blistered rods. Each tube provides a compartment for a failed or damaged rod. The canister is accurately aligned for receipt of the rods by an index clamp similar to that at the fuel disassembly station. 


\section{End Fitting Station}

At this work station, the end fittings are systematically loaded into a waste box for long term storage in or out of the spent fuel pool. The end fitting station is designed to accept a consolidated fuel storage box if long term storage within the spent fuel pool is elected. A shorter version of the consolidation box which fits into a standard shipping cask, such as the Chem-Nuclear model CS-113 which has a depth of 36 inches, can also be accepted at the station. This option is provided to facilitate off-site storage should that prove to be practicable.

\section{Compactor Station}

The compactor station incorporates the mounting and support brackets for the compactor system. A connection to the filter system is provided so that metal chips and crud, which may be released during the compaction cycle, can be retained in the filters.

\section{Fuel Rod Transfer Station}

The fuel rod transfer station is shrouded and connected to the filter system manifold. The fuel rod transfer station is designed to accept a consolidated fuel storage box, and includes a multi-stage telescoping piston which controls the rate of transfer of the fuel rods and transferable floor from the ITC into the consolidated fuel storage box.

There is a framework above the work station to stabilize the ITC when it mates with the top of the consolidated fuel storage box. The upper end of the consolidated fuel storage box is held in accurate alignment with the ITC by a piston operated clamp mounted on the base of the framework. The framework also aids in stabilizing the fuel rod transfer tool.

\section{TV SYSTEM}

The TV System is comprised of:

- Three cameras

- Three monitors

- Two camera mounts

- One tracking system

- One video recorder 
Two of the cameras are supported on mounts having two degrees of freedom. The camera support can be remotely controlled to move up and down and to rotate in the vertical plane.

One mount is fastened to a table which is propelled by a water-powered rodless cylinder and track-guided along the entire length of the lower work platform, providing viewing for any of the work stations. A second mount is fastened to the top of the fuel disassembly station and scans the work platform at a $90^{\circ}$ angle to that of the tracking system's field of view. The camera supported by the stationary mount is equipped with a zoom lens to provide better resolution when viewing the more distant stations. A third camera is "hand-held" by an operator to view any part of the cask laydown area.

The monitors and the video recorder are located in the main control console.

ROD TRANSFER TOOL

The rod transfer tool represented in Figure 2-16 is used to verify the transfer of fuel rods from the ITC into the consolidated fuel storage box.

It consists of 360 tubes which are laterally stabilized by support plates. The tube assembly slides within a shroud, which acts as a guide. A detection system on the tubes alerts the operator in the event of a rod problem during the transfer.

MISCELLANEOUS TOOLING

A listing of the miscellaneous tooling, along with a brief description of each, follows:

- Sleeve Pulling Tool: The sleeve pulling tool is a hydraulically powered unit used to withdraw sleeves from the guide tubes of sleeved fuel assemblies.

- Fuel Handling Tool: The fuel handling tool is designed to handle fuel bundles, upper end fittings, and the loaded consolidated fuel box.

- Single Rod Puller: The single rod pulling tool uses a pneumatically actuated cylinder to operate a collet which grips the fuel rod. 


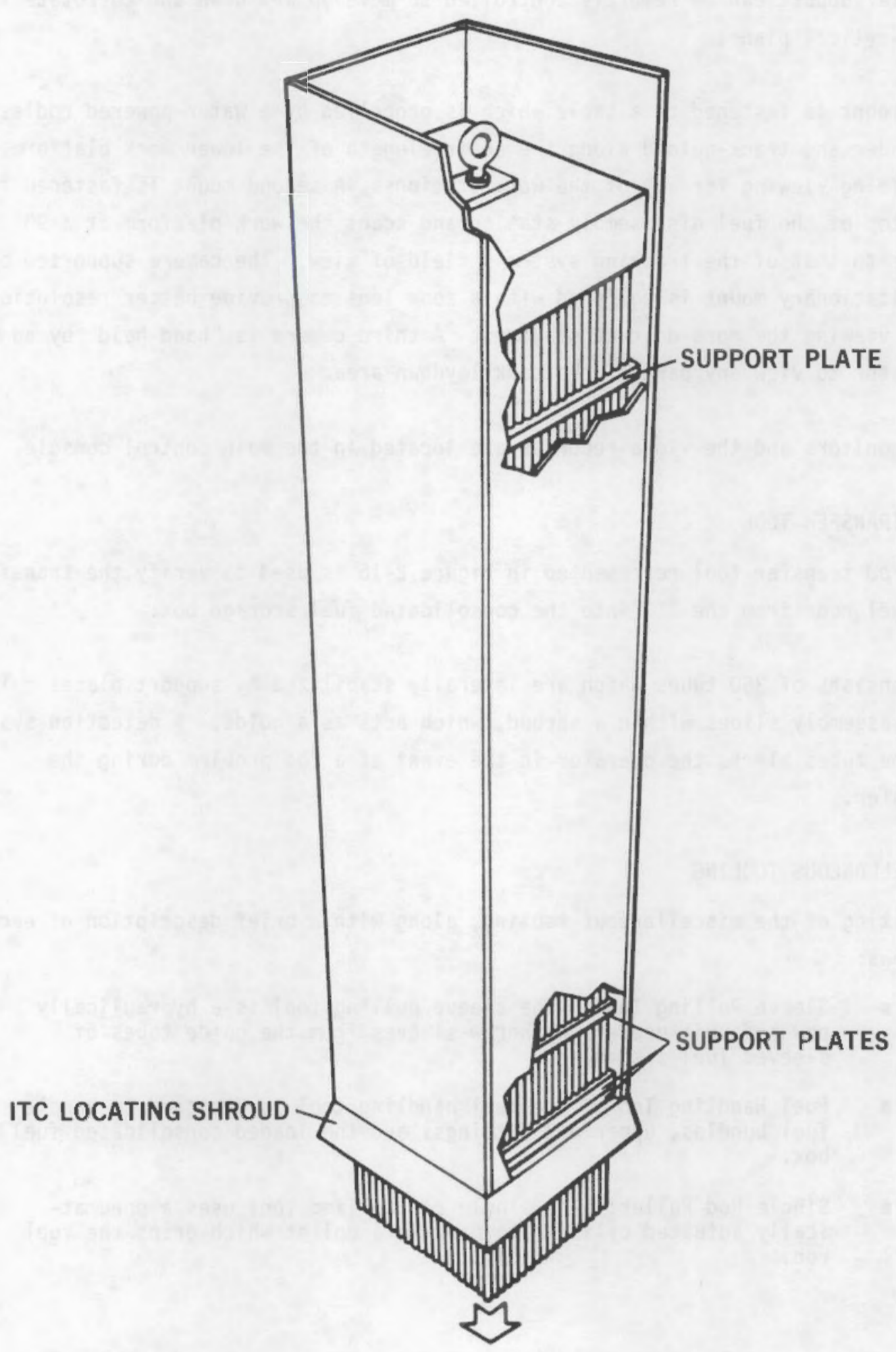

Figure 2-16. Rod Transfer Tool 
- Filter System Tooling: The filter system tooling includes grappling devices for filter cartridge removal and lid removal/ installation.

- Lower End Fitting Handling Tool: The lower end fitting handling tool is used to transport the end fitting from the fuel disassembly station and load it into the end fitting storage box.

- Grid Cage Handling Tool: The grid cage handling tool is utilized to move sections of the grid cage or the entire grid cage from the fuel disassembly station to the compactor system.

CONSOLIDATED FUEL STORAGE BOX

The consolidated fuel storage box, shown in Figure $2-17$, is sized to accept the fuel rods from two fuel assemblies in a tightly-packed triangular array. The floor, or insert assembly, which supports the fuel rods, is transferred from the interim transfer canister with the fuel rods. The floor plate of the insert assembly includes flow holes for fuel rod cooling. A locking cover assembly, also depicted in Figure 2-17, is installed into the upper portion of the consolidated fuel storage box to contain the fuel rods. The cover design permits grappling of the loaded storage box in a manner similar to grappling of the spent-fuel assembly. A locking tab, not designed to be removable, provides for visual fuel accountability.

\section{FUEL RACKS}

The following description is of the fuel storage racks to be employed at Millstone Unit 2. A number of different rack designs, however, are amenable to fuel consolidation.

The fuel storage racks are C-E design and are fabricated from type 304 low carbon stainless steel. The racks are monolithic honeycomb structures with square fuel storage locations as shown in Figure 2-18. Each storage location is formed by welding stainless steel sections along the intersecting seams, permitting the assembled cavities to become the load bearing structure, as well as forming the storage cell enclosures.

Each module is of a free-standing design, and is seismically qualified without mechanical dependence on neighboring modules or pool walls. This feature enables remote installation (or removal if required for pool maintenance) with minimal effort. Reinforcing plates at the upper peripheral edges provide the required strength for handling. 


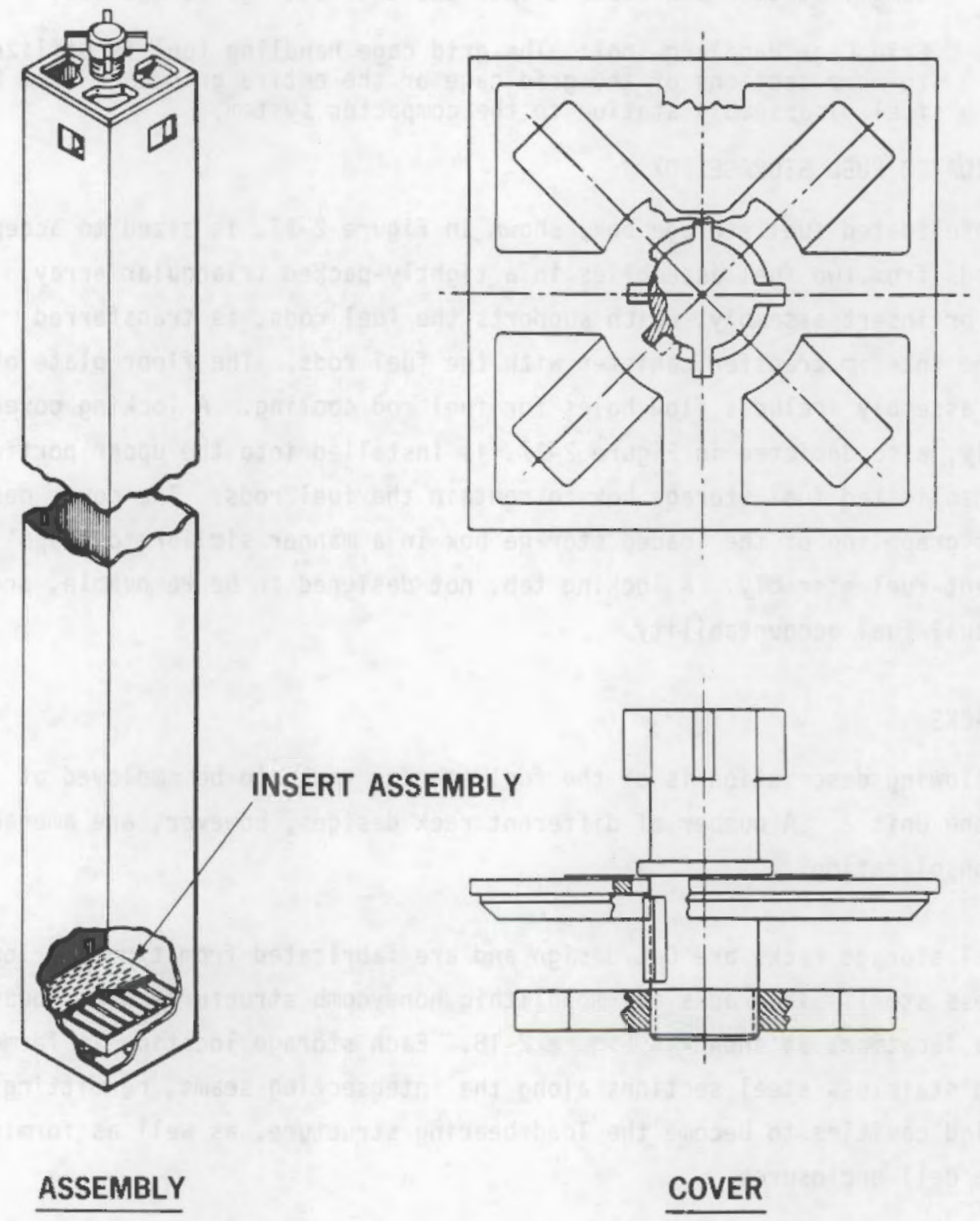

Figure 2-17. Consolidated Fuel Storage Box and Cover Assembly 


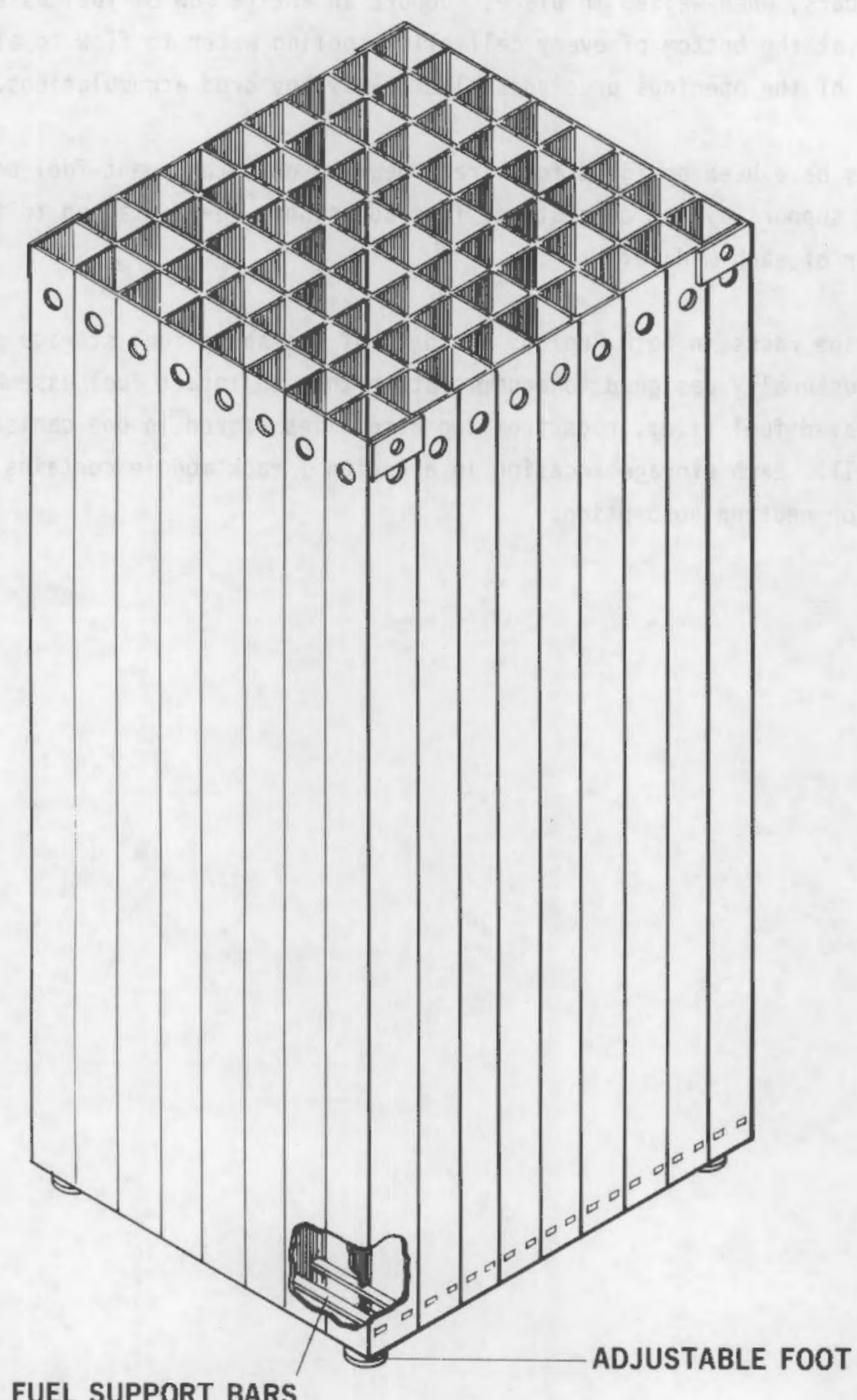

FUEL SUPPORT BARS

Figure 2-18. Spent-Fuel Storage Rack 
Stainless steel bars, which are inserted horizontally through the rectangular slots in the lower region of the module, support the fuel assemblies. These support bars, when welded in place, support an entire row of fuel assemblies. Passages at the bottom of every cell allow cooling water to flow to all cells. The size of the openings precludes blockage by any crud accumulations.

The racks have been designed for direct bearing onto the spent-fuel pool floor. The rack support system consists of four adjustable feet attached to the perimeter of each module.

The storage racks in both Regions I and II of the spent-fuel storage pool have been structurally designed to accommodate either an intact fuel assembly or consolidated fuel (i.e., rods from two assemblies stored in one canister) in every cell. Each storage location in a Region I rack module contains a poison insert for neutron absorption. 


\section{Section 3}

\section{DISPOSAL OF FUEL ASSEMBLY SCRAP AND WASTE}

Fuel assembly scrap and waste, that is the grid cage assemblies, upper and lower end fittings and expended filter cartridges, can ultimately be removed along with consolidated fuel rods and intact spent fuel assemblies for storage in a federal high level waste repository to be established in accordance with the 1982 Nuclear Waste Policy Act. This act also obligates utilities to provide on-site spent fuel storage until 1998, when the government repository is scheduled to begin receiving shipments. Since fuel assembly scrap can reduce the space available for fuel in the Millstone Unit 2 spent fuel storage racks by as much as $20 \%$ or the equivalent of five years' plant operation, depending on the compaction ratio achieved, other means of disposing of the scrap were considered. In particular, the feasibility of shipping it to one of the existing radioactive waste burial facilities was investigated.

A study (4) was performed to estimate the quantities, isotopic composition and activities of the scrap components, and to evaluate the impact of these and various other factors on the cost of transport and burial.

The amount of activation products in the scrap from a fuel assembly is dependent on fuel burnup and decay time, elemental and isotopic composition of the materials of construction, and the quantity of the materials. The activation product calculation was made separately for each component, to identify any components having a disproportionately large fraction of the total inventory. Millstone Unit 2 has two types of $14 \times 14$ fuel assemblies, one manufactured by $C-E$ and the other by Westinghouse. The non-fuel portion of the C-E fuel assembly consists of stainless steel upper and lower end fittings with Zircaloy control element guide tubes and spacer grids. The Westinghouse fuel assembly is of similar design but the material of the guide tubes and grids is Inconel instead of Zircaloy. Total estimated activity of the scrap from a C-E assembly is 266 curies, of which 239 curies are in the upper and lower end fittings. As estimated by Westinghouse, the activity of the scrap from a Westinghouse fuel assembly is 600 curies. The greater activity of the Westinghouse assembly scrap is mainly due to the Inconel grid cages and guide tubes and the total activity is relatively evenly distributed in comparison to that of the C-E assembly. Inconel contains up to $0.5 \%$ of cobalt and $70 \%$ of nickel (26\% of which is nickel 60 which can potentially be 
converted to cobalt 60 under core neutron flux). The quantity and activity of crud released from the surface of the fuel rods were also estimated. The crud is scraped off when the rods are pulled through the grid cages, and is caught in the filters of the fuel consolidation filtration system. Estimates are 0.47 lbs of crud scraped off per assembly and 0.37 curies of cobalt 60 (the only isotope of significance at the time of consolidation) total activity per assembly.

The economic evaluation revealed that the cost of disposing of the fuel assembly scrap and waste at an existing radioactive waste burial facility is significant, and might be the highest cost activity in fuel consolidation. Furthermore the choice of which disposal scheme to use is complex and there is no certainty that the scrap and waste will be acceptable either for shipment or for burial. Factors considered in the evaluation included the amount of activity, achievable volume reduction ratio, storage box size, makeup of shipments, type of shipping cask, shipping cost and burial site cost. The analysis focused on C-E fuel, which constitutes the majority of Millstone Unit 2 fuel and is expected to be used in the consolidation demonstration, and assumed disposal of scrap as lowlevel waste at the Chem-Nuclear burial facility at Barnwell, South Carolina. Low level waste shipments are limited by federal regulation to a maximum of 5000 curies in any one shipment. The basis for classifying the scrap and waste as low-level waste is that it contains no fuel material. It could not be determined whether this classification would be accepted in practice.

Ninety percent of the activity of $C-E$ fuel scrap is in the end fittings and as a consequence the analysis indicated that it would initially be more costeffective to ship only the grid cage/guide tube assemblies off-site, after shearing and compacting them to a volume reduction of $10: 1$. The end fittings would be stored in the spent-fuel pool, which would result in a potential fuel pool capacity reduction of about $6 \%$. The cost of shipping the end fittings off-site also might eventually be justified to avoid such a reduction in fuel storage capacity. As expected, moderate compacting of the grid cage/guide tube assemblies results in substantial savings, primarily in transportation costs and to a lesser extent in burial costs. However, there appears to be little incentive for reducing the volume for shipping much more than ten times, if standard shipping casks are used, because of the 5000 curie shipping limit. On the other hand, if the scrap is to remain in the spent fuel storage pool, then its volume should be reduced as much as possible. 
It should be noted that there is an uncertainty of $\pm 50 \%$ in the waste activity values developed in this study. This is mainly because they are based on the nominal chemical composition of the materials of construction. In particular, cobalt is an impurity and only the maximum permissible content is specified. It is recommended, and probably will be required, that radioisotopic scans of the scrap from actual spent fuel assemblies be made for use in waste shipment calculations. In the case of Millstone Unit 2 this could conveniently be done during or after the fuel consolidation demonstration.

Additional study would be required to optimize the disposal of scrap from Westinghouse-manufactured fuel or combinations of $C-E$ and Westinghouse fuel. Even if the end fittings are retained in the fuel pool, shipping and burial costs for the Inconel grid cage/guide tube assemblies from Westinghouse fuel will be much higher than for all-C-E fuel.

At the time of writing this report, regional compacts were being formed by the states under the provisions of the Federal Low Level waste Policy Act of 1981. Each compact was to establish a repository by January 1986 for the low level wastes generated in the states in that compact, but the rate of progress offered little hope that this schedule would be met. The existing repositories at Barnwell, South Carolina, and Richland, Washington, would each serve a regional compact, but will not be obligated to accept waste from other regions after January 1986.

For Millstone Unit 2 and many other utilities, it appears prudent to assume that the option of shipping fuel assembly scrap and waste to a regional repository will not become available, if at all, for a number of years. Northeast Utilities is therefore investigating the feasibility of storing fuel assembly scrap in the spent-fuel pool at Millstone Unit 2 without making use of the spent-fuel storage racks.

Dry storage of fuel assembly scrap on site may be a feasible alternative for some utilities. However consideration of this alternative was not within the scope of the Fuel Consolidation Demonstration Program. 



\section{Section 4}

SAFE HANDLING OF ZIRCALOY

Consolidation of $C-E$ fuel assemblies in the system being developed involves the cutting and shearing of the Zircaloy guide tubes, and the subsequent disposal of the compacted guide tube/grid cage assemblies and spent consolidation system filter cartridges. It is well known that the storage, handling, shipping and processing of zirconium metal and its alloys are potentially hazardous, depending on the form of the material. A review ( $\underline{5}$ ) was made of industry experience and guidelines for the safe handling of Zircaloy. In general, it appears that dry coarse materiai (1/16 inch or larger) will not ordinarily ignite unless in close contact with burning finely-divided material. Dry fine material ignites easily and moist fines may explode. Neither coarse nor fine material is a hazard while under water. Since the fuel consolidation process itself is conducted entirely under water, safety concerns begin when Zircaloy material is removed from the fuel pool in preparation for shipping.

From the standpoint of zirconium handling, the pertinent processing steps start with the cutting off of the upper end fitting to expose the fuel rods for remova1. This initial cutting through the Zircaloy guide tubes may generate a small amount of fine (swarf) material that will be collected by the underwater filtration system. The removal of the fuel rods may also produce particulates caused by scraping as the rods pass through the spacer grids. This material will probably consist mostly of crud and will also be collected in the filtration system.

More particulate material may be produced by the guide tube/grid cage assembly volume reduction process. The method chosen (see Section 2) shears off a section which is then compacted in three stages by hydraulic rams. The sheared sections are several inches long and pose no fire danger for shipping. Shearing of ductile Zircaloy with a sharp blade should not produce fine particulates. However, irradiated Zircaloy has reduced ductility and a dulled shearing blade might cause work hardening. Hence there is a possibility that some Zircaloy fines will be produced. The compactor station is connected to the underwater filtration system. 
It thus appears that the removal from the spent-fuel pool of material collected in the filters and its drying out, handling, and packaging for shipping off-site raise safety issues that need to be addressed, as follows:

- Precautions necessary while the material is drying out.

- Method of packaging. Whether Zircaloy fines should be packaged dry, diluted with sand or remain underwater. Whether material from the filters must be kept separate from compacted Zircaloy material.

- More generally, the applicability of proposed industry guidelines and criteria for the safety handing of zirconium.

- The applicability of federal and state regulations governing packaging, shipping, and long-term storage of radioactive material that may be a fire hazard.

- The relevance of industry experience.

These issues cannot be addressed completely without knowledge of the particle quantity and size distribution produced by consolidating C-E spent fuel, and it is recommended that this be determined during the initial consolidation demonstration to be performed at Millstone Unit 2 . 
Section 5

VOLUME REDUCTION OF ASSEMBLY MATERIALS AFTER FUEL ROD REMOVAL

The method adopted in the fuel consolidation conceptual design for reducing the volume of fuel assembly scrap after the fuel rods and upper end fitting have been removed is to cut off the lower end fitting (and its attached lower retention grid) and then hydraulically compact the remaining grid cage/guide tube assembly as described in Section 2. Compacted grid cage/guide tube assembiies and end fittings are stored in separate containers. This method was chosen after a study $(6,7)$ of various potential volume reduction methods that was performed in parallel with the studies of scrap disposal and handling of Zircaloy discussed in Sections 3 and 4.

The volume reduction study assessed the principal types of equipment comamercially available with a view to identifying the type or types with the potential for achieving the greatest reduction in volume combined with adaptability to the rather severe design requirements. These requirements were: reliable operation under 25 feet of water; resistance to corrosion; ease of remote maintenance and replacement of parts subject to wear; ease of installation and removal; and ease of decontamination. Other methods, not involving commercially available equipment, were also assessed. The target compaction ratio for the study was $10: 1$.

A number of equipment manufacturers were approached for assistance and information. The equipment assessed included compactors, shredders, crushers, pulverizers, hammer mills and granulators. Each type of machine had specialized features to process selected bulk materials, such as municipal waste, industrial waste, tires, appliances, plastics, sandstone, coal and iron oxide.

Based on the information provided by the equipment vendors the study focused on four basic volume reduction methods:
1) stacking
2) compaction 

3) shredding
4) granulation

Crushers, pulverizers and hammer mills were eliminated from consideration. This equipment is normally used to process quarry and mining products such as rock, sandstone, coal, iron oxide and alumina. Typically crushing is done between rotating hammers and breaker blocks located immediately below the infeed throat. The hamners may be either free-swinging or fixed to a rotor assembly. The free falling material is dropped in front of the hammers, the force of whose impact projects the material on to the stationary breaker block. The reduced particles drop through a discharge chute. The process is most suitable for brittle and hard material that shatters easily, whereas the fuel assembly scrap materials were expected to retain some ductility although irradiated.

The methods which were evaluated are described in the following paragraphs. In order to compare potential volume reduction ratios in a consistent way, it was assumed that the reduced material in each case would be stored in standard containers $8 \frac{1}{2}$ inches square and 36 inches long. The framework of the $C-E 14 \times 14$ fuel assembly consists of five Zircaloy guide tubes approximately 12 feet long attached to eight equally spaced Zircaloy grid cages and to the upper and lower end fittings. Both end fittings are austenitic stainless steel and the lower end fitting has a stainless steel grid cage welded to it.

\section{STACKING}

The stacking concept evaluated involved the rearrangement of framework elements instead of mechanical processing to achieve volume reduction. It consisted of cutting the end fittings and all the grid cages away from the guide tubes and loading the sections systematically into the standard containers. This required the guide tube cutting tool to make 75 cuts at 16 different elevations, in addition to the cuts at the end fittings. As each piece was separated it had to be transferred to the storage container.

The disassembled framework from two fuel assemblies required three storage containers. Two containers each held eight grid cages and two end fittings, and the third held 8016 inch long sections of guide tubes. The volume reduction ratio (envelope volume of intact framework divided by reduced envelope volume) was 3.3. This was far from satisfactory, especially in view of the amount of 
cutting and handling involved. A variant of the stacking concept in which the guide tube/grid cage assemblies were first granulated was considered in the evaluation of granulation and is described below.

\section{COMPACTION}

In the compaction concept considered the end fittings were cut off the guide tube/grid cage assembly, which was then cut up into four or five sections prior to compaction. The sections were transferred from the workstation into a press in a predetermined orientation and flattened. After this, the compressed pieces, approximately the length of the storage box, had to be transferred to the storage container and inserted in a laminar configuration. Springback, which is inherent in this type of process, made it difficult to predict the number of sections which could be inserted and hence to estimate the achievable volume reduction ratio.

Somewhat less cutting and handling would be required than in the stacking concept due to the longer guide tube/grid cage sections involved, but a bulky and heavily built underwater press would be necessary. An alternative method of pressing the guide tube/grid cage sections longitudinaliy instead of transversely was tried experimentally later in the study with unsatisfactory results as described below.

\section{SHREDDING}

Information and data from vendors and other sources indicated that shredding could be used to process the guide tube/grid cage assembly. Shredding is generally used to process high volume bulk material such as wire, drums and tires. Shredders are low speed machines operating at less than $60 \mathrm{rpm}$, and hence minimize noise, the hazards of flying objects, and requirements for a strong supporting structure. They also have low power requirements, and pumping action when operated under water should not be a major problem.

A typical bulk material shredder has two counter-rotating horizontal shafts situated below a feed hopper. Cutter blades separated by spacers are stacked on each shaft, the blades on one shaft meshing with those on the other to produce a shearing action. Material to be shredded is fed by gravity from the hopper into the cutters. Particle size is determined by the infeed throat opening and the thickness of the cutters. Further reduction can be achieved by employing 
additional stages with progressively decreasing infeed throat and cutter sizes, at the expense of increased power requirements.

Equipment vendors estimated that it should be possible to produce $\frac{1}{2}$-inch sized chips by shredding the Zircaloy guide tube/grid cage assembly. A fairly coarse chip size is desirable in order to avoid problems with the pyrophoricity of Zircaloy, as discussed in Section 4. One vendor processed a partial assembly to a density of about 44 pounds per cubic foot, equivalent to a volume reduction ratio for the guide tube/grid cage assembly of about $8: 1$, but multi-stage processing was necessary. This ratio was unacceptably lower than the target ratio of 10 since end fittings were not included, but it could probably be improved by supplementary processing such as compacting.

\section{GRANULATION}

The granulation equipment considered also works with a shearing action, but operates at higher speeds (500-600 rpm) than the shredding equipment and has only one rotor, to which several knife blades are attached. The horizontal rotor is in a cylindrical housing attached to the infeed throat of the feed hopper. The rotating knives sweep the material to be granulated against fixed knives attached to the inside of the cylindrical housing, the lower part of which is a sizing screen. Particles which are not small enough to fall through the screen are recycled for further shearing.

Granulation has much more potential for volume reduction than shredding. An equipment vendor processed grid cages and guide tubes to a density of 142 pounds per cubic foot, equivalent to a volume reduction ratio of over $25: 1$. This is well within the acceptable range for compaction. If the scrap fuel assembly framework were loaded into standard storage containers in the sequence of upper end fitting, granulated guide tube/grid cage assembly, lower end fitting, and so on, it would be possible to package seven frameworks into three containers, with an equivalent volume reduction ratio of 10:1. Two containers would hold five end fittings and one container would hold four fittings. The granulated assemblies would fill the open volume in the upper end fittings, as well as additional space between the upper and lower fittings.

However, the granulated material produced in the test included a considerable quantity of fine particles, which in the case of Zircaloy pose the greatest fire hazard, particularly when still moist during removal from storage in the spent 
fuel pool. This probably means that the granulated Zircaloy should be mixed with an inert material such as sand when it is eventually shipped offsite. This would be difficult to do reliably with combined end fitting and granulated assembly packaging. Also, combined packaging would preclude the possibility of shipping the Zircaloy offsite to a low level waste repository (the end fittings are highly radioactive stainless steel). It therefore appears desirable to segregate the end fittings from the granulated guide tube/grid cage assemblies. In this case it would only be possible to package six frameworks in three standard containers, resulting in a volume reduction ratio of $8.7: 1$. One container would hold all the Zircaloy and the other containers would hold the end fittings.

\section{EVALUATION}

The preliminary evaluation was that granulation had the most potential for achieving the target volume reduction, with shredding second. Shredded material would probably require further volume reduction treatment.

Recognizing the problems associated with operation underwater in a radiation environment, a comprehensive performance specification was prepared and discussed with the equipment manufacturers in an effort to make a realistic assessment that took into account manufacturing feasibility, material testing, operating environment and capital cost.

It became apparent that the existing designs being considered would require extensive redevelopment to make them suitable for the consolidation system application. Major concerns were:

- the inability to retain the necessary lubrication while operating underwater, resulting in a drastically reduced parts life and the need for frequent parts replacement,

- the unpredictability of cutter life and the need for a special blade design to handle irradiated materials,

- the difficulty of replacing parts and cutters due to the complex method of assembly, which also made decontamination difficult,

- the possibility of material chips jamming in the cutter undercuts and between stationary and rotating members

- the production of Zircaloy fines 
These concerns applied particularly to granulation, and less so to shredding because of the lower rotational speed. On the other hand, the need for a supplementary method of final material reduction adversely impacted shredding, both as regards cost and the space required in the work area.

Mainly because of the estimated cost of developing a rotary granulator or shredder for this application, it was decided that compaction was the most economically feasible method to adopt. Instead of flattening the guide tube/grid cage assemblies in a press as in the preliminary concept however, crushing by means of hydraulically operated rams in an enclosed chamber was chosen in order to make it easier to isolate the Zircaloy fines produced, should that prove to be necessary.

The first approach in adopting the compaction concept was to investigate compacting the fuel assembly frameworks longitudinally. The advantage of this was that the framework could be compacted directly into the disposal container by a single ram, no shearing would be required, no small pieces would have to be handled and loaded, the spread of debris could easily be controlled, and oniy one moving part would be required. It was theorized that as the guide tubes collapsed they would act like wedges, side loading and pushing individual grid cage elements over and thereby assisting the overall compaction process. Two experiments ( ) were performed to test this theory.

The first experiment compacted a single grid cage. The objective was to determine the load required, and to ascertain whether wedges welded to the ram facilitated the process. The second experiment compacted a section of framework containing two grid cages connected by guide tubes approximately 18 inches long. The objective of this experiment was to determine whether an effective volume reduction could be achieved with longitudinal compaction. Both experiments used an 81 inch square compacting ram of one inch thick plate with three pieces of angle iron welded to one side of the plate to act as wedges. The compaction chamber was $8 \frac{1}{2}$ inches square inside by three feet long, and was made from one inch thick plate. The bottom of the chamber was bolted on for ease of removing the test specimens. Loading of the test fixture was provided by a universal testing machine equipped with a plotter for load versus deflection. The procedures for compacting both test specimens were identical. The samples were 
placed in the compaction chamber, the compacting ram was set in place and then the load was slowly applied. Compaction was terminated when the maximum machine capacity of 60,000 pounds was reached.

The effective volume reduction achieved with the single grid cage was small. The wedges did collapse some individual cells but many of the adjacent cells showed very little deformation. The short guide tube sections collapsed or split, but did little to collapse adjoining cells. The wedges penetrated through the grid, pushing material aside, until they came within about $3 / 8$ inch of the bottom plate of the compaction chamber. The space below the wedges was filled by then with compacted metal making further grid compaction impossible.

In the guide tube/grid cage assembly compaction experiment the guide tubes collapsed at a load of 30,000 pounds after a compression of 1.2 inches, whereupon the load fell off to about 6,000 pounds and remained between 5,000 and 7,000 pounds for the next ten inches of compression. In the following 1.8 inches the load increased to 42,000 pounds, and then rapidly rose to 60,000 pounds in another 0.3 inches. At this point the test was stopped. Examination of the test specimen revealed that the guide tubes all buckled to the same side of the compaction chamber, and this appeared to have caused one side of the bundle to offer more resistance to load than the other. All of the welds between the guide tubes and the grid cages were broken. The collapsing guide tubes did not act like additional wedges to any significant degree. Two of the guide tubes extruded about five inches through the $1 / 4$ inch clearance between the compacting ram and the wall of the compaction chamber. The overall volume reduction ratio was $2.9: 1$.

The experiments, as they were designed, failed to demonstrate that longitudinal compaction was a viable approach for volume reduction. The available maximum test load did not volume reduce the grids sufficiently, nor did it appear to set up a collapsing mechanism that would assist compaction within the grid structure. While higher loads and different wedge and compaction chamber designs might have produced satisfactory results, the project schedule did not permit a follow up effort. 
It was therefore decided to concentrate development on compaction in two or more directions with hydraulically driven rams, one of which would also be designed to shear the guide tube/grid cage assembly into sections of suitable length for compacting. 
Section 6

REFERENCES

1. Fuel Consolidation Demonstration Program, EPRI Research Project 2240-1, Interim Report, Program Overview, November 1984.

2. Ibid, Interim Report, Generic Application of Fuel Consolidation System to Fuel Assembly Designs, November 1984.

3. Design Requirements for Fuel Consolidation System, C-E Document No. 13783DR-1, Revision 1, November 1984.

4. Fuel Consolidation Demonstration Program, EPRI Research Project 2240-2, Subtask Report, Design Considerations for Low Level Waste from Fuel Consolidation, M. Wiatrowski, April 30, 1984.

5. Ibid, Subtask Report, Safe Handling of Zircaloy, N. Fuhrman, November 2, 1983.

6. Ibid, Subtask Report, Design Evaluation of Grid Cage Assembly Volume Reduction System, N. Giuggio, March 2, 1984 (C-E Document No. TR-ESE-563).

7. Ibid, Subtask Report, Engineering Evaluation of Granulator/Shredder Volume Reduction, N. Giuggio, April 9, 1984 (C-E Document No. TR-ESE-591).

8. Ibid, Subtask Test Report, Grid Cage Compaction for Spent Fuel Consolidation System, W. 8iercz, August 21, 1984 (C-E Document No. TR-ESE-612). 

Appendix A

CONSOLIDATION TOOLING AND EQUIPMENT

DESIGN, FABRICATION AND TESTING

As indicated in Section 1, detailed design and performance requirements for the fuel consolidation system and equipment for Millstone Unit 2 were established (3). Full scale prototypes of the multiple rod pulling tool head and its control system, the interim transfer canister, and the consolidated fuel storage box were built and tested under dry conditions in the C-E nuclear laboratory in Windsor, Connecticut. The prototypes were used together with fuel rods containing depleted uranium to demonstrate the principle of rod consolidation.

Design and performance specifications were written for commercial components to be engineered for the application by vendors. These components were:

- Hoist assembly.

- Telescoping cylinder for the fuel rod transfer work station.

- Filtration system.

- Compactor.

In the case of the compactor, difficulties were experienced with the selected vendor and $\mathrm{C}-\mathrm{E}$ elected to produce a compactor of its own design. This is the design described in Section 2 of this report. Detailed build-to-print drawings were prepared for the compactor and for components and tools that were not commercially available.

The component features outlined in Section 2 were generally retained in the detailed designs. In the following paragraphs such significant changes or additions as were made are identified, design performance data given, and instrumentation sensors enumerated for each principal item of equipment. In addition the consolidation system controls are described. 


\section{INTERIM TRANSFER CANISTER}

The only modification to the interim transfer canister (ITC) design was a provision to prevent weld distortion of the outer shell restricting the free movement of fuel rods in the outer channels.

Total number of fuel rod channels: 360

Control activator

: Remote manual for ITC gate

Instrumentation sensors

: None

MULTIPLE ROD PULLING TOOL

The prototype multiple rod pulling tool (MRPT) head referenced above was utilized in the production MRPT and shroud assembly without modification other than refurbishing as necessary. The mast and shroud assemblies were built as described in Section 2.

Control Activators: $\quad 14$ double acting air cylinders for fuel rod grippers, normally held closed by spring pressure. Normal maximum rod pulling force $50 \mathrm{lbs}$, override force $100 \mathrm{lbs}$. 4 double acting air cylinders for fuel rod alignment bars on shroud. 4 air cylinders for "mast up" and "mast down" lock pins on shroud.

Instrumentation Sensors: 14 linear variable differential transformers (LVDT's) for measurement of fue 1 rod insertion depth in grippers. 6 limit switches on shroud ( 4 for MRPT head elevation indication and 2 for shroud rotation indication).

\section{$X-Y$ TABLE}

The X-Y table assembly was built as described in Section 2, except that after initial testing the rodless cylinder table drive system was replaced with a linear nut system driven by hydraulic motors. The rodless cylinder drive was found to be incapable of consistently maintaining the required positioning accuracy of 0.050 inches. After the cold demonstration, the linear nut drive system was in turn replaced with a stainless steel ball screw drive (see Section 6 of the Cold Demonstration Interim Report) due to incipient corrosion indications. In addition to the $X-Y$ table assembly features described in Section 2 , the $Y$ table has 4 vertical guide bars which center the circular bottom flange 
of the MRPT shroud as it is lowered into position on the table, and the index clamps at the fuel disassembly and separation/recovery work stations for the fuel assembly upper grid cage and the damaged rod storage canister, respectively, are located on the stationary base plate of the $X-Y$ table assembly. A row of rod insertion standards is located on each side of the disassembly station clamp. The standards are used for calibrating MRPT gripper rod insertion and slip indications. Each row consists of 14 rods of the same diameter as the fuel rods and of uniform height. One row is for verifying minimum insertion indication and the other row, which is 0.5 inches higher, is for verifying the maximum insertion indication.

Table load capacity: 1200 lbs.

Table travel (limited

by control software): $\quad 33.50$ inches in $\mathrm{X}$-direction

12.50 inches in Y-direction

Control activators: $\quad 1$ hydraulic motor each for $X$ and $Y$ table linear nut drives (total of 2).

8 pressurized water operated cylinders for work station clamps (4 each for fuel disassembly and damaged rod stations).

Instrumentation sensors: 3 LVDT's for $\mathrm{X}$-direction position indication. (LVDT coils are clamped one above the other on the vertical centerline of one side of the $x$ table. They slide on 3 parallel rods clamped to the stationary base of the $X-Y$ table assembly and each rod has an LVDT core insert whose center is aligned with the vertical centerline of the work station for which its LVDT coil provides the $\mathrm{X}$-direction position indication signal).

1 LVDT for Y-direction position indication. (A11 three work stations are located on the same plan view centerline in the $X$-direction, so only one $Y$ position sensor is required. The LVDT coil and core installation is similar to that for the $X$-direction, but with the coil clamped to the $Y$ table and the core insert rod clamped to the $X$ table). 


\section{FILTER SYSTEM}

The filter system was built as described in Section 2, except that only three work stations (fuel disassembly, interim transfer, and fuel transfer) were manifolded to the filter units for service in the cold and hot fuel consolidation demonstrations. The need for a connection to the compactor, which handles non fuel-bearing material, is to be evaluated during and after the hot demonstration. If a connection is found to be necessary, design requirements for it will be established based on the observed characteristics of the particulate material to be entrained. Each of the installed work station branches off the manifold has an isolation valve and a paddle-wheel flow sensor. The manifold itself has a bellows connection to each filter unit suction inlet, and a valve between the connections to enable one filter unit to be isolated from the other. The isolation valve stems are extended up to the lower work platform level, where they can be engaged by the Hex Turning Tool and operated manualiy.

There are two commercial filter units, mounted on separate skids. Each unit has two parallel suction strainers, a pump, two parallel first stage filters, two parallel second stage filters, and two self-energized discharge flow regulators which regulate the flow to 250 gallons per minute plus or minus $5 \%$ as the filter cartridges load up.

Pump (per unit): $15 \mathrm{HP}, 440$ volts, $60 \mathrm{~Hz}$, 3-phase, submersible.

Inlet strainer cartridges

(per unit) : 2,3-1/4 inches outside diameter $\times 24$ inches wire wound with 0.015 inch spacing between wires.

First stage discharge

filter cartridges

(per unit) : 2, disposable type, 5 micron rated.

Second stage discharge

filter cartridges

(per unit) : 2, disposable type, 1 micron rated. 


\section{VOLUME REDUCTION SYSTEM/COMPACTOR}

Development of the volume reduction system was taken considerably further during detailed design. The most important additions to the compactor as it was described in Section 2 were:

1) a retractable comb guide

2) a cylinder for elevating the movable floors of the compacted waste containers (CWC's)

3) a delivery system for moving loaded CWC's from under the compactor discharge gate to a point from where they can be removed by the fuel handling machine to storage in the spent fuel pool, and vice versa for new empty CWC's

The mode of operation of the compactor was also somewhat modified, as described below.

The function of the comb is to hold the guide tube/grid cage assembly while the guide tubes are being sheared by the horizontal shear/first stage compaction ram. The comb moves in and out of a horizontal slot just above the shear chamber at the base of the compactor inlet chute and is driven by a water-operated cylinder through a scissors linkage (space limitations require the cylinder axis to be at right angles to the comb stroke). The comb is a flat plate with three slots which engage the five guide tubes. An LVDT with its core rod actuated by the scissors linkage provides a drive cylinder extension indication signal to the main control panel. The guide tubes are sheared into four inch sections and are pushed into the compaction chamber by the first stage ram which then retracts, allowing another section of guide tubes to drop into the shear chamber. After five sections have been sheared, a grid cage should be just above the comb guide. The guide is retracted to allow the grid cage to fall into the shear chamber and then the comb guide is extended again for further guide tube shearing.

The shearing sequence described above is repeated until there are four grid cages and their guide tube sections, comprising half of a complete grid cage/grid tube assembly, in the compaction chamber. These are then compacted by extending and retracting the horizontal and vertical compaction rams and the horizontal shear/compaction ram in sequence, after which the gate is opened and the vertical ram is actuated to push the compacted grid cages and guide tubes into a CWC underneath the compactor. All compaction takes place inside the compaction chamber before the gate is opened, and not in the CWC as described in Section 2. 
The purpose of the CWC water-operated floor cylinder is to prevent the compacted waste from breaking up due to the impact from dropping into the CWC. Commencing with an empty CWC, the floor is raised to the top of the box so that it is just below the compactor discharge gate. After the gate is opened, the compactor vertical compacting and loading ram is extended downwards through the gate opening and the floor cylinder simultaneously retracted to move the compacted waste down so that its top surface is just below the gate. The vertical compacting ram is then retracted, the gate closed and the compactor cycled to compact another half grid cage/guide tube assembly. This compacted waste in turn is moved down into the top position in the CWC by simultaneous extension of the vertical compacting ram and retraction of the floor cylinder. The sequence of compaction and CWC floor lowering continues until the CWC is full of compacted waste, the moving waste material being at all times contained between the vertical compacting ram and the floor cylinder. The floor cylinder travel is measured by a transducer that is mounted on the end of the cylinder and is part of the compactor's ultrasonic position indicating system.

The box delivery system consists of a carriage assembly running on rails outwards from underneath the compactor discharge gate at an angle of $30^{\circ}$ to the longitudinal axis of the first stage ram to a position such that the CWC can be lifted or lowered vertically through the space between the compactor body and the cask laydown pool wall. The carriage is controlled by a hydraulic motor through a linear nut drive. Limit switches at each end of the track provide an indication of when the carriage is at the gate position or the CWC pickup/setdown position. A clamp, controlled by a water-operated cylinder, holds the CWC in position under the gate while compacting is being performed.

Control activators: $\quad$ 1-10 inch bore servo-hydraulic cylinder for horizontal shear/compaction ram (20-inch stroke).

2-10 inch bore hydraulic cylinders for vertical compaction ram (18 inch stroke), and horizontal compaction ram (10 inch stroke). 1 pressurized water operated cylinder for comb guide. 1 pressurized water operated cylinder (45 inch stroke 1 imited to 20 inches by control software) for compacted waste container floor support.

1 pressurized water operated cylinder for compacted waste container clamp. 
1 hydraulic motor and chain drive for discharge gate drive screw.

1 hydraulic motor for box delivery carriage linear nut drive.

Instrumentation sensors: 4 ultrasonic positional transducers for:

horizontal shear/compaction ram, vertical compaction

ram, horizontal compaction ram, compacted waste

container floor cylinder.

1 LVDT for extension of comb guide cylinder (note that

comb guide travel is not linear with respect to cylinder extension because of scissors linkage).

2 limit switches for discharge gate open and closed positions.

2 limit switches for box delivery carriage at discharge gate or at the CWC pickup/setdown position.

\section{HOIST ASSEMBLY}

The hoist assembly is a commercial design and was built essentially as described in Section 2.

Main hoist:

Rated capacity $6000 \mathrm{lb}$.

Speed, raising and lowering, 0.5 to $15 \mathrm{ft} / \mathrm{min}$, variable. Maximum hook elevation 250 inches above top of rails.

Motor, 6 horsepower.

Hoist encoder (for hook elevation) and upper and lower hook elevation limit switch, reduction gear driven. Hook load measurement by strain-gaged clevis pin in hoist equalizer sheave.

Auxiliary hoist: $\quad$ Rated capacity $1000 \mathrm{lb}$. Speed, raising and lowering, $15 \mathrm{ft} / \mathrm{min}$. Maximum hook travel 300 inches.

Motor, 0.5 horsepower.

Reduction gear driven upper and lower hook elevation limit switch. Loading limiting slip clutch. 
Trolley (main hoist): Low speed $8 \pm 2 \mathrm{ft} / \mathrm{min}$.

High speed $21 \pm 2 \mathrm{ft} / \mathrm{min}$.

Range 104 inches.

Zero reference, 3-3/4 inches off cask laydown pool north wall.

Motor, 0.5 horsepower.

Trolley encoder (for " $X$ " coordinate, or distance

travelled by trolley), cable operated.

8 trolley position limit switches for frequently used " $x$ " coordinates.

Gantry bridge: $\quad$ Low speed $5 \pm 2 \mathrm{ft} / \mathrm{min}$.

High speed $15 \pm 2 \mathrm{ft} / \mathrm{min}$.

Zero reference, cask laydown pool west wall.

Motor, 0.75 horsepower.

Bridge encoder (for " $Y$ " coordinate, or distance

travelled by bridge), cable operated.

8 bridge position limit switches for frequently used " $\gamma$ " coordinates.

\section{LOWER WORK PLATFORM}

The lower work platform was built as described in Section 2, except that as previously noted the compactor station was not connected to the filter system for the cold and hot demonstrations.

Control activators: $\quad 16$-stage telescoping double acting hydraulic cylinder for fuel transfer piston at fuel transfer station. Stroke 161 inches.

1 water-operated cylinder for CFSB clamp at fuel transfer station.

2 remote manual operators at fuel disassembly station, for lower end fitting clamp and for adaptor shim for reconstitutible fuel assemblies.

Instrumentation sensor: Fuel transfer cylinder encoder (for piston travel). 


\section{TV CAMERA MOUNT SYSTEMS}

The two TV camera mount systems were built as described in Section 2. The camera system mounted outboard of one long side of the lower work platform has a horizontal traversing capability of 85 inches, vertical traversing capability of 31 inches and camera pan and tilt capability of $\pm 135^{\circ}$. The system mounted on the ITC stabilizer assembly has a vertical traversing capability of 24 inches and camera/mirror rotation capability of $\pm 135^{\circ}$.

Control activators: $\quad 3$ rodless water-operated cylinders ( 2 for horizontal and 1 for vertical traversing) and 2 water-operated rotary actuators ( 1 each for camera pan and tilt), for system mounted on the lower work platform.

2 rodless water-operated cylinders ( 1 each for vertical traversing and tilting mirror) and 1 water-operated rotary actuator, for system mounted on ITC stabilizer assembly.

Instrumentation sensors: None (except TV cameras).

ROD TRANSFER TOOL

In the conceptual design of the rod transfer tool (RTT) described in Section 2 the tube assembly is encased in a shroud which guides the sliding support plates. In the detailed design the shroud was eliminated and support plate guidance provided by an open framework consisting of vertical angle sections at the corners tied together by a fixed drilled plate at the base and a series of narrow horizontal plates at approximately 15 inch intervals up the sides of the frame. This change was made to reduce overall weight and to enable the top of the tube assembiy to be scanned by the TV camera if a stuck fuel rod signal is given by the RTT as described below.

Each RTT tube is capped at the top with a 6 inch long plunger whose base is slightly larger in diameter than the tube. The base rests on top of the uppermost sliding support plate so that the tube is free to move upward relative to the plate if the fuel rod that it is in contact with sticks in the interim transfer canister during fuel transfer. The upper end of the plunger is guided by a drilled plunger guide plate that is held at a fixed distance of 5-3/4 inches above the uppermost sliding guide plate by four stand-off pins, and the plunger is spring loaded against the underside of the plunger guide plate. A lift 
fixture plate is held at a fixed distance of 2 inches above the plunger guide plate by four more stand-off pins, and the lift plate has an electrical contact plate attached to $i$ ts underside (the contact plate and fasteners are insulated from the lift plate). Thus when the RTT tube moves upward about $1-1 / 2$ inches relative to the uppermost sliding guide plate due to a stuck fuel rod, an electrical contact is made that causes a stuck rod signal at the main control panel. The location of the stuck rod can be found by observing with the underwater TV camera which RTT tube plunger is raised above the top of the plunger guide plate. The top side of the lift plate has a central boss drilled and tapped to accept the RTT lift tool. Two ball lock pins under opposite corners of the uppermost sliding guide plate lock the RTT tube assembly to the guide frame while the RTT is being moved into position over the interim transfer canister.

Control actuators: Speed is software-controlled through the hoist to match the downward (fuel rod transfer) speed of the fuel transfer cylinder.

Instrumentation sensor: 1 electrical contact plate as described above.

MISCELLANEOUS TOOLING

In addition to the tooling described in Section 2, a lift rig for the interim transfer canister was designed and fabricated. This consists of a lifting beam which is picked up at its center with the main hoist hook. Vertical tubular arms are pivotally connected to each end of the beam and terminate in hooks which. engage with two lifting lugs attached to upper sidewalls of the ITC. After engaging the lugs, the tubular arms are manually rotated to retract the hooks and lock the ITC to the lift rig.

\section{SYSTEM CONTROLS}

The fuel consolidation system is operated from the main control console situated on the work platform of the hoist assembly. As it was described in Section 2, the control console housed the programmable controller which monitors the entire consolidation process and implements control logic. In the detailed design of the control system the programmable controller was moved to the separate main power distribution cabinet (see below) and was supplemented by four microprocessors in the control console. The programable controller basically 
routes control signals and data to their correct destinations while the four microprocessors perform complex processing or high speed control functions. The signals from the microprocessors are passed to the programmable controller through a serial link, and vice versa.

In addition to the equipment housed in the cabinets of the main control console, there are five control subsystems that have their equipment housed in separate enclosures, most of which are positioned on the spent fuel pool operating floor. These subsystems are operated from the main console, but most operating setpoints are adjusted at the subsystem cabinets. In the following paragraphs the functions and equipment of the subsystems are summarized first and then the controls and instrumentation of the main control console are described.

\section{Control Subsystems}

There are five control subsystems: pneumatic supply; deionized (DI) water supply; hydraulic supply; electrical supply; and crane power and control.

Pneumatic Supply System. This system provides control, air for the following:

1) Multiple rod pulling tool grippers (14).

2) MRPT shroud mast locks and fuel rod alignment bars.

3) Single rod pulling tool gripper.

4) Sleeve removal tool purge locations (2).

Air is provided by a 175 psi air compressor through solenoid-actuated, air piloted spool control valves.

DI Water Supply System. This system provides pressurized demineralized water to operate the following:
1) A11 TV camera tracking actuators.
2) Damaged fuel station clamp.
3) Fuel disassembly station clamp.
4) Fuel transfer station clamp.
5) Compacted waste container clamp. 
6) Compacted waste container floor cylinder.

7) Compactor comb guide cylinder.

Water is provided by a multi-stage pump, with bypass and return flow filtration, pressure regulators, and solenoid actuated control valves.

The pneumatic and DI water supply system equipment is mounted in a common free-standing cabinet except for the air compressor which has its own housing.

Hydraulic Supply System. This system provides high pressure hydraulic fluid to operate the following:

1) Fuel transfer cylinder.

2) Compactor horizontal shear/compaction ram.

3) Compactor vertical compaction ram.

4) Compactor horizontal compaction ram.

5) Compactor gate drive motor (1).

6) Compacted waste container rail drive motor.

7) $X-Y$ table drive motors (2).

8) Sleeve removal tool pull and gripper cylinders.

Each circuit contains a solenoid actuated spool control valve, pressure regulating valve, and pressure relief valve. The sleeve removal pull circuit contains pressure regulating valves for each cylinder port, and the relief valve connects only to the rod side of the cylinder. Electro-hydraulic servo valves precisely control flow to the fuel transfer cylinder, the compactor horizontal shear/compaction ram, and the $X-Y$ table motors. Manual flow controls (meter-in) are installed in all other circuits. All cylinder circuits contain dual pilot operated check valves to allow load locking and prevent creep. The hydraulic motor circuits contain cross port relief valves to protect the motors from starting and stopping line pressure surge. 
The hydraulic pump is rated at 20 gallons per minute at 3500 pounds per square inch. The pump is a variable displacement, open circuit type, with pressure compensation control and separate case drain. In-line filters are located at the pump discharge and the tank return line. An oil to air heat exchanger cools fluid returning to the tank.

The piston side of the fuel transfer cylinder is fitted with an anti-runaway orifice to control any load (i.e. fuel rods) if a breakage or uncontrollable leakage occurs in that hydraulic line.

The hydraulic supply system equipment is housed in its own free-standing cabinet.

Electrical Power Distribution System. The main power distribution (MPD) cabinet handles all electrical power routing and includes:

1) Main breaker, 480 volts 300 amps 3 phase.

2) Hydraulic pump motor starter ( 50 horsepower).

3) Consolidation filter system pump motor starters $(2 \times 15$ horsepower).

4) Transformer, $480 / 117$ volts.

5) Crane (hoist assembiy) contactor.

6) 117 volt distribution breakers.

7) Pool light contactors.

8) Main programnable controller processor.

9) Input/output racks.

10) Remote input/output interface (serial link).

11) 24 volt power supply.

All systems' solenoid-actuated valves and limit switches are hardwired to the main power distribution cabinet input/output racks, except for the hydraulic servo valves which receive analog signals from the main control console. The main programmable controller processor communicates with the four microprocessors in the main control console by means of a serial link between the local/remote interface in the MPD cabinet rack assembly and the corresponding racks in the main control console. 
The main power distribution cabinet is free-standing.

Crane (Hoist Assembly) Power and Control System. This system includes all motor contactors for the hoist, bridge and trolley motors; the bridge and trolley position limit switches; the encoders for hook elevation and bridge and trolley travel; and the hook load cell. This equipment is mounted in enclosures on the hoist assembly framework. The controls are hardwired to the main control console input/output rack.

\section{Main Control Console}

The console consists of left, center and right sections on a common base and contains control and instrumentation cabinets that perform different operational functions, switch and instrumentation cabinets, monitor cabinets, input/output rack assemblies, and power supplies. Each section has a large rear access door. The layout of the front of the console is shown in Figure A-1. The upper and lower levels are separated by a writing shelf.

The four large control and instrumentation cabinets which have their own microprocessors are mounted in the upper level at the front as follows: compactor and filter system (in left section); hoist assembly (in center section); multiple rod pulling tool (in right section); and $X-Y$ table (also in right section, below MRPT cabinet). These cabinets are rail mounted with pullout handles for easy maintenance access.

TV monitor cabinets are mounted at the top of the left and center sections. Each cabinet has two monitors, those in the left cabinet being respectively a spare and the monitor for camera No. 1. The monitors in the center cabinet are for camera Nos. 2 and 3. The cabinets for the TV camera controls are mounted below the monitors. The cabinet in the left section has the controls for camera No. 1, and also the emergency stop button and the push button switches for electrical power to the fuel consolidation system. The cabinet in the center section has the controls for camera Nos. 2 and 3. A switch cabinet for power to each TV camera, and for the pool lights, is located in the right console section above the MRPT cabinet. There are additional TV camera control switches in the upper corner of the left console section below the writing shelf; these duplicate the functions of the camera controls below the monitors and are not nomally used by the console operator. The individual cabinets are described in more detail below. 


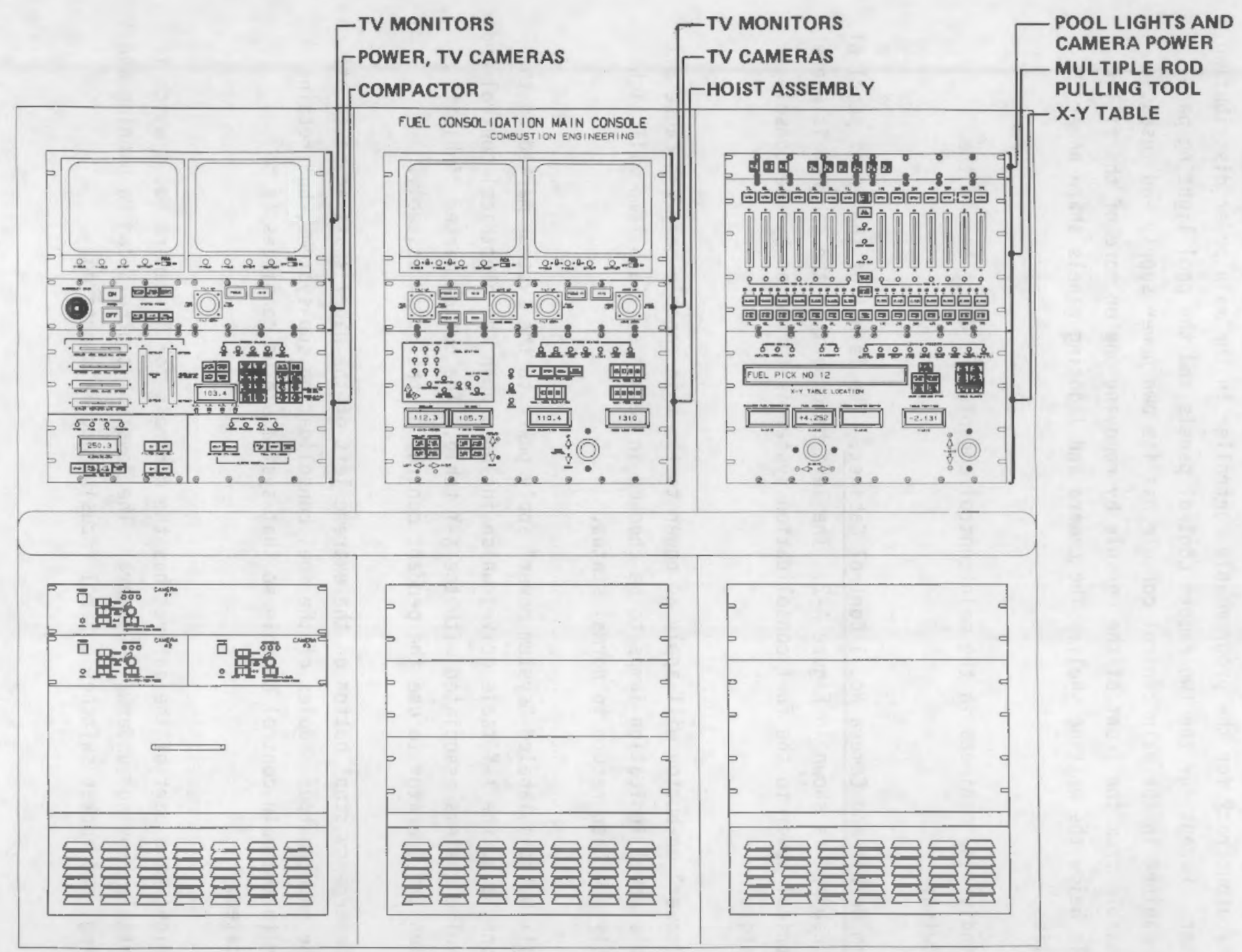

Figure A-1. Main Control Console Front Panel 
The cabinet input/output terminal blocks are wired to five printed circuit input/output racks in the control console. The racks are wired together by a serial link, which also connects them with the local/remote interface in the input/output rack for the programmable controller in the main power distribution cabinet. Except for the two camera control panels and the pool lighting panel, each cabinet in the main control console has its own power supply and fuses, accessible from the front of the console by removing one or more of the filler panels below the writing shelf. The camera and lighting panels share power supplies.

The individual cabinets in the main control console are described in the following:

System On/Off and Camera No. 1 Control Cabinet. The layout of the front panel of this cabinet is shown in Figure A-2. The left hand part of the cabinet is where electrical power to the fuel consolidation system is turned on by the console operator.

The "power" on-button will apply ac power to the main console only and cause all console panel indication lamps to be checked in sequence. Each lamp will light briefly and then return to normal status.

The six buttons labeled "system power" apply power to the systems marked on the buttons, e.g. the $X-Y$ table drive, which includes both the electrical control and hydraulic systems associated with the $X-Y$ table. The button marked "inhibit" enables the operator to use the pendant control of the hoist assembly.

The "emergency stop" button on the extreme left of the panel shuts ac power off to the input/output modules of the fuel consolidation sub-systems, but retains power to the main control console so that system status continues to be indicated.

The right-hand part of the cabinet has the controls for TV camera No. 1 which is a portable "roving" underwater camera. The joystick controls camera panning and tilting, and rocker switches control focusing and iris opening. 

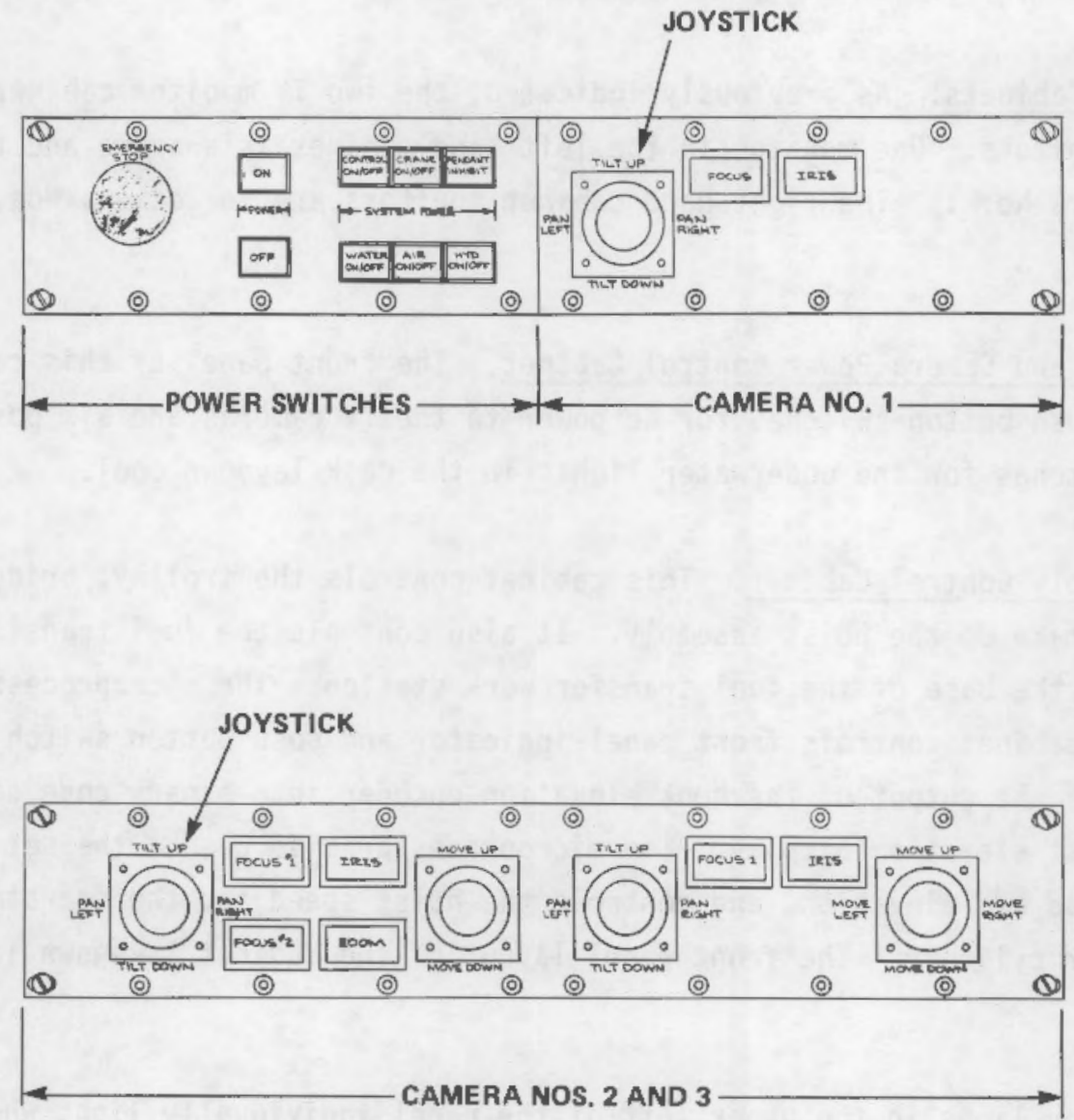

Figure A-2. Front Panels - System Power and Camera Control Circuits. 
Control Cabinet for Camera Nos. 2 and 3 . The front panel layout of this cabinet is also shown on Figure A-2. Each camera has "focus" and "iris" rocker switches, and two joysticks. For camera No. 2, which is in the system mounted on the ITC stabilizer frame, one joystick is for camera panning and tilting and the other joystick is for moving the camera vertically up and down. Camera No. 2 also has rocker switches for "zoom" and "focus" (required for refocusing after zooming). For camera No. 3, which is in the system mounted on the edge of the lower work platform, one joystick is for camera panning and tilting, and the other is for moving the camera horizontally as well as vertically.

TV Monitor Cabinets. As previously indicated, the two TV monitor cabinets each have two monitors. One monitor in the left hand cabinet is a spare and the other is for camera No. 1. The right hand cabinet monitors are for camera Nos. 2 and 3.

Pool Lights and Camera Power Control Cabinet. The front panel of this cabinet has three push button switches for ac power to the TV cameras and six push buttons switches for the underwater lights in the cask laydown pool.

Hoist Assembly Control Cabinet. This cabinet controls the trolley, bridge and hoist that make up the hoist assembly. It also controls the fuel transfer cylinder in the base of the fuel transfer work station. The microprocessor inside the cabinet controls front panel indicator and push button switch lights and converts the output of the hook elevation encoder into binary code decimals for the hoist elevation display. The microprocessor also checks the set limits on hoist load and elevation, and controls the hoist speed and the operation of the transfer cylinder. The front panel layout of the cabinet is shown in Figure A-3.

Hook location lamps in the upper left of the panel individually light when the bridge and trolley are positioned at one of sixteen frequently used work positions. These lamps are activated by the cam operated switches on the bridge rails and trolley runway. The trolley and bridge control switches for movement direction and fast or slow speed, together with the digital displays of trolley and bridge positions on the $X$ and $Y$ axes, are below the hook location lamps. The switches illuminate when pushed and are extinguished when released. The position digital displays are as measured by the trolley and bridge travel encoders. 


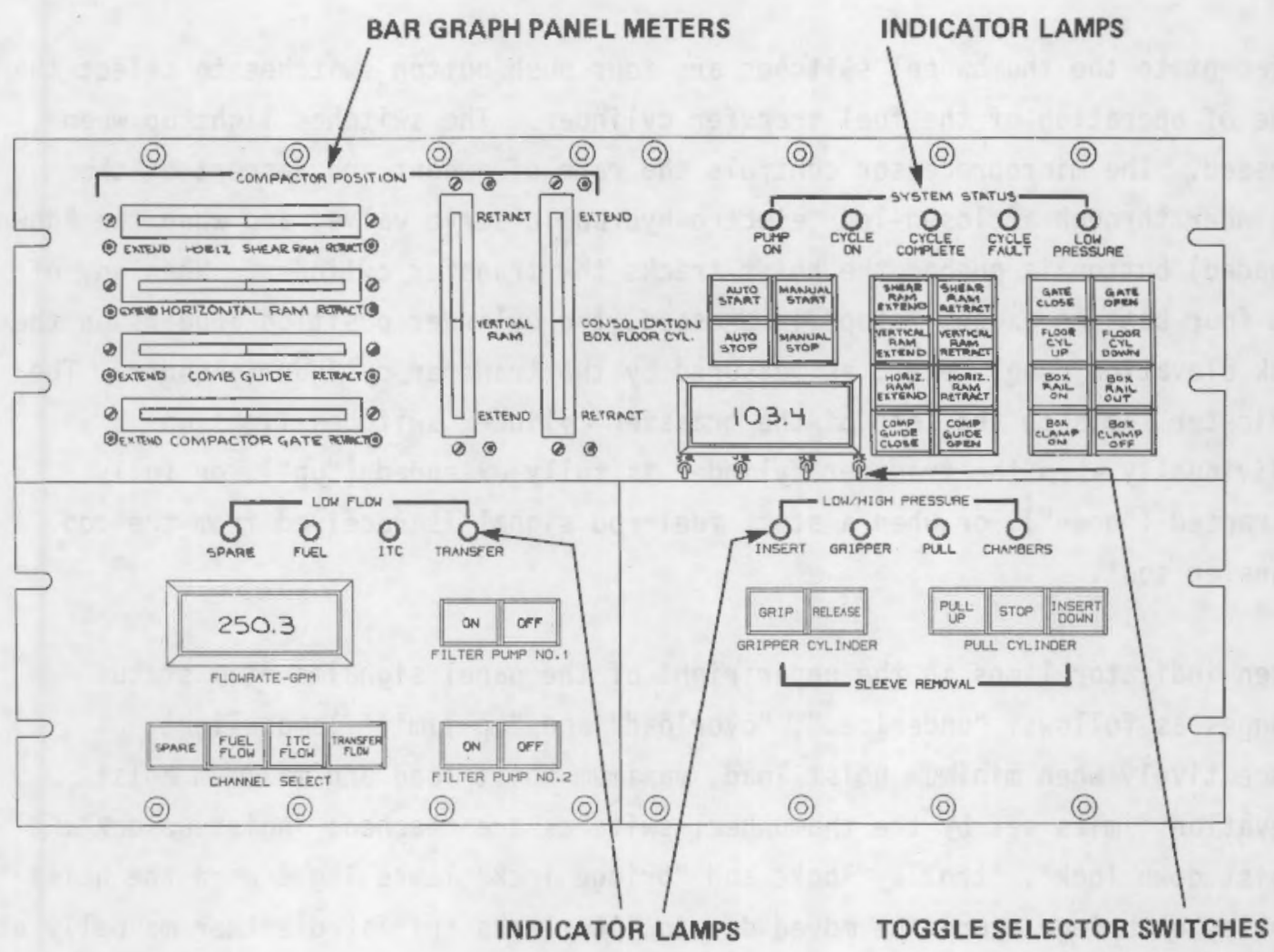

Figure A-3. Front Panel - Hoist Assembly Control Cabinet 
To the right of the trolley and bridge control switches is the joystick for raising or lowering the hoist hook, and above the joystick are digital displays of the hook elevation and the load on the hoist. The hook elevation display is from the hoist encoder, and the hook load display from the hook load cell. The panel has thumbwheel switches for setting the desired maximum and minimum hook load limits and the maximum hook elevation limit, and the hoist will automatically stop when these limits are reached (for the elevation limit the hoist will only stop when going up). The thumbwheel switches are above the digital displays for hook elevation and load.

Adjacent to the thumbwheel switches are four push button switches to select the mode of operation of the fuel transfer cylinder. The switches light up when pressed. The microprocessor controls the rate of ascent and descent of the cylinder through a closed-loop electro-hydraulic servo valve, and when the "down" (loaded) button is pushed the hoist tracks the transfer cylinder. When any of the four buttons except "stop" is pressed, the cylinder position appears on the hook elevation panel meter, as measured by the transfer cylinder encoder. The indicator lamps to the left of the transfer cylinder switches light up individually when the transfer cylinder is fully extended ("up"), or fully retracted ("down"), or when a stuck fuel rod signal is received from the rod transfer tool.

Seven indicator lamps in the upper right of the panel signal system status changes as follows: "underload", "overload" and "up limit" lamps light respectively when minimum hoist load, maximum hoist load and maximum hoist elevation limits set by the thumbwheel switches are reached; "hoist uplock", "hoist down lock", "trolley lock" and "bridge lock" lamps light when the hoist trolley or bridge cannot be moved due to interlocks initiated either manually at other control panels or by the programmable controller or microprocessors. For example, movement of any one of the hoist, trolley or bridge automatically blocks movement of the other two.

$X-Y$ Table Control Cabinet. This cabinet controls the $X-Y$ positioning table on the lower work platform, together with the positioning clamps at the work stations and the multiple rod pulling tool mast locking pins. The microprocessor in the cabinet handles the tasks of energizing the lights on the front panel 
after switches are depressed, routing the switch outputs, and controlling the front panel location displays. The front panel layout of the $X-Y$ cabinet is shown in Figure $\mathrm{A}-4$.

Table movements are controlled by two joysticks, one for the $x$ direction along the lower work platform and the other for the $Y$ direction across the platform. Acting through electro-hydraulic servo valves in the hydraulic cabinet, the joysticks regulate the speed of the table drive motors. The joysticks have locking collars which must be pulled up to allow movement. Software prevents movement in both directions at the same time and stops table motion before the physical limits of travel are reached.

The upper $X-Y$ table location display indicates to the operator which section the table is over and displays fuel pick and drop locations. It flashes to indicate when the table is approaching a pick or drop location. The four lower panel meters give the measurements of the LVDT's on the $X$ and $Y$ tables, three for the $X$ direction and one for the $Y$ direction. The $X$ direction values illuminated on the panels are plus or minus from zero at the centers of the damaged fuel/separation, fuel disassembly and interim transfer work stations. If the table $x$ position is within the range of one of the X LVDT's, the associated meter indicates position and the others remain dark. If the table position is not within the range of an LVDT, all three meters are illuminated. The $Y$ direction value is zero on the axis joining the centers of the three work stations. Indicated measurements are in inches.

Six table clamp push button switches open or close the clamps on the lower work table at the damaged fuel/separation, fuel disassembly, and fuel transfer work stations. The buttons light when pushed, and stay lit.

To the left of the table clamp switches, four push button switches open or close the multiple rod pulling tool upper and lower mast clamps, and lock the MRPT in the up or down position. These buttons also light when pushed, and stay lit. A fifth push button switch, while depressed, overrides all interlocks preventing hoist upward and downward movement. This override is provided only for use in certain off-normal procedures prescribed in the operating procedure. 


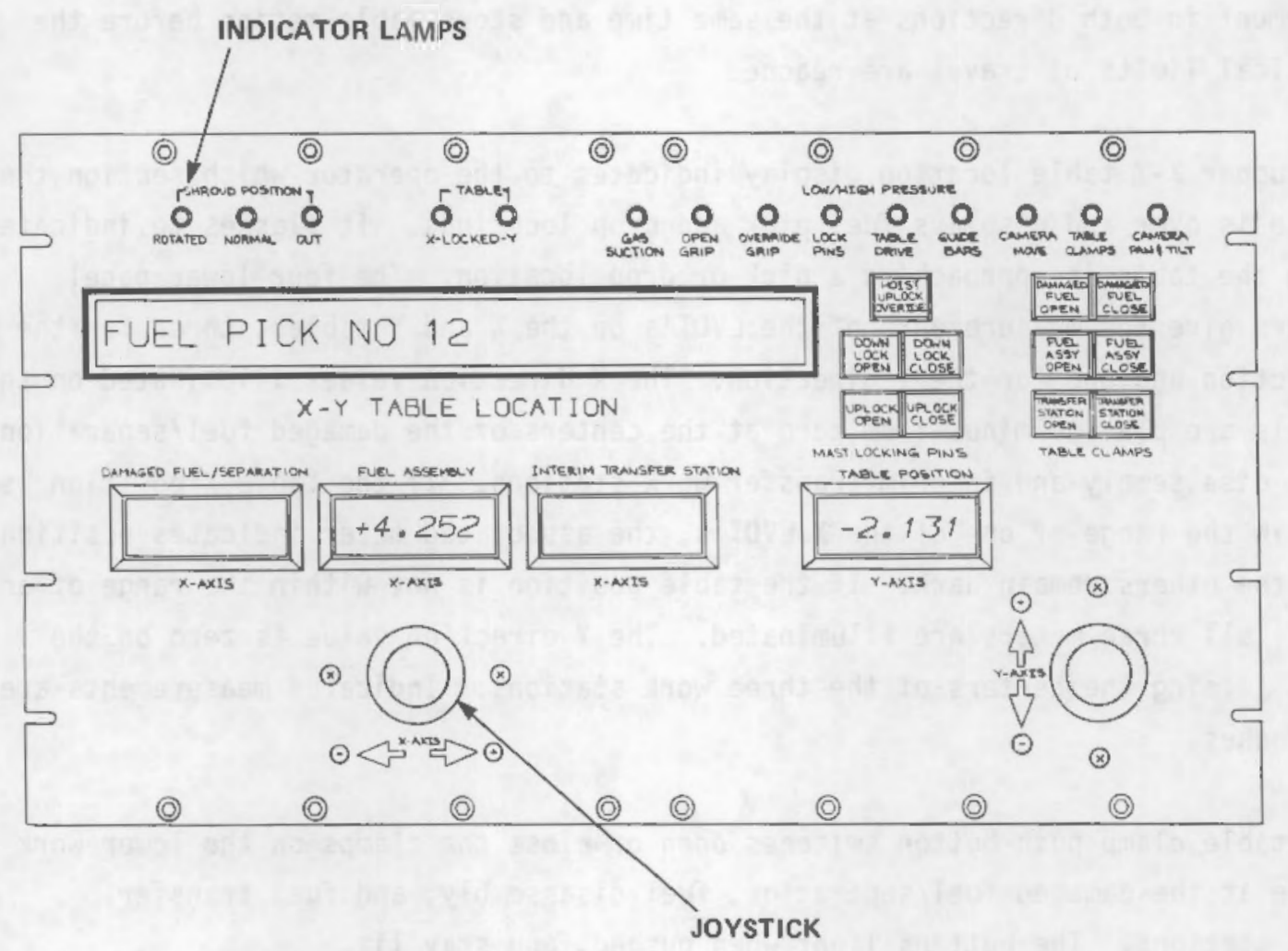

Figure A-4. Front Panel - XY Table Control Cabinet 
Indicator lamps across the top of the front panel are as follows:

- three shroud position lamps which light when the MPPT shroud is in its normal angular position; is rotated $90^{\circ}$ from normal; or is out of the $X-Y$ carriage.

- two $X-Y$ table lamps which light when the table is locked in the $X$ or $Y$ direction.

- nine pressure switch lamps which light to indicate that the air, water or hydraulic fluid pressure for the labeled operation is lower than the preset value.

Multiple Rod Pulling Tool Control Cabinet. This cabinet controls the fourteen fuel rod grippers and the rod alignment guide bars of the multiple rod pulling tool. The microprocessor in the cabinet activates the lights on the front panel after switches are depressed and monitors rod insertion in the grippers. If it detects rod slippage the microprocessor activates the corresponding rod slip warning light on the panel and causes the hoist to stop if it is moving upwards. The front panel layout of the multiple rod pulling tool control cabinet is shown in Figure $\mathrm{A}-5$.

The panel is divided into left and right sections, each of which contains the push button switches, indicator lamps and panel..meters for seven fuel rod grippers. Each gripper has an "open" push button switch at the top of the panel. This will only open the gripper if the MRPT is below the head down position in the shroud or the hook is at its lower elevation limit of four inches.

Alternatively, all the grippers can be opened simultaneously by means of the "all open" push button switch located between the two rows of panel meters. To guard against unintentional gripper opening, the "open lock" push button switch between the bottom two rows of "override" switches must be depressed at the same time as the "open" or "all open" switch. A vertical panel meter below the "open" switch displays the distance that the fuel rod is inserted into the gripper in bar graph form. Visible dual setpoints indicate the maximum and minimum insertion limits, and these are adjustable by potentiometer screws below the meter. If the insertion signal is outside the setpoint limits, the display will flash on and off. For a signal within the limits, a steady LED display will be maintained. A "rod slip" warning lamp is also located immediately below the panel meter. If rod slip is detected the hoist will also be stopped. The "close" push button switch for the gripper is below the "rod slip" lamp. Th gripper may only be closed when the fuel rod insertion is within the set point limits. Grippers can 


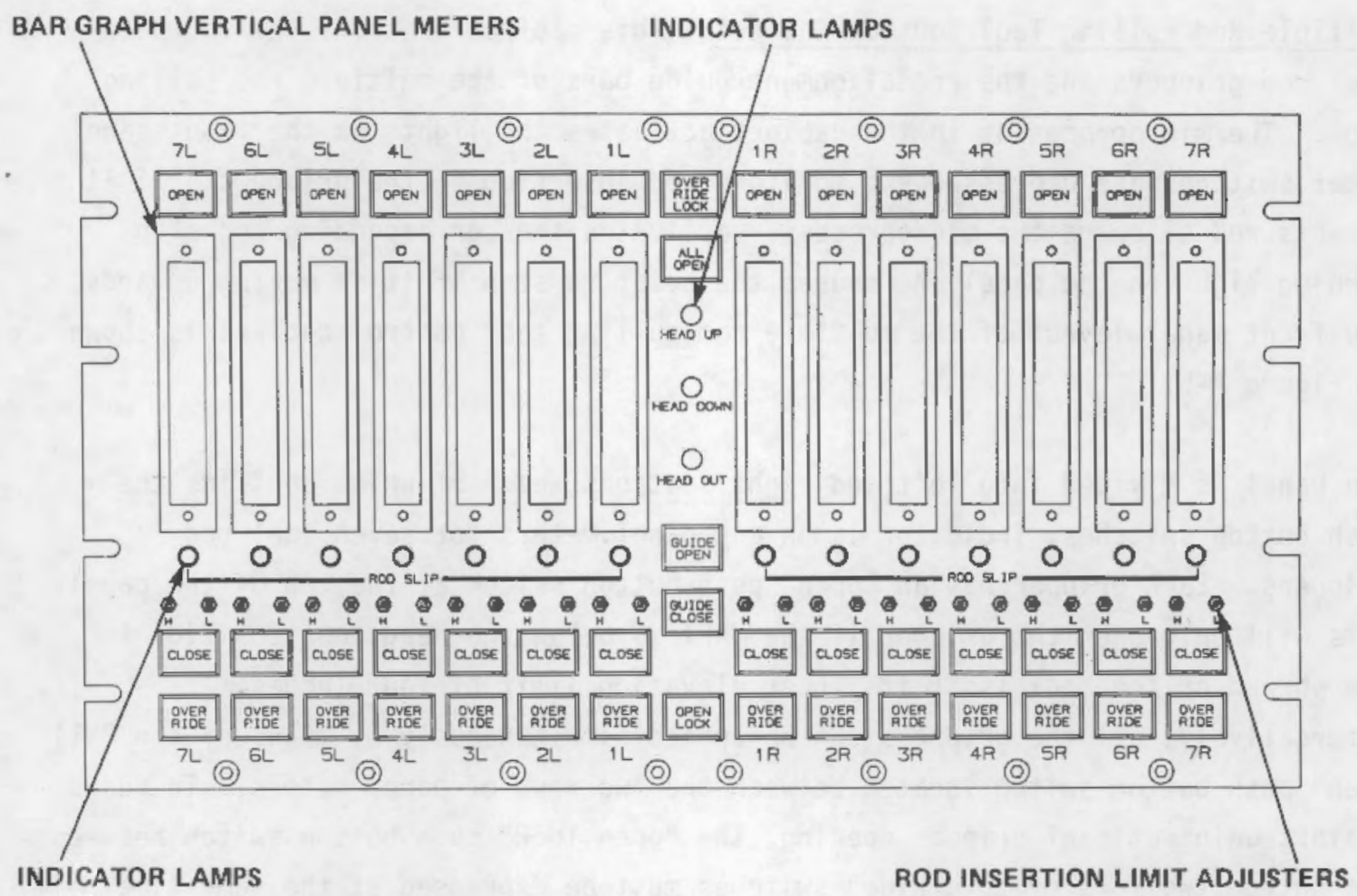

Figure A-5. Front Panel - Multiple Rod Pulling Tool Control Cabinet 
only be closed one at a time by the operator, but loss of power causes all the grippers to close automatically in a "fail-safe" mode. The "override" push button switch below the "close" switch allows the operator to increase the gripping pressure applied to the rod. This may be done initially or after rod slip occurs, but in both cases the rod insertion must be within set point 1 imits. The "override lock" push button between the top two rows of "open" switches must be depressed at the same time as the "override" switch. The two remaining push buttons switches on the MRPT control panel are the "guide open" and "guide closed" switches located respectively between the two rows of rod slip warning lights and rod insertion limit potentiometer adjusters. These switches open and close the fuel alignment guide bars on the MRPT shroud. If any grippers are closed or overridden the guide bars cannot be opened when the head is up or the hook elevation is above 142 inches. Three indicator lamps above the guide bar switches light up when the MRPT head is up, down, or out of, the shroud.

Compactor Control Cabinet. This cabinet controls the non-fuel bearing waste compactor, and also the consolidation filtration system and the sleeve removal equipment for sleeved fuel assemblies. The microprocessor in the cabinet marshalls the panel switch outputs and activates panel indicator lamps. It also monitors travel of the compactor rams and various other devices, and maintains it within required limits. If the automatic option is selected at the panel, the microprocessor will control a complete compaction cycle without further operator intervention. The microprocessor also monitors flow rates in the suction lines to the filtration system and warns when flow falls below a preset limit. The front panel layout of the compactor control cabinet is shown in Figure A-6.

The compactor controls and instrumentation are in the upper half of the front panel. The push button switches for control of the compactor are located on the right. The "auto start" button when depressed starts the automatic compaction cycle. The button will light when pushed, and stay lit until the "auto stop" button is pushed. If the "auto stop" button is pressed before the end of the cycle, completion of the cycle has to be done manually. If the compactor is to be operated in the manual mode instead of automatic, the "manual start" push button switch must be depressed. This then allows the individual device switches to the right of the start switches to be activated. The "manual start" button will light and remain lit until the "manual stop" button is depressed. 


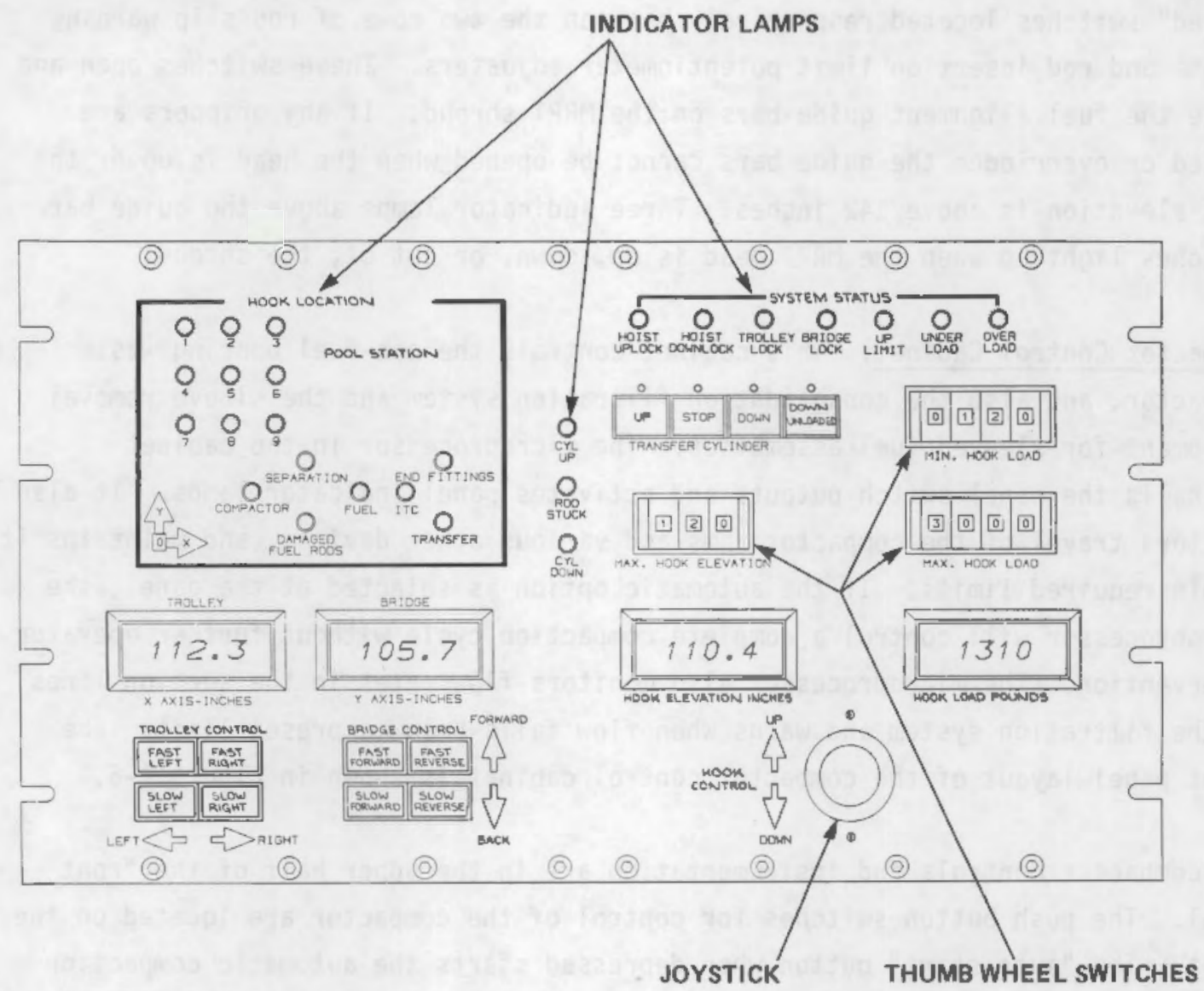

Figure A-6. Front Panel - Compactor Control Cabinet 
The "shear ram extend" push button switch when depressed causes the horizontal shear/compaction ram to advance through the inlet chamber and into the compaction chamber. The hydraulic cylinder for the ram is electro-hydraulic servo valve controlled to maintain a constant speed independent of the set pressure of the hydraulic fluid. The "shear ram retract" button reverses the ram's direction. The "vertical ram extend", "vertical ram retract", "horizontal ram extend" and "horizontal ram retract" push buttons perform similar functions for the vertical and horizontal compaction rams. The hydraulic cylinders for these rams are not servo-controlled. The "compactor guide close" and "compactor guide open" switches respectively cause the comb guide to advance into the inlet chamber to support the guide tube/grid cage section being sheared and to retract out of the chamber. The "gate close" and "gate open" push button switches activate the hydraulic drive motor for the compactor discharge gate. Limit switches on the drive stop the gate at the full in and full out positions. The "floor cylinder up" and "floor cylinder down" switches activate the vertical pressurized water operated cylinder which raises or lowers the floor in a compacted waste canister (CWC) at the compactor discharge location. The "box rail in" and "box rail out" switches activate the hydraulic motor drive which moves the CWC's from the canister pick-up and set-down location to the compactor discharge location and vice versa. Limit switches on the drive stop the CWC box carriage at the two locations. The "box clamp on" and "box clamp off" switches activate the pressurized water operated cylinder on the clamp which stabilizes CWC's at the compactor discharge location.

All of the above motions continue while the appropriate buttons are depressed, and stop when the buttons are released. In certain cases as noted above, limit switches also stop motion at specific locations. The buttons light only while the functions are performed, except that if the function is stopped by a limit switch, the light stays on to indicate that the movement has been fully completed. The push button switches also light up in sequence when the compactor is operating in the automatic mode.

System status indicating lamps are provided above the push button switches. The "pump on" and "low pressure" lamps function whenever power is on to the compactor and hydraulic control cabinets, since they relate to the hydraulic system status and their information is relevant to the entire fuel consolidation system. The "pump on" light warns that either the fluid level or temperature of the hydraulic 
system has changed from its initial set point, and the "low pressure" light warns that the hydraulic system pressure is low because its filter is beginning to clog. The "cycle on", "cycle complete", and "cycle fault" lamps only function when the compactor is operating in the automatic mode. Recovery from a cycle fault is performed manually.

Six analog panel meters to the left of the push button switches provide bar graph type indication of the positions (e.g. amount of extension or retraction) of the devices actuated by the switches. Each panel meter is oriented the same way as the device being metered; thus the horizontal shear/compaction ram, horizontal compaction ram, comb guide and gate meters are horizontal; the vertical compaction ram meter is vertical with the indication extending downwards; and the CWC floor cylinder meter is vertical with the indication extending upwards. U1trasonic sensors in the hydraulic or pressurized water cylinders provide the signals for the ram and floor cylinder meters, an LVDT provides the signal for the comb guide and limit switches provide the signal (closed or open) for the gate. Bar graph indications are adequate for conveying device positions to the operator at a glance, especially while the compactor is in the automatic mode. For manual control, however, it is necessary to be able to position the rams and the floor cylinder very precisely to avoid mutual interference. A digital panel meter is therefore also provided, below the manual/auto push buttons. This meter has four toggle switches to select the three rams and the floor cylinder one at a time. The meter taps off the voltage signal to the analog panel meter for the device selected, converts it to digital and displays it. A voltage divider in each panel connector scales the signal so that it can be read as inches of travel.

The lower half of the compactor control cabinet front panel contains the controls and instrumentation for the filter system on the left, and for the sleeve removal tool on the right.

There is a pair of push button switches for starting and stopping each of the two filter pumps. The buttons are lit when the pumps are running. A flashing lamp indicates that the pump has tripped on overload. To the left of the switches is a digital panel meter indicating flowrates in the suction manifold connections to the work stations. Signals from flow sensors in each of the connections to the fuel disassembly, interim transfer canister, and damaged fuel/separation work 
stations are displayed when the appropriate buttons of the four below the meter are depressed (the fourth channel is spare). The four "low flow" indicator lamps (one is spare) above the meter light up when the limiting low flow rates in the suction connections are reached, warning of filter cartridge exhaustion. Flow rate $l i m i t s$ are adjustable inside the cabinet by thumbwheels on the flow limit cards.

The sleeve removal tool is only used when consolidating fuel assemblies whose guide tubes have had sleeves installed as a repair measure. The sleeves have to be removed before cutting the guide tubes to free the upper end fittings because the chrome plating on the internal diameter makes it impractical to cut through the sleeve itself. The sleeve removal gripper is of the split collet type expanded by a hydraulically operated gripper cylinder. The gripper and cylinder assembly is extended out of and retracted back into the bottom of the sleeve removal tool mast by a second hydraulic cylinder called the pull cylinder. Tool positioning and extension/retraction of the gripper assembly are verified visually using the underwater TV camera. There are three push button switches for the pull cylinder. Respectively, these retract the gripper assembly into the tool mast ("pull up"), stop the cylinder, and extend the gripper assembly out of the mast ("insert down"). The gripper has two push button switches respectively to expand the collet ("grip") and relax it ("release"). Four indicator lamps above the switches give warning during sleeve removal operations of hydraulic tluid pressure outside ot preset limits.

\section{SAFETY INTERLOCKS}

Over 30 interlocks are incorporated in the control software, many of which are referred to above in the description of the main control console. Typically, they protect the fuel rods from potentially damaging situations such as: pulling rods from a fuel assembly while a rod is slipping in the MRPT gripper; pulling rods with the MRPT guide bars open after the rods have cleared the fuel assembly; or bridge and trolley movement before fuel rods have been hoisted completely clear of the fuel assembly. The interlocks are itemized in the operating procedure (1). 
SEISMIC/STRUCTURAL ANALYSIS

On completion of the detailed design of the lower work platform and the hoist assembly, these components were seismically and structurally analyzed to determine interface reactions with the spent fuel pool structure during a safe shutdown earthquake (SSE) and to verify that the components will not break loose from their supports and damage adjacent equipment. For both components, assembly framework stresses during the SSE were calculated to ascertain that they will be within acceptable limits. The ANSYS structural analysis computer code was used to create three-dimensional finite element models of the work station and hoist assembly, calculate natural frequencies and then perform 1 inear response spectrum analyses for the Millstone Unit 2 SSE at $4 \%$ damping.

\section{ASSEMBLY AND TESTING}

After the parts had been fabricated by vendors for the non-commercial components they were assembled in the C-E laboratory, where instrumentation, control and electrical equipment was also installed. Each component was then checked out and functionally tested under dry conditions. All consolidation equipment was finally tested as an integrated system in a specially constructed water tank in the laboratory during the cold demonstration, which preceded the field demonstration with actual spent fuel at Millstone Unit 2. Both the cold demonstration and the field demonstration are described in a separate report.

\section{REFERENCE}

1. Consolidation of Spent Fuel Assemblies, C-E Procedure No. 00000-ESE-656, July 1987. 
Table A-1

FUEL CONSOLIDATION EQUIPMENT

DRAWING LIST

Drawing No.

Title

E-18767-161-001

E-13782-667-022

E-FUEL-501-005

E-FUEL-501-009

E-FUEL-501-010

E-FUEL-501-012

J-FUEL-501-014

E-FUEL-501-015

E-FUEL-501-016

E-FUEL-501-017

E-FUEL-501-018

E-FUEL-501-019

E-FUEL-501-020

E-FUEL-483-022

E-FUEL-483-023

E-FUEL-501-026

E-FUEL-501-027

E-FUEL-501-028

E-FUEL-501-029

E-FUEL-501-030

E-FUEL -501-031

E-FUEL-501-032

D-FUEL-501-033

E-FUEL -501-034

E-FUEL-501-035

E-FUEL-501-036

E-FUEL-501-037

E-FUEL-501-038

E-FUEL-501-D39

E-FUEL-501-040

E-FUEL-501-041
$14 \times 14$ Fuel Assembly, Millstone Unit 2

$3 \times 3$ Temporary Storage Rack

Fuel Consolidation Hoist Assembly Installation

Interim Transfer Canister Assembly

Pull Head Assembly \& Details - Multiple Rod Pull Tool

Internal Tube Cutter Assembly $14 \times 14$ Fuel Consolidation

TV Mounting Assembly, Movable TV

End Fitting Consolidation Box

Lower Work Platform Assembly

TV Mounting Assembly \& Details

Multiple Fuel Rod Pull Tool Mast Assembly

Lower Platform \& Details

Station Shroud Assembly \& Details

Consolidated Fuel Storage Box

Cover Assembly, Consolidated Fuel Storage Box

ITC Stabilizing Structure

Multiple Fuel Rod Pulling Tool Shroud Assembly \& Details

$X-Y$ Positioning Table

Sleeve Removal Tool Assembly \& Details

Sleeve Removal Tool - Mast Assembly

Long Fuel Handling Tool Assembly \& Details

Lower Platform Miscellaneous Details

Cask Pool/Lower Platform Interface

Rod Transfer Tool

Hex Turning Tool

Single Rod Pulling Tool

Gripper Assembly - Single Rod Pull Tool

TV Camera - Work Platform Mount

ITC Shell Assembly \& Details

Spear Assembly \& Details

Gate Mechanism Assembly \& Details 
Table A-1

FUEL CONSOLIDATION EQUIPMENT

DRAWING LIST (Cont'd.)

Orawing No.

J-FUEL -501-042

E-FUEL-501-044

E-FUEL-501-045

0-FUEL-501-046

0-FUEL-501-047

E-FUEL-501-048

E-FUEL-501-049

0-FUEL-501-050

E-FUEL-501-051

E-FUEL-501-052

D-FUEL-501-053

E-FUEL-501-054

E-FUEL-502-055

0-FUEL-501-056

D-FUEL-501-057

D-FUEL-501-058

E-FUEL-501-059

E-FUEL-501-060

0-FUEL-501-061

0-FUEL-501-062

0-FUEL-501-063

E-FUEL-501-064

E-FUEL-501-065

D-FUEL-501-066

D-FUEL-501-067

0-FUEL-501-068

E-FUEL-501-069

E-FUEL-501-070

E-FUEL-501-071

D-FUEL-501-072

D-FUEL - 501-073
Title

Multiple Fuel Rod Pulling Tool Stackup

Muttiple $14 \times 14$ Fuel Rod Pulling Tool ( 1 × 14 Array)

Rod Pulling Control Cabinet

Rod Pulling Control Front Panel Assembly

Rod Pulling Control Panel Cutouts

Rod Pulling Control Schematics

Fuel Consolidation Electrical Layout

Rod Pulling Control Rear Panel Assembly

Lower End Fitting Lifting Tool Assembly \& Details

Spent Fuel Consolidation Vacuum System Piping

Fuel Consolidation Main Console

Mounting Plate Assembly, Single Rod Pulling Tool

$X-Y$ Positioning Control Cabinet

$X-Y$ Positioning Panel Assembly - Front

$X-Y$ Positioning Panel Assembly - Rear

$X-Y$ Positioning Panel Cutouts

$X-Y$ Positioning Panel Control Schematics

Crane Control Cabinet Assembly

Crane Control Panel Assembly - Front

Crane Control Panel Assembly - Rear

Crane Control Panel Cutouts

Crane Control Electrical Schematics

Compactor Control Cabinet Assembly

Compactor Control Panel Assembly - Front

Compactor Control Panel Assembly - Rear

Compactor Control Panel Cutouts

Compactor Control Electrical Schematics

Camera Panel No. 1 Assembly

Camera Panel No. 2 Assembly

Monitor Panel No. 1

Monitor Panel No. 2 
Table A-1

FUEL CONSOLIDATION EQUIPMENT

DRAWING LIST (Cont'd.)

Drawing No.

E-FUEL - 501-074

E-FUEL-501-075

E-FUEL-501-078

E-FUEL-501-079

E-FUEL-501-080

E-FUEL-501-081

E-FUEL-501-082

E-FUEL-501-083

E-FUEL-501-084

E-FUEL-501-085

E-FUEL-501-086

E-FUEL-501-087

E-FUEL-501-D88

E-FUEL-501-089

E-FUEL-501-090

E-FUEL-501-091

E-FUEL-501-099

D-FUEL-501-100

E-FUEL-501-101

E-FUEL-501-102

E-FUEL-501-103

E-FUEL-501-104

E-FUEL-501-105

E-FUEL-501-106

E-FUEL-501-107

E-FUEL-501-108

E-FUEL-501-109

E-FUEL-501-110

D-FUEL-501-111

E-FUEL-501-112
Title

Main Console Power Distribution

Main Power Distribution

Compactor System

Compactor System Details

Top Cylinder Mount Assembly - Compactor

Top Funnel Assembly - Compactor

Gate Mechanism - Compactor

Stanchions and Details - Compactor

Compactor Miscellaneous Details

Compacted Waste Canister Clamp - Compactor

Compacted Waste Canister

Cover Assembly, Compacted Waste Canister

Compactor Miscellaneous Details

Comb Guide Plate Assembly

Compacted Waste Canister Delivery System

Compactor Hydraulic Cylinder Assembly

Damaged Rod Storage Container

Main Console to Pool Instrumentation

Main Console to Crane Cable Connections

Main Console to Power Distribution Panel Connections

Fuel Consolidation Installation

Water/Air Schematic Circuits

Water/Air Hydraulic hose Configuration

MRPT/SRPT Upper and Lower Storage Racks

RTA/VT Lift Tool

Vise Grip Tool

3/4-10 Tool

Tool Rack Assemblies

Pool Light and Camera Power Control Cabinet

Main Power Distribution Center to Hydraulic Cabinet Wiring

Diagram 
Table A-1

FUEL CONSOLIDATION EQUIPMENT

DRAWING LIST (Cont'd.)

Drawing No.

$\underline{\text { Title }}$

D-FUEL-501-113 Main Power Distribution Center to Air and DI Water Cabinet Wiring Diagram

D-FUEL-501-114 Compactor Control Cabinet Flow Chart

D-FUEL-501-115 Main Console Cable Interconnection Diagram

E-FUEL-501-116 Main Power Distribution Center to Crane Wiring Diagram

E-FUEL-501-117 Main Power Distribution Center to Pool Wiring Diagram

E-FUEL-501-118 Main Power Distribution Center Cable Connection

E-FUEL-501-120 Hydracon Signal Conditioner J-Box Layout

E-FUEL-501-121 T-Strut Panel Stiffener Assemblies

D-FUEL-501-122 Fuel Transfer Cylinder

E-FUEL-501-123 3-in-1 Tool

D-FUEL-501-226 ITC Lift Rig Assembly 


\author{
Appendix B \\ APPLICATION OF CONSOLIDATION EQUIPMENT TO NON-C-E FUEL
}

\title{
INTRODUCTION
}

Combustion Engineering. Inc. (C-E) has designed and developed a spent-fuel consolidation system for consolidating C-E $14 \times 14$ spent fuel (Figure B-1). A review program was instigated to ascertain the applicability of the system to other C-E fuel sizes and to fuel bundles* designed by other manufacturers. Design information available through open literature was utilized for this review (1). Fuel bundle configurations were compared with the tooling and procedures of the C-E system.

The review procedure concentrated on the design specifics of each fue 1 bundle and on what changes are needed in the C-E tooling and procedures. Differences in number of fuel rods per bundle, attachment schemes of top and bottom nozzles, grid assemblies, fuel rod diameters, and control element guides were reviewed. The review concentrated on determining fuel bundle design differences, as the consolidating procedure, once the fuel rods are removed from the fuel bundle assembiy, is basically the same for all fuel rods.

\section{PROCEDURE}

A comprehensive review was made of the available descriptive documentation on fuel bundles of the following manufacturers: Babcock and Wilcox. Exxon. General Electric, and Westinghouse. Fuel bundles for both pressurized water reactors (PWRS) and boiling water reactors (BWRS) were included in the review.

The configurations of the fuel assemblies were compared with the existing design and operation of the fuel consolidating equipment. Overall dimensions as well as specific design configurations were checked (see

\footnotetext{
*The terms "fuel bundle" and "fuel assembly" are used interchangeably by the nuclear industry, although generally the former term is associated with the fuel for BWRs and the latter term with fuel for PWRs.
} 
Figures B-2 and B-3 and Tables B-1 and B-2). Individual engineering techniques for fuel rod attachment to upper and lower tie plates as well as support spacers and grid assemblies were examined. Support rod attachment designs were also checked for tooling adaptability. Owing to the fact that there is no standard design for fuel assemblies and fuel bundles, potential problems in indexing the different designs on the $X-Y$ table were examined in detail. Grappling procedures for manipulation of fuel assemblies were also considered. The compatibility of the different designs of grappling provisions was verified.

\section{FINDINGS}

The following specific areas and concerns were examined in detail.

\section{Handling Fuel Assemblies}

The lifting range and capacity of the hoist assembly are sufficient to handle both fuel rod lengths and fuel assembly weights of the fuel assemblies investigated.

\section{X-Y Positioning Table}

The manufacturer's drawings will be used to determine reference points on each design of fuel assembly to be used for precise alignment and indexing of the fuel assembly on the $X-Y$ table.

\section{Guide Tube Cutter}

The guide tube cutter assembly design is flexible enough to be easily modified to handle the different sizes and configurations of guide tubes that must be cut.

\section{Fuel Rod Removal}

The number of fuel rods in a row within the fuel assembly can be accommodated by the individually actuated rod grippers. Also, the different fuel rod diameters are within the capacity of the rod grippers.

Volume Reduction System Compactor

The compactor is of sufficient size and capacity to handle the spacing grids that are to be compressed.

\section{Interim Transfer Canister}

The canister is capable of handling the rod diameters of all fuel rods examined. 


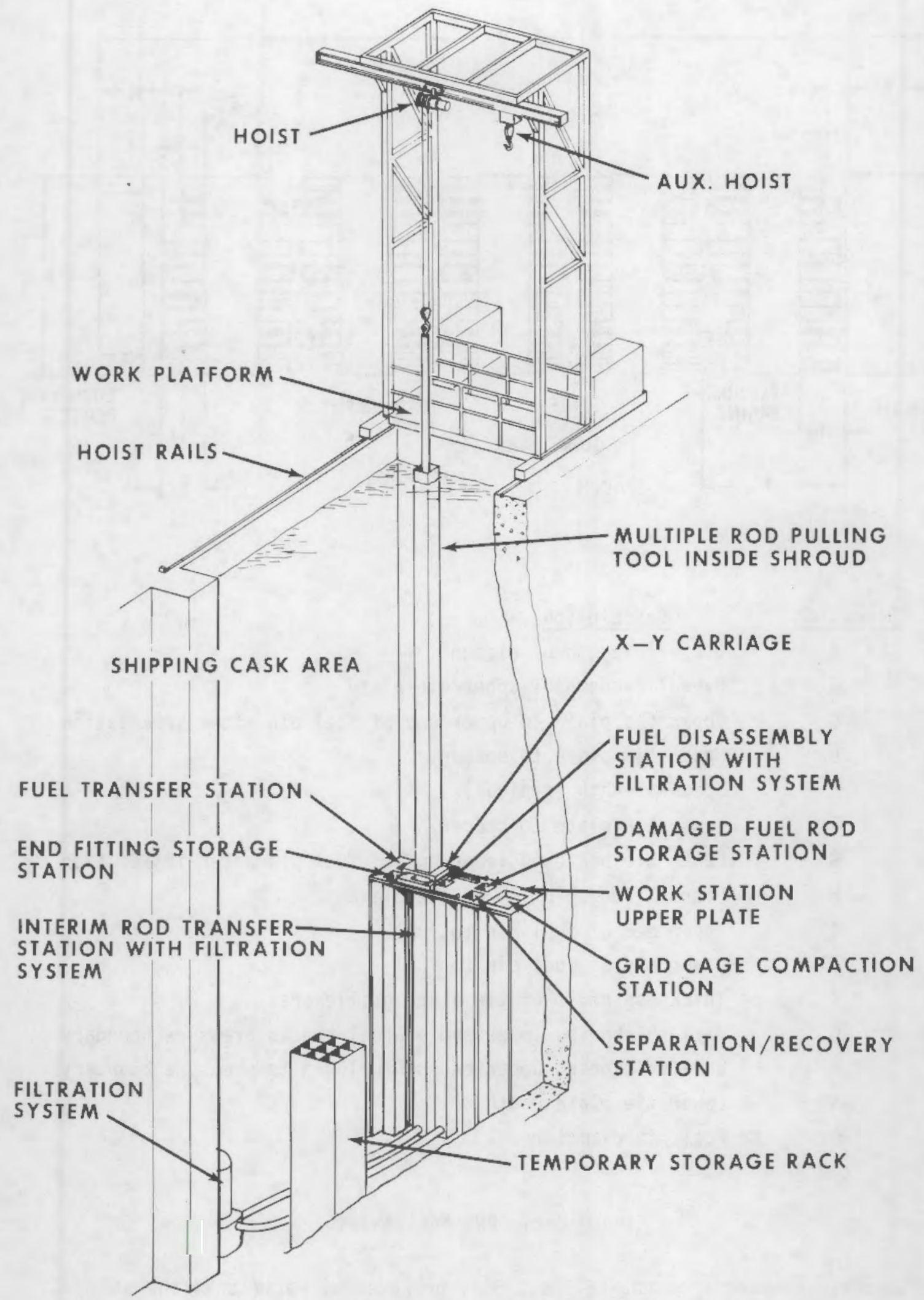

Figure B-1. Spent Fuel Consolidation System 


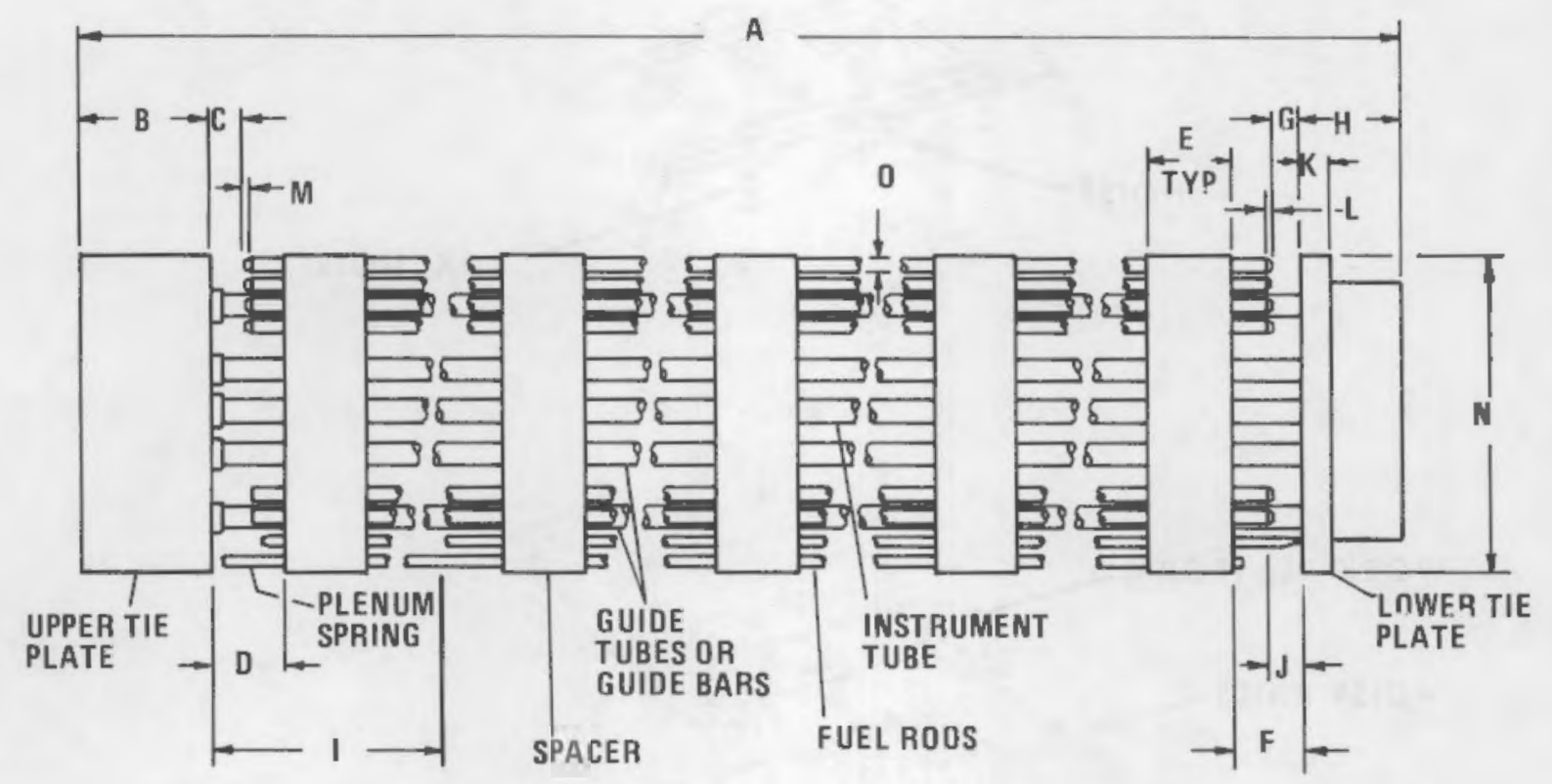

\begin{tabular}{ll} 
Dimension & \multicolumn{1}{c}{ Description } \\
A & Overall length of element \\
B & Overall length of upper tie plate \\
C & Upper tie plate to upper end of fuel pin after irradiation \\
D & Upper tie plate to spacer \\
E & Spacer length (typical) \\
F & Lower tie plate to spacer \\
G & Lower tie plate to lower end of fuel pin after irradiation \\
H & Overall length of lower tie plate \\
I & Upper end of fuel pin to fuel \\
J & Lower end of fuel pin to fuel \\
K & Thickness of lower tie plate grille area \\
L & Wall thickness, lower end of fuel pin to pressure boundary \\
M & wall thickness, upper end of fuel pin to pressure boundary \\
$\mathrm{N}$ & Lower tie plate width \\
O & Fuel pin diameter
\end{tabular}

Figure B-2. PWR Fue1 Assemb1y

Source: Adapted from PNL-2575 (UC-85), prepared by Pacific Northwest Laboratory. September 1979. 
Table B-1

PWR SCHEMATIC DIMENSIONS

\begin{tabular}{|c|c|c|c|c|c|c|c|c|c|c|c|c|c|c|c|c|}
\hline \multirow{2}{*}{ Designation } & \multirow{2}{*}{$\begin{array}{l}\text { Fuel } 1 \\
\text { Element } \\
\text { Array }\end{array}$} & \multicolumn{3}{|r|}{ PWR } & \multicolumn{6}{|c|}{ Fuel Assembly Schematic Dimensions, Inches } & 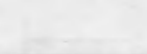 & & & & \multirow[b]{2}{*}{0} \\
\hline & & A & B & $\mathrm{C}$ & D & $-\frac{E}{2}$ & $\mathrm{~F}$ & $\frac{G}{6}$ & $\mathrm{H}$ & $\frac{1}{1}$ & $\mathrm{~J}$ & K & $\mathrm{L}$ & M & $\mathrm{N}$ & \\
\hline $\begin{array}{l}\text { EXXON } \\
\text { (Combustion } \\
\text { Engineering) }\end{array}$ & $14 \times 14$ & 156.7 & 6.10 & 0.5 & 1.52 & $\begin{array}{l}2.75 \\
(\max .)\end{array}$ & 1.52 & 0.5 & 2.68 & 9.20 & 0.60 & -- & -- & -- & - & 0.440 \\
\hline $\begin{array}{l}\text { EXXON } \\
\text { (Westinghouse) }\end{array}$ & $15 \times 15$ & 159.7 & 5.05 & 0.5 & 1.63 & $\begin{array}{l}2.75 \\
(\max .)\end{array}$ & 1.80 & 0.5 & 2.72 & 7.40 & 0.60 & -. & -- & -- & -. & 0.424 \\
\hline $\begin{array}{l}\text { EXXON } \\
\text { (Combustion } \\
\text { Engineering) }\end{array}$ & $15 \times 15$ & 148.9 & 3.39 & 1.0 & 1.40 & $\begin{array}{l}2.75 \\
(\max .)\end{array}$ & 1.40 & 0 & 4.86 & 7.06 & 0.59 & $\cdots$ & -- & -- & -- & 0.415 \\
\hline $\begin{array}{l}\text { EXXON } \\
\text { (Westinghouse) }\end{array}$ & $17 \times 17$ & 159.7 & 3.67 & 0.5 & 1.60 & $\begin{array}{l}2.75 \\
(\max .)\end{array}$ & 1.80 & 0.5 & 2.74 & 7.40 & 0.50 & $\cdots$ & -- & 8.425 & -- & 0.380 \\
\hline $\begin{array}{l}\text { Combustion } \\
\text { Engineering }\end{array}$ & $14 \times 14$ & 157.2 & 5.8 & -- & 2.3 & 1.4 & 2.6 & 0 & 3.3 & -- & 0.95 & $5 / 8$ & $5 / 8$ & $3 / 8$ & 8.4 & 0.440 \\
\hline $\begin{array}{l}\text { Combustion } \\
\text { Engineering }\end{array}$ & $15 \times 15$ & 149.1 & 3.5 & -- & 15.7 & 1.2 & 15.7 & 0 & 5.1 & -- & 0.69 & $5 / 8$ & - & 0.49 & 8.55 & 0.4135 \\
\hline $\begin{array}{l}\text { Combustion } \\
\text { Engineering }\end{array}$ & $16 \times 16$ & 176.8 & 10.4 & -- & 3.0 & 1.4 & 2.7 & 0 & 3.8 & -- & 0.90 & $5 / 8$ & $1 / 2$ & $3 / 8$ & 8.18 & 0.382 \\
\hline Westinghouse & $14 \times 14$ & 159.8 & 3.67 & 0 & -- & -- & -- & 0 & $\cdots$ & -- & - & -- & -- & -- & - & 0.422 \\
\hline Westinghouse & $15 \times 15$ & 159.76 & 3.67 & 0 & -- & -- & $\cdots$ & 0 & -- & -- & -- & -- & - & -- & 8.426 & 0.422 \\
\hline Westinghouse & $17 \times 17$ & $\begin{array}{l}159.765 \\
+1.789 \\
\text { for spring }\end{array}$ & 3.67 & 0 & 1.790 & 2.142 & 1.793 & 0 & 2.738 & 6.950 & 0.688 & -- & -- & -- & 8.426 & 0.374 \\
\hline $\begin{array}{l}\text { Babcock \& } \\
\text { Wilcox }\end{array}$ & $14 \times 14$ & NO LONGER & MANUFAC & TURED . & - ALL & REPROCESSED & & & & & & & & & & \\
\hline \multirow[t]{2}{*}{$\begin{array}{l}\text { Babcock \& } \\
\text { Wilcox }\end{array}$} & $\begin{array}{l}15 \times 15 \\
\text { Mark } 82\end{array}$ & 165.6 & $6-7 / 16$ & 0 & 0 & $1.5 / 4.15$ & 0 & 0 & $4-5 / 8$ & $5-9 / 16$ & $4-1 / 8$ & 1 & -- & -- & 8.54 & 0.430 \\
\hline & $\begin{array}{l}\text { Mark } \\
\text { B3 \& B4 }\end{array}$ & 165.6 & $6-1 / 16$ & $5 / 8$ & 0 & $1.5 / 4.15$ & 0 & 0 & $4-1 / 4$ & $\begin{array}{l}5-11 / 32 \\
\text { to } \\
7-11 / 32\end{array}$ & $4-11 / 32$ & $5 / 8$ & -- & - & 8.54 & -- \\
\hline $\begin{array}{l}\text { Babcock \& } \\
\text { Wf lcox }\end{array}$ & $\begin{array}{l}17 \times 17 \\
\text { Mark C } \\
\text { PNL-2575 }\end{array}$ & 165.7 & $7-15 / 16$ & $5 / 8$ & 0 & $1.5 / 4.17$ & 0 & 0 & $3-15 / 32$ & $6-11 / 32$ & $3-11 / 32$ & $5 / 8$ & -- & -- & 8.54 & 0.379 \\
\hline
\end{tabular}

Source: Adapted from (UC-85), prepared by Pacific Northwest Laboratory. September 1979. 

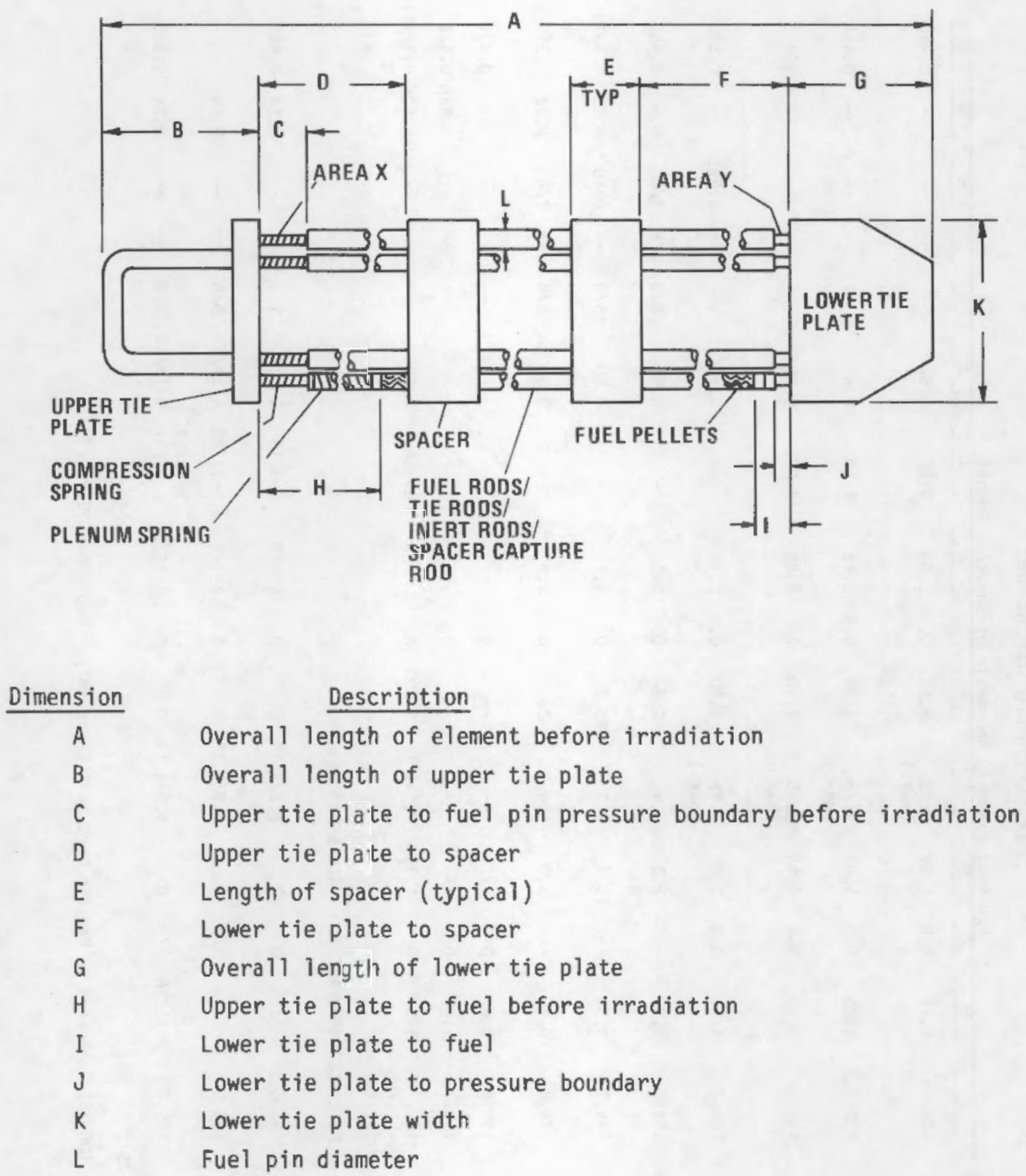

Figure B-3. BWR Fuel Bundle Schematic

Source: Adapted from PNL-2575 (UC-85), prepared by Pacific Northwest Laboratory. September 1979. 
Table B-2

BWR SCHEMATIC DIMENSIONS

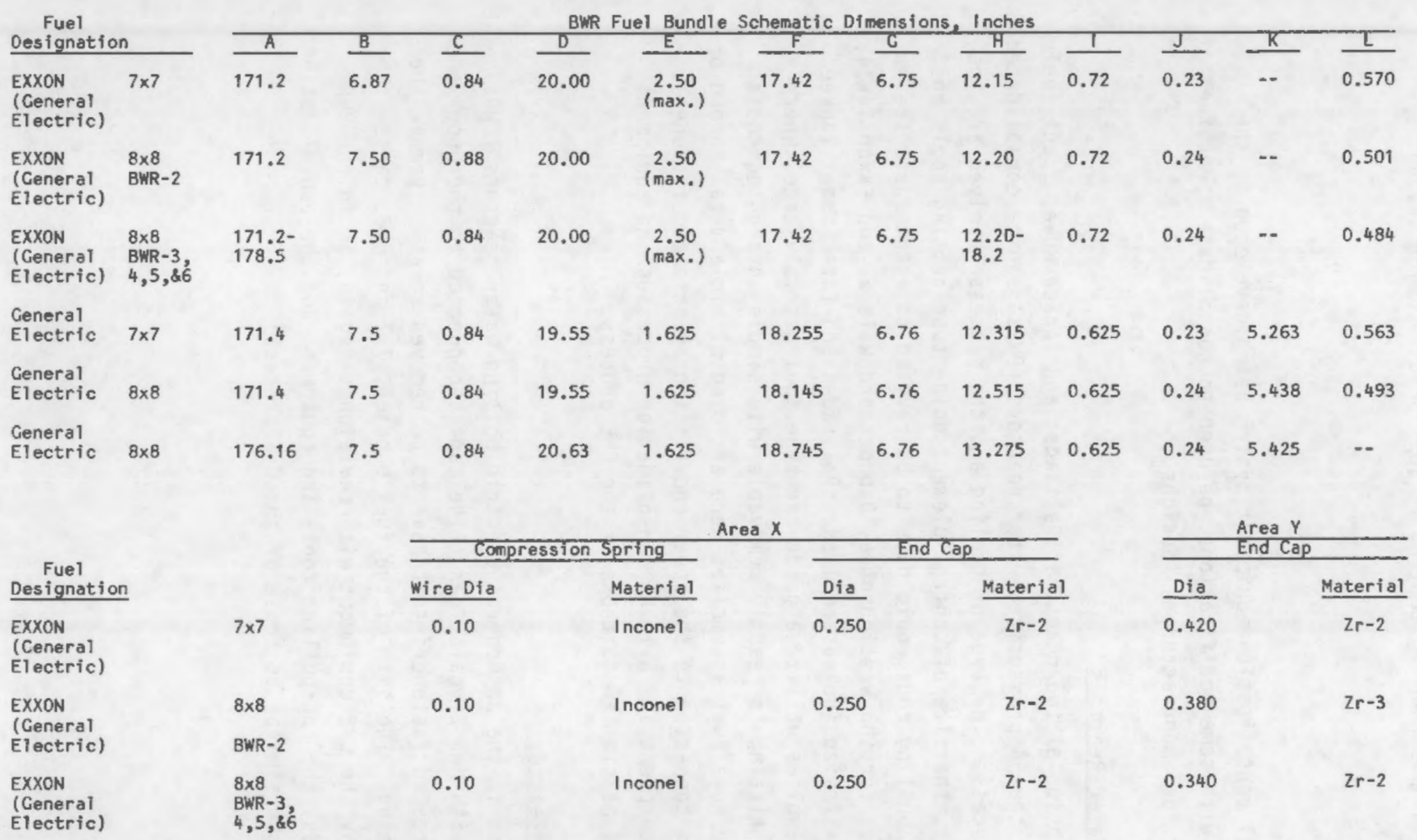

Source: Adapted from PNL-2575 (UC-85), prepared by Pacific Northmest Laboratory. September 1979. 


\section{Grapoling}

The grappling provisions of the reviewed fuel assemblies are within the capabilities of the handling tooling if appropriate design changes are made.

\section{CONCLUSIONS}

The spent-fuel consolidation equipment system being developed in the program can, with some modifications, be used to consolidate spent fuel of other nuclear fuel manufacturers " designs.

\section{Pressurized Water Reactors}

With the exception of two reactors. Palisades and Yankee Rowe, spent-fuel assemblies in the 54 pressurized water reactors (PWRs) can be consolidated by the $C-E$ process. The type of tooling and the process involved are the same. However, the size of control element guide tube cutting tools and the tools for pulling rods would have to be revised to accommodate the different sizes for the Westinghouse, Babcock and Wilcox, and Exxon $14 \times 14$, $15 \times 15$, and $17 \times 17$ size fuel assemblies. Palisades and later-model Yankee Rowe fuel assemblies utilize a guide-bar type fuel assembly cage, where the upper end fitting is readily removable with simple untorquing tools. Earlier Yankee Rowe fuel assemblies were enclosed within a metal shroud or can, which was connected to the upper end fitting by threaded fasteners. Rod-pulling equipment and all the consolidation processes and equipment required would be similar to those of the $C-E$ process.

\section{Boiling Water Reactors}

Fuel assemblies in the 30 General Electric boiling water reactors (BWRs) are enclosed within a Zircaloy can. The can is connected to the upper end fitting by threaded fasteners that have to be removed so as to remove the upper end fitting. The size of the fuel bundles, $7 \times 7$ and $8 \times 8$, can be accommodated by the C-E equipment with revisions. Again, as in the PWR fuel assemblies, the rod-pulling tools and equipment and the consolidation process would be similar to those of the C-E process. 


\section{REFERENCES}

1. W. B. Weihermiller and G. S. Allison. LWR Nuclear Fuel Bundle Data

Use in Fuel Bundle Handling. PNL-2575. Pacific Northwest Laboratories. Richland, WA. September 1979.

\section{SOURCES}

1. $17 \times 17$ Optimized Fuel Assembly Outline, WCAP 9500 (1 page).

2. Table 1, Selected Design Parameters of $17 \times 17$ and $15 \times 15$ Fuel Assemblies, and various figures $8122-4$ (5 pages).

3. Figure 4.2 - 27, FSAR Ammend 3, July 1974 (1 page).

4. Table 2; A-3 Various Westinghouse Design Parameters (1 page).

5. Westinghouse $14 \times 14$ Fuel Assembly Outline (5 pages).

6. Summary of C-E, Westinghouse, B\&W, KWU, and Exxon Mechanical Design Parameters (2 pages), 2-17-76.

7. Westinghouse Reactor Design Comparison Table (Table 4.1-1) from RESAR-414, October 1976 (1 page).

8. Westinghouse Region 6 Nuclear and Mechanical Design Information, RG\&E $14 \times 14$ (1 page).

9. US Patent 4,323,428, Apri1 6, 1982 (3 pages).

10. Various Westinghouse Design Sketches $\mathrm{N}-. .8555-42,6234-89,90,91$ and 7579-59 (6 pages).

11. Fuel Assembly Outline for the Zion Reactor (3 pages).

12. Fuel Assembly Outline for Westinghouse $17 \times 17$ (2 pages).

13. Fuel Assembly Outline for Indian Point ( 5 pages).

14. Fuel Assembly Outline for Indian Point 2 (7 pages).

15. Fuel Assembly Outline for B\&W - Oconee $15 \times 15$ (3 pages).

16. US Patent $4,208,248$, June 17,1980 B\&W - UEF ( 3 pages).

17. B\&W Fuel Assembly for RG\&E (3 pages).

18. B\&W Standard Fuel Assembly (2 pages)

19. B\&W Standard $241-17 \times 17$ Fuel Assembly ( 3 pages).

20. B\&W $15 \times 15$ Fuel Assembly, Oconee 2, Mark-B, Mark-C (10 pages).

21. G.E. Fuel Assembly, NEDO-20944 (5 pages). 
